Final Report

FHWA/IN/JTRP-2004/1

\title{
Remediation of Soils and Ground Water Contaminated by Aromatic and Chlorinated Hydrocarbons and Metals
}

\author{
By \\ Inez Hua, Associate Professor, Lead PI \\ P. Suresh C. Rao, Lee A. Reith Distinguished Professor, CO-PI \\ School of Civil Engineering \\ Purdue University \\ and \\ Linda S. Lee, Professor, CO-PI \\ Department of Agronomy, School of Agriculture \\ Purdue University \\ Editors: \\ Barry K. Partridge, Chief, Division of Research \\ Indiana Department of Transportation \\ Ben Lawrence, Environment, Planning and Engineering Division \\ Indiana Department of Transportation \\ Joint Transportation Research Program \\ Project No. C-36-68O \\ File No. 4-7-15 \\ SPR-2623 \\ Conducted in cooperation with the \\ Indiana Department of Transportation and \\ the U.S. Department of Transportation \\ Federal Highway Administration
}

The contents of this paper reflect the views of the authors, who are responsible for the facts and the accuracy of the data presented herein, and do not necessarily reflect the official views or policies of the Federal Highway Administration and the Indiana Department of Transportation, nor do the contents constitute a standard, specification, or regulation.

Purdue University

West Lafayette, Indiana

May 2004 


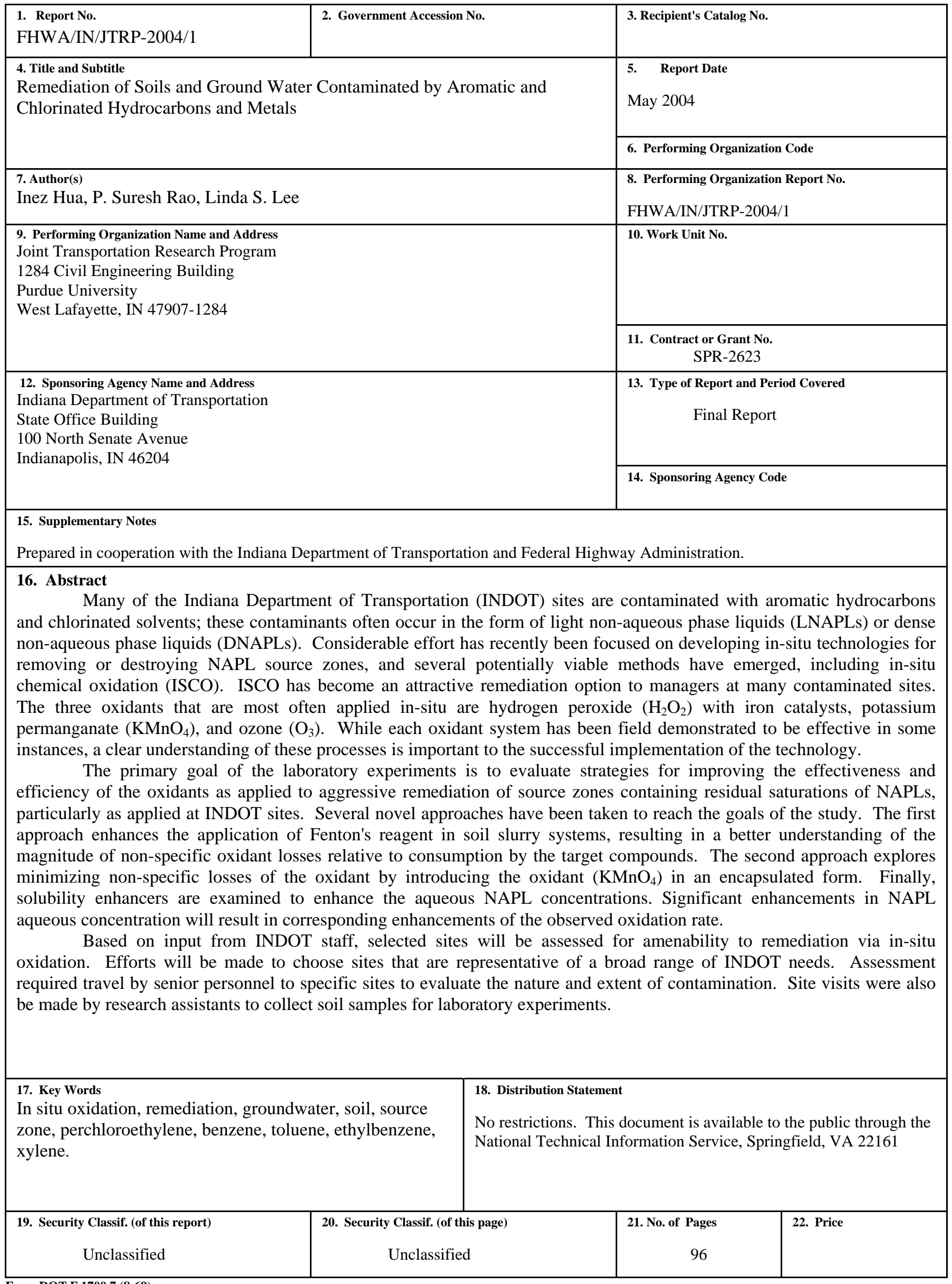




\section{TECHNICAL Summary}

INDOT Research

Technology Transfer and Project Implementation Information

TRB Subject Code: 23-8 Ecological Impact Abatement

May 2004

Publication No.: FHWA/IN/JTRP-2004/1, SPR-2623

Final Report

\section{Remediation of Soils and Ground Water Contaminated by Aromatic and Chlorinated Hydrocarbons and Metals}

\section{Introduction}

Many of the Indiana Department of Transportation (INDOT) sites are contaminated with aromatic hydrocarbons and chlorinated solvents; these contaminants often occur in the form of light non-aqueous phase liquids (LNAPLs) or dense non-aqueous phase liquids (DNAPLs). Considerable effort has recently been focused on developing in-situ technologies for removing or destroying NAPL source zones, and several potentially viable methods have emerged, including in-situ chemical oxidation (ISCO). ISCO has become an attractive remediation option to managers at many contaminated sites. The three oxidants that are most often applied in-situ are hydrogen peroxide $\left(\mathrm{H}_{2} \mathrm{O}_{2}\right)$ with iron catalysts, potassium permanganate $\left(\mathrm{KMnO}_{4}\right)$, and ozone $\left(\mathrm{O}_{3}\right)$. While each oxidant system has been field demonstrated to be effective in some instances, a clear understanding of these processes is important to the successful implementation of the technology.

A primary goal of the research project is to improve the efficiency and effectiveness of chemical oxidation systems during in-situ treatment of non-aqueous phase liquid (NAPL) source zones. Efficiency and effectiveness are defined in Table 1-1; other selection criteria include time required to achieve acceptable levels of treatment, oxidant selectivity, and oxidant delivery methods. Several novel approaches have been taken to reach the goals of the study. The first approach enhances the application of Fenton's reagent in soil slurry systems, resulting in a better understanding of the magnitude of non-specific oxidant losses relative to consumption by the target compounds. The second approach explores minimizing non-specific losses of the oxidant by introducing the oxidant $\left(\mathrm{KMnO}_{4}\right)$ in an encapsulated form. Finally, solubility enhancers are examined to enhance the aqueous NAPL concentrations. Significant enhancements in NAPL aqueous concentration will result in corresponding enhancements of the observed oxidation rate.

\section{Findings}

In order to enhance the rate and extent of in situ oxidation of BTEX compounds, Fenton-type treatment of BTEX-contaminated soil slurries was investigated. A characterized soil (Warsaw, IN) was spiked with BTEX compounds, and the performance of Fenton treatment was evaluated using a matrix of $\mathrm{H}_{2} \mathrm{O}_{2}$ concentrations and iron catalysts (Fe(II), $\mathrm{Fe}(\mathrm{III})$, and $\mathrm{Fe}(\mathrm{III})$-organic ligand complexes) in the range of near-neutral $\mathrm{pH}$. The results indicate that for initial concentrations of BTEX
(20.3-36.1 mg/kg soil), 63.3-96.1 \% mass reduction in $24 \mathrm{~h}$ was achieved by Fenton processes where $\mathrm{H}_{2} \mathrm{O}_{2}$ (150 and $300 \mathrm{mM}$ ) with combinations of $\mathrm{Fe}(\mathrm{II})$ or $\mathrm{Fe}(\mathrm{III})$ or $\mathrm{Fe}(\mathrm{III})$ organic ligand complexes (2 and $5 \mathrm{mM}$ ) were utilized. The mass ratios of iron catalyst to hydrogen peroxide were $1: 18,1: 37$, and 1:92.

Soluble iron catalyst was a key parameter for effective performance of Fenton oxidation. In addition, Fenton treatment of toluene could be significantly enhanced in the 
presence of a chelating agent for Fe(III). It is anticipated that as long as a sufficient amount of soluble iron is augmented or effective chelating agents are employed, Fenton processes could be effectively utilized for remediation of gasoline-contaminated soils and groundwater within a fairly short clean-up time scale (hours to days).

It is possible minimize non-specific losses during ISCO by controlling the release of oxidant into the aqueous phase. Paraffin wax was applied as an environmentally benign and inert matrix for protecting solid $\mathrm{KMnO}_{4}$ particles from rapid dissolution and undesirable reactions in moist conditions. The release of $\mathrm{KMnO}_{4}$ from the encapsulated potassium permanganate-particles (EPPs) into reagent grade water was characterized by a relatively fast initial rate due to fast dissolution of partly coated $\mathrm{KMnO}_{4}$ near the surface of the paraffin wax matrix, followed by a significantly slower rate in the later phase due probably to reduced mass of $\mathrm{KMnO}_{4}$ that remained in the paraffin wax matrix. The wax coating completely dissolved almost immediately upon contact with a target contaminant (PCE). When transported with ground water flow, organic contaminants such as TCE and PCE dissolved in aqueous phase would preferentially partition into the paraffin wax coating due to their significant solubilities in the paraffin wax. Consequently, enhanced contact may occur between the contaminant and the locally high concentrations of $\mathrm{KMnO}_{4}$ released into the interfacial region of EPPs and the aqueous phase. The $\mathrm{KMnO}_{4}$ concentration in the vicinity of the EPPs will be close to its maximum aqueous solubility.

The time-efficiency of PCE oxidation by potassium permanganate is enhanced under solubility conditions that mimic a contaminant source zone. Both TBA and acetone are sufficiently recalcitrant to oxidation by $\mathrm{KMnO}_{4}$ to be used individually as co-solvents. At specific volume fractions, TBA (20\%) and acetone $(<50 \%)$, increase the solubility of PCE significantly without mobilizing the DNAPL. The chloride production from PCE oxidation with $\mathrm{KMnO}_{4}$ in a $20 \%$ acetone system was about twice as much as that in the absence of co-solvent, indicating the former system has a higher time-efficiency in utilizing $\mathrm{KMnO}_{4}$.

Based on input from INDOT staff, selected sites have been assessed for amenability to remediation via in-situ oxidation. Site visits were also be made by research assistants to collect soil samples for laboratory experiments.

\section{Implementation}

INDOT should consider the use of ISCO when standard excavation of contaminated source soil would not be practical or costeffective. This might be due to the depth of the source (especially with DNAPLs) or proximity to utilities, buildings, or a roadway. Ideally INDOT would have ownership or unlimited access rights to the prospective property. This would simplify investigation and implementation of the chosen remedial option.

Geologically, porous soil would help in dispersing oxidants and improving access to the contaminant plume. The "ideal" situation would consist of a small, concentrated source zone (especially if free-phase NAPL is present) that feeds a large, relatively dilute plume. Plumes composed of long-chain hydrocarbons or polyaromtics (diesel, fuel oil or waste oil) would be most useful for the study. They are less mobile (and therefore easier to gain regulatory approval for unconventional treatment methods) and traditionally more limited in treatment options compared to more volatile constituents such as BTEX. High molecular weight hydrocarbons will also show a higher affinity for the proposed paraffin wax encapsulated permanganate, improving selectivity.

The co-solvent approach would be most useful at sites where solubility is a limiting factor, such as at chlorinated hydrocarbon sites, including dry cleaner sites. Choice of solvent must take into account any neighboring receptors. Remote or industrial locations will be amenable to a more aggressive solvent than those in an urban or residential area. As with any of the techniques described in this report, regulatory approval at an early stage is critical to the success of such a remediation approach.. 


\section{Contacts}

For more information:

Prof. Inez Hua

Principal Investigator

School of Civil Engineering

Purdue University

West Lafayette IN 47907

Phone: (765) 494-2409

Fax: (765) 496-1988

E-mail: hua@ecn.purdue.edu
Indiana Department of Transportation

Division of Research

1205 Montgomery Street

P.O. Box 2279

West Lafayette, IN 47906

Phone: (765) 463-1521

Fax: (765) 497-1665

Purdue University

Joint Transportation Research Program

School of Civil Engineering

West Lafayette, IN 47907-1284

Phone: (765) 494-9310

Fax: (765) 496-7996

jtrp@ecn.purdue.edu

http://www.purdue.edu/jtrp 


\section{Table of Contents}

Chapter 1. Introduction and Problem Statement

1.1. Background Information and Problem Statement

1.2. Research Scope and Approach

1.3. Objectives and Purpose Of The Study

Chapter 2. Fenton Oxidation of Benzene, Toluene, Ethylbenzene, Xylene (BTEX) in Soil Slurry Systems

2.1. Abstract

2.2. Introduction

2.3. Methodology

2.4 Results and Discussion

2.5 Conclusions

2.6 References

Chapter 3. Characterization and Controlled Release of Potassium Permanganate Encapsulated by Paraffin Wax

3.1. Abstract

3.2. Introduction

3.3. Experimental Materials and Methods

3.4 Results and Discussion

3.5 Conclusions

Chapter 4. Co-solvent Enhanced Chemical Oxidation of Perchloroethylene by Potassium Permanganate

4.1. Abstract

4.1.2. Introduction

4.1.3. Materials and Methods

4.1.4 Results and Discussion

4.1.5 Conclusions

4.1.6 References

69

4.2 Preliminary Two-Dimensional Studies

Chapter 5. Field Site Visits and Assessment

Chapter 6. Conclusions and Implementation Suggestions 


\section{List of Figures}

\section{Chapter 2. Fenton Oxidation of Benzene, Toluene, Ethylbenzene, Xylene (BTEX) in Soil Slurry Systems}

Fig. 2-1.

Effect of catalyst type on toluene destruction at near-neutral pH (Expts. 10, 16, 17).

Fig. 2-2.

(A) Influence of soluble iron concentrations on Fenton oxidation of toluene at nearneutral pH (Expts. 10-12, 16-18); (B) Soluble iron catalyst-limited condition for toluene destruction (Expts. 16, 18, 19). $\left[\mathrm{H}_{2} \mathrm{O}_{2}\right]_{0}=300 \mathrm{mM}$; [soluble iron $]_{0}=5$ or $10 \mathrm{mM}$; [toluene $]_{0}=0.3 \mathrm{mmol} / \mathrm{kg} ; \mathrm{pH} 5-7$.

Fig. 2-3.

Effects of organic chelating agents on mass reduction of toluene by Fenton oxidation at near-neutral pH (Expts. 11-15, 20).

Fig. 2-4.

Influence of $\mathrm{H}_{2} \mathrm{O}_{2}$ concentrations on Fenton degradation of toluene at near-neutral $\mathrm{pH}$ (Expts. 1-6, 10, 16, 17).

Fig. 2-5.

Comparison of Fenton degradation of BTEX compounds (A) As single contaminants (Expts. 6-9) (B) In a contaminant mixture (Expt. 21).

\section{Chapter 3. Characterization and Controlled Release of Potassium Permanganate Encapsulated by Paraffin Wax}

Fig. 3-1.

Characterization of uncoated $\mathrm{KMnO}_{4}$ particles. (A1) SEM image before milling (scale bar, $10 \mu \mathrm{m}$ ) (A2); SEM image after milling for $20 \mathrm{~min}$ (scale bar, $10 \mu \mathrm{m}$ ); (B) particle size reduction as a function of milling time.

Fig. 3-2.

Pulverized encapsulated $\mathrm{KMnO}_{4}$ particles. ESEM images (scale bar, $200 \mu \mathrm{m}$ ) for 1:1 $\mathrm{W}: \mathrm{P}$ (A1) and 2:1 W:P (A2); (B) particle size distribution as volume percent for 2:1 $\mathrm{W}: \mathrm{P}$.

Fig. 3-3.

Differential scanning thermograms. (A) paraffin wax; (B) physical mixture of paraffin wax and uncoated $\mathrm{KMnO}_{4}$ particles; and (C) encapsulated $\mathrm{KMnO}_{4}$ particles $(1: 1 \mathrm{~W}: \mathrm{P})$. Fig. 3-4.

Time profiles of $\mathrm{KMnO}_{4}$ released from the paraffin wax matrix into reagent grade water. (A) overall plots; (B) data points near $\mathrm{t}=0$.

Fig. 3-5.

ESEM image of the surface of an encapsulated $\mathrm{KMnO}_{4}$ particle $(1: 1 \mathrm{~W}: \mathrm{P}$; scale bar, 150 $\mu \mathrm{m})$ after 4 days of stirring in reagent grade water. Note crevices which remain after the $\mathrm{KMnO}_{4}$ has dissolved in the water.

Fig. 3-6.

Accumulation of pulverized encapsulated $\mathrm{KMnO}_{4}$ particles $(0.05 \mathrm{~g}, 2: 1 \mathrm{~W}: \mathrm{P})$ at the surface of a PCE droplet $(0.7 \mathrm{~mL})$ in reagent grade water. (A) Before agitation; (B) 10 
min after the system was agitated for $1 \mathrm{~min}$.

\section{Chapter 4. Co-solvent Enhanced Chemical Oxidation of Perchloroethylene by Potassium Permanganate}

Fig. 4-1.

Log of normalized solubility $\left(\mathrm{S}_{\mathrm{m}} / \mathrm{S}_{\mathrm{w}}\right)$ versus the volume fraction of cosolvent.

Fig. 4-2.

Log of interfacial tension (IFT) between cosolvent/water mixture and PCE versus log of solubility of PCE in the mixtures.

Fig. 4-3.

Relative residual saturation $\left(\mathrm{Sn}^{\prime}\right)$ versus total trapping number $\left(\mathrm{N}_{\mathrm{T}}\right)$.

Fig. 4-4.

Pseudo-first order model for PCE concentration in kinetic experiment (absence of free phase PCE).

Fig. 4-5.

Chlorine mass balance for PCE oxidation in the absence of free phase PCE.

Fig. 4-6.

Chloride production during co-solvent enhanced oxidation of PCE. $2 \mathrm{~mL}$ free phase

$\mathrm{PCE}$ in $250 \mathrm{~mL}$ glass reactor, $25^{\circ} \mathrm{C}$ water bath, $\left[\mathrm{KMnO}_{4}\right]_{0}=17 \mathrm{mM}$.

Fig. 4-7.

$\mathrm{KMnO}_{4}$ concentration in the presence of $2 \mathrm{~mL}$ free phase PCE in $250-\mathrm{mL}$ glass reactor, $25^{\circ} \mathrm{C}$ water bath, $\left[\mathrm{KMnO}_{4}\right]_{0}=17 \mathrm{mM}$.

Fig. 4-8.

Breakthrough of $\mathrm{KMnO}_{4}$ from the box during the dye tracer test.

Fig. 4-9.

Distribution of $\mathrm{KMnO}_{4} 40$ minutes after injection. 


\section{List of Tables}

\section{Chapter 1:}

Table 1-1: Oxidant Selection Criteria and Weighting Factors

\section{Chapter 2}

Table 2-1: Selected physical and chemical characteristics of BTEX compounds.

Table 2-2: Soil Characteristics (Warsaw, IN)

Table 2-3: Summarized results for Fenton oxidation of BTEX in soil slurries

Table 2-4: Proposed reactions for BTEX destruction by Fenton oxidation in soil slurries

\section{Chapter 3}

Table 3-1: Estimated rate and time for $90 \%$ permanganate release into reagent grade water

Table 3-2: Solubility of paraffin wax (melting point of $51.4-53{ }^{\circ} \mathrm{C}$ ) in various organic solvents

\section{Chapter 4}

Table 4-1. Solvent stability in the presence of permanganate

Table 4-2. Second order rate constants of oxidation of aqueous PCE by $\mathrm{KMnO}_{4}$

\section{Chapter 5}

Table 5-1: Potential Sites for ISCO Field Test/Study in Indiana 


\section{Acknowledgements}

This research project was sponsored by the Indiana Department of Transportation (INDOT) in cooperation with the Federal Highway Administration through the Joint Transportation Research Program. The authors would like to thank the study advisory committee members, Ben Lawrence, Barry Partridge, Bruce Oertel, and Richard Dierkes for their valuable assistance and guidance. In addition, the authors are grateful to Dr. Changhe Xiao and Ms. Irene Poyer, who contributed their technical expertise to various aspects of the laboratory work conducted during this research project. Xihong Zhai, Namgoo Kang, and Amy Clore performed much of the experimental work described in this report. Dr. Michael Beckett performed some of the initial co-solvent screening experiments. The authors thank Dr. Lawrence C. Murdoch of Clemson University for providing a sample of polymer coated potassium permanganate and technical information. 


\section{Chapter 1. Introduction}

Inez Hua, P. Suresh C. Rao, Linda S. Lee

\subsection{Background Information and Problem Statement}

Many of the Indiana Department of Transportation (INDOT) sites are contaminated with aromatic hydrocarbons and chlorinated solvents; these contaminants often occur in the form of light non-aqueous phase liquids (LNAPLs) or as dense non-aqueous phase liquids (DNAPLs). Contamination from various metals is also of concern. A considerable effort has recently been focused on developing in-situ technologies for removing or destroying NAPL source zones, and several potentially viable methods have emerged. Emphasis on source zone treatment is appropriate as an integral component of contaminated site management because even small sources can sustain extensive dissolved plumes.

Most of the new methods involve removal of the NAPL through enhanced evaporation (air sparging/soil vapor extraction; steam stripping, electrical heating), enhanced dissolution (surfactant, co-solvent and cyclodextrin flushing), or separate phase mobilization (steam, surfactant, and co-solvent flooding). In-situ chemical oxidation (ISCO) is different from the extraction technologies because the NAPLs are converted to innocuous by - products. It is not known, however, how ISCO compares to these other alternative technologies for NAPL sourcezone remediation. Furthermore, there is little quantitative field data on the efficiency with which NAPL is destroyed in-situ using ISCO. All in-situ methods, including oxidation, offer advantages over more conventional techniques, such as pump - and -treat or excavation.

Chemical oxidation is a well-established technology in water and wastewater treatment but the process is relatively new for in-situ applications. Field implementations are limited to the past 8 years or so, yet ISCO has become an attractive remediation option to managers at many contaminated sites. As of November 1999, at least 42 field applications of ISCO had been reported, and many of these involved sites contaminated with chlorinated hydrocarbons (ESTCP, 1999). Detailed information about the sites, contaminants, and the success of ISCO in each case is available (EPA, 1998; ESTCP, 1999; Yin et al., 1999). ISCO field sites are also profiled online at Websites such as http://www.clu-in.org/databases/\#Chemical_Oxidation_Site_Profiles.

The three oxidants that are most often applied in-situ are hydrogen peroxide $\left(\mathrm{H}_{2} \mathrm{O}_{2}\right)$ with iron catalysts, potassium permanganate $\left(\mathrm{KMnO}_{4}\right)$, and ozone $\left(\mathrm{O}_{3}\right)(\mathrm{EPA}, 1998)$. These oxidants 
differ substantially in their oxidation potential, oxidation pathways, stability, physical state (liquid, solid, and gas, respectively), and cost. As of late 1999, the majority of reported field applications (37/42) had involved hydrogen peroxide with a few tests (4/42) using permanganate and only a single test using ozone (ESTCP, 1999). While each oxidant system has been field tested and demonstrated to be effective in some instances (EPA, 1998; Yin, 1999), the overall success of ISCO could be significantly improved. Despite success reported at several field sites, the fundamental processes, mechanisms, and kinetics of oxidants in complex, heterogeneous environmental matrices are poorly understood, thus hindering full realization of the technology. Different chemical reactions and mechanisms occur with each of the three ISCO oxidants, and a clear understanding of these processes is important to the successful implementation of the technology.

\section{- Fenton's Reagent}

Many researchers have investigated the use of $\mathrm{H}_{2} \mathrm{O}_{2}$ in the form of Fenton's reagent to treat contaminated soils (Barbeni et al., 1987; Berry and Boyd, 1985; Schnarr et al., 1998; Watts and Bottenberg, 1999; Watts and Udell, 1999; Siegrist and Lowe, 1999; Bier and Singh, 1999a; Kubarewicz and Pfeffer, 1985). The utility of Fenton's reagent relies on the formation of the non-selective oxidant species, hydroxyl radical $\left({ }^{\circ} \mathrm{OH}\right)$ (Haber and Weiss, 1934;Walling, 1975a; Kitajima et al., 1978; Weinstein and Bielski, 1979). The decomposition of $\mathrm{H}_{2} \mathrm{O}_{2}$ is most often catalyzed by dissolved iron (either naturally occurring or amended into the system). Therefore,

• $\mathrm{OH}$ formation and the effectiveness of Fenton's reagent can be controlled via manipulations of the soluble iron concentrations. Although iron is more soluble under acidic (low $\mathrm{pH})$ systems, it is much more desirable to apply Fenton's reagent at near-neutral $\mathrm{pH}$ conditions.

\section{- $\quad$ Potassium Permanganate}

Permanganate ion, $\mathrm{MnO}_{4}^{-}$, has also been utilized as a general oxidant in the treatment of wastewater and drinking water, and as an oxidant in many industrial processes. Permanganate is generally considered a more specific oxidant than either Fenton's reagent or ozone.

Permanganate has recently been applied in-situ to oxidize chlorinated hydrocarbons in laboratory and field studies (EPA, 1998; Schnarr, 1998; Siegrist et al., 1999). Complete oxidation to chloride and carbon dioxide was observed. However, it is possible for $\mathrm{MnO}_{2}$ (a solid precipitate) to form during oxidation. These precipitates can pose significant problems in pore plugging, or impeding access to NAPL ganglia. Several innovative methods for application of the oxidant will 
be examined in the proposed experiments, with the intent of minimizing or avoiding these problems.

\section{- Ozone}

The ozone reaction mechanisms in aqueous systems vary according to $\mathrm{pH}$ and target compound. Ozone decomposition produces the non-selective oxidant, hydroxyl radical $(\bullet \mathrm{OH})$. However, ozone also directly reacts with alkenes (carbon - carbon double bonds), and with aromatic compounds, two functional groups that are characteristic of the contaminants which interest INDOT. Some chlorinated compounds, such as trichloroethylene and perchloroethylene, also contain carbon-carbon double bonds. Although the reaction kinetics, mechanisms and byproducts of ozone in the aqueous phase have been characterized for numerous compounds, fewer studies have been performed with geologic matrices. Detailed mechanistic studies in geologic matrices are lacking, although ozone transport and demand in soil and soil surrogates has been investigated (Hsu and Masten, 1997; Masten and Davies, 1997).

More extensive descriptions of Fenton's reagent and potassium permanganate are included in Chapters 2, and 4.

\subsection{Research Scope and Approach}

A substantial amount of laboratory work has been conducted, with an emphasis on applying ISCO to INDOT groundwater and soil remediation needs. The primary goal of the laboratory experiments is to evaluate strategies for improving the effectiveness and efficiency of the oxidants as applied to aggressive remediation of source zones containing residual saturations of NAPLs. Based on these lab evaluations involving batch tests and one-dimensional (1-D) and two-dimensional (2-D) flow systems, effective strategies for using these oxidants under field conditions will be developed.

The laboratory work served three main purposes. First, laboratory batch and column experiments were conducted with clean and spiked soil collected from appropriate INDOT sites. The purpose of these tests will be to optimize the composition and amount of specific oxidants for site-specific conditions to help in the design of the field tests. Secondly, more fundamental laboratory research focused on understanding and reducing local-scale mass transfer limitations between the oxidants and contaminants, especially those present as a NAPL rather than as dissolved aqueous constituents. Third, innovative approaches were undertaken to improve the 
oxidant efficiency by decreasing interactions with components other than NAPL. This lab work will lead to strategies for increasing local mass-transfer rates, and minimizing oxidant losses.

\subsection{Objectives and Purpose Of The Study}

A primary goal of the laboratory investigations is to improve the efficiency and effectiveness of chemical oxidation systems during in-situ treatment of non-aqueous phase liquid (NAPL) source zones. Efficiency and effectiveness are defined in Table 1-1. Several groups of obstacles must be overcome in order to accomplish this goal.

Since oxidation reactions for NAPLs occur primarily in the aqueous phase, limited aqueous solubility of the contaminant and its mass-transfer into the aqueous phase will reduce the efficiency of the oxidant. Also, because the oxidants generally tend to be non-selective, they can attack a variety of inorganic and organic components of the aquifer solid matrix. As a result, loss of oxidant to non-selective reactions during application and delivery can also limit the effectiveness and efficiency. Oxidation by-products, either from partial oxidation of the NAPL or reaction with other reduced components, may be an issue. That is, partial oxidation of NAPLs may yield unacceptable intermediates or precipitates (e.g., manganese oxide with permanganate). In addition, colloid mobilization or gases released may lead to a decrease in aquifer permeability or oxidant effectiveness. Another obstacle to efficient delivery of the oxidant is posed by the heterogeneities in NAPL distribution and aquifer hydraulic properties. The hydrodynamic inefficiencies in the delivered oxidant being able to contact the NAPL must be overcome by a better design of the flow field for in-situ applications.

Several novel approaches will be taken to overcome the limitations discussed above. The first approach involves enhancing the application of Fenton's reagent in soil slurry systems and understanding the magnitude of non-specific oxidant losses relative to consumption by the target compounds. Several modifications of Fenton's reagent for groundwater and soil remediation are investigated. For example, in soils where the native iron is either unavailable or insufficient to destroy target contaminants by Fenton reaction, iron amendment is required. Thus, sufficient amounts of soluble iron must be maintained by amendment and/or addition of effective chelating agents.

In a second innovative approach, we examine ways to minimize non-specific losses of the oxidant by introducing the oxidant in an encapsulated form. $\mathrm{KMnO}_{4}$ is most appropriate for 
encapsulation, because it is a solid. The oxidant can be coated in a thin layer of polymer, which is insoluble in water but will dissolve once in contact with the NAPL. Exposure of the $\mathrm{KMnO}_{4}$ to NAPL (and water) will then result in oxidation of the NAPL. Since the $\mathrm{KMnO}_{4}$ is released at the NAPL-water interfacial region, locally high oxidant concentrations will be generated. Thus, the encapsulation and targeted oxidant delivery approach could significantly enhance the efficiency of $\mathrm{KMnO}_{4}$. This task will build on a recent investigation where $\mathrm{KMnO}_{4}$ was successfully encapsulated in a polymer as millimeter sized particles. These coarse grains slowly release oxidant, and appear to provide some selectivity to the dissolved species that become oxidized. The results detailed in this study describe smaller particles that target NAPLs.

In the third approach, we examine ways to enhance the aqueous NAPL concentrations by adding solubility enhancers (e.g., co-solvents). The overall rate (change in concentration with respect to time) of oxidation will be enhanced, according to the equation below:

$$
\frac{\mathrm{d}[\mathrm{NAPL}]}{\mathrm{dt}}=-\mathrm{k}[\mathrm{NAPL}]^{\mathrm{a}}[\text { Oxidant }]^{\mathrm{b}}
$$

where $k$ is the oxidation rate constant specific to the oxidant-contaminant pair; and $a$ and $b$ are empirically determined constants (which can be zero). Significant enhancements in NAPL aqueous concentration will result in corresponding enhancements of the observed oxidation rate. It should be noted that a secondary benefit accruing from addition of alcohols is that the NAPLwater surface area may increase which, in turn, can increase mass-transfer kinetics for solubilization.

Based on input from INDOT staff, selected sites will be assessed for amenability to remediation via in-situ oxidation. Efforts will be made to choose sites that are representative of a broad range of INDOT needs. Assessment required travel by senior personnel to specific sites to evaluate the nature and extent of contamination. Site visits were also be made by research assistants to collect soil samples for laboratory experiments. 
Table 1-1. Oxidant Selection Criteria and Weighting Factors

\begin{tabular}{|c|c|c|c|}
\hline Criteria & Definition & Physical or Chemical Metric & $\begin{array}{l}\text { Weighting } \\
\text { Factor }\end{array}$ \\
\hline Effectiveness & $\begin{array}{l}\text { Mass of contaminant destroyed at } \\
\text { a given dosage }\end{array}$ & Initial and final contaminant mass & 1 \\
\hline Efficiency & $\begin{array}{l}\text { Mass of contaminant destroyed per } \\
\text { unit mass oxidant applied }\end{array}$ & $\begin{array}{l}\text { Initial and final contaminant mass; } \\
\text { total mass of oxidant applied }\end{array}$ & 1 \\
\hline Cost & $\begin{array}{l}\text { Cost per unit mass of NAPL } \\
\text { destroyed }\end{array}$ & $\begin{array}{l}\text { Less than that needed for comparable } \\
\text { aggressive technology or ex situ } \\
\text { treatment }\end{array}$ & 1 \\
\hline $\begin{array}{l}\text { Time } \\
\text { (RATE) }\end{array}$ & $\begin{array}{l}\text { Time to achieve an acceptable } \\
\text { level of treatment ( } 30-40 \text { days) }\end{array}$ & $\begin{array}{l}\text { Flux averaged aqueous concentration } \\
\text { of NAPL }\end{array}$ & 2 \\
\hline Delivery & $\begin{array}{l}\text { Delivery of oxidant to the } \\
\text { subsurface and contact with NAPL } \\
\text { source zones }\end{array}$ & $\begin{array}{l}\text { Aqueous concentration of oxidant } \\
\text { contacting NAPL or } \\
\text { Mass of oxidant contacting NAPL } \\
\text { (encapsulation) }\end{array}$ & 1 \\
\hline $\begin{array}{l}\text { Health and } \\
\text { Safety }\end{array}$ & $\begin{array}{l}\text { Risk to workers of handling a } \\
\text { particular oxidant }\end{array}$ & OSHA and NIOSH guidelines & 2 \\
\hline $\begin{array}{l}\text { Exothermic } \\
\text { nature of } \\
\text { oxidant }\end{array}$ & $\begin{array}{l}\text { Quantity of heat released during } \\
\text { application of oxidant }\end{array}$ & Subsurface Temperature & 2 \\
\hline $\begin{array}{l}\text { Gas } \\
\text { production } \\
\text { during } \\
\text { oxidation }\end{array}$ & $\begin{array}{l}\text { Production of gases resulting from } \\
\text { oxidation of NAPL }\end{array}$ & $\begin{array}{l}\text { Increase in hydraulic head, decrease } \\
\text { in permeability, gas volume vented } \\
\text { at the surface }\end{array}$ & 2 \\
\hline Precipitation & $\begin{array}{l}\text { Precipitation of oxidation by- } \\
\text { products }\end{array}$ & $\begin{array}{l}\text { Increase in hydraulic head, decrease } \\
\text { in permeability }\end{array}$ & 2 \\
\hline Colloids & Colloids generated and mobilized & $\begin{array}{l}\text { Increase in hydraulic head, decrease } \\
\text { in permeability }\end{array}$ & 2 \\
\hline Selectivity & $\begin{array}{l}\text { Reactivity of oxidant with non- } \\
\text { target substrates relative to } \\
\text { reactivity with NAPL }\end{array}$ & $\begin{array}{l}\text { Oxidant "demand" - consumption of } \\
\text { oxidant above stoichiometric dosage }\end{array}$ & 1 \\
\hline $\begin{array}{l}\text { Regulatory } \\
\text { constraints }\end{array}$ & $\begin{array}{l}\text { Regulations pertaining to injection } \\
\text { of reagents into subsurface }\end{array}$ & UIC permitting protocols & 2 \\
\hline $\begin{array}{l}\text { Oxidant } \\
\text { residuals }\end{array}$ & $\begin{array}{l}\text { Oxidants remaining after target } \\
\text { compound oxidized to acceptable } \\
\text { level }\end{array}$ & $\begin{array}{l}\text { Aqueous concentration of any } \\
\text { oxidant deliberately introduced into } \\
\text { the subsurface }\end{array}$ & 3 \\
\hline $\begin{array}{l}\text { Oxidation } \\
\text { by-products }\end{array}$ & $\begin{array}{l}\text { Partial oxidation products of } \\
\text { NAPL and non-target substrates }\end{array}$ & $\begin{array}{l}\text { Total mass of by-products in soil and } \\
\text { groundwater (at any time during } \\
\text { treatment) }\end{array}$ & 3 \\
\hline
\end{tabular}




\subsection{References}

Andreozzi, R. and R. Marotta (1999). "Ozonation of p-chlorophenol in aqueous solution." Journal of Hazardous Materials. 69(3): 303-317.

Barbeni, M., Minero, C. and Pelizzetti, E. (1987). Chemical degradation of chlorophenols with Fenton's Reagent. Chemosphere, 16:2225-2237.

Beltran, F. J., G. Ovejero, et al.. (1995). "Oxidation of polynuclear aromatic hydrocarbons in water. 1. ozonation." Industrial \& Engineering Chemistry Research 34: 1596-1606.

Beltran, F. J., J. Rivas, et al.. (1999a). "A kinetic model for advanced oxidation processes of aromatic hydrocarbons in water: Application to phenanthrene and nitrobenzene." Industrial \& Engineering Chemistry Research. 38(11): 4189-4199.

Beltran, F. J., J. Rivas, et al.. (1999b). "Atrazine removal by ozonation processes in surface waters." Journal of Environmental Science \& Health - Part B: Pesticides, Food Contaminants, \& Agricultural Wastes. 34(3): 449-468.

Berglund, S., 1997. Aquifer remediation by pumping: A model for stochastic-advective transport with nonaqueous phase liquid dissolution. Water Resour. Res., 33(4): 649-661.

Berry, D.F. and Boyd, S.A. (1985). "Decontamination of Soil through Enhanced Formation of Bound Residues". Environmental Science and Technology . 19:1132-1133.

Bier, E. L., J. Singh, et al.. (1999). "Remediating hexahydro-1,3,5-trinitro-1,2,5-trazinecontaminated water and soil by Fenton oxidation." Environmental Toxicology and Chemistry 18(10): 2400-2400.

Brambilla, A., E. Bolzacchini, et al.. (1997). "Reactivity of two models of non-ionic surfactants with ozone." Water Research 31: 1839-1846.

Brooks, M.C. 2000. Characterization and Remediation of DNAPL Resulting from a Controlled Release. PhD Dissertation, University of Florida, Gainesville, FL.

Enfield, C.G., 2000. Tracers forecast the performance of NAPL remediation projects.

Groundwater 2000, P.L. Bjerg, P. Engesgaard, and T.D. Krom (Eds.), Copenhagen, Denmark, 6-8 June 2000. pp. 25-26.

EPA, (1997). Cleaning Up the Nation's Waste Sites: Markets and Technology Trends, 1996 Edition, EPA 542-R-96-005, U.S. EPA, Washington, DC. 
EPA, (1998). Field Applications of In situ Remediation Technologies: Chemical Oxidation.Washington, D.C., Environmental Protection Agency, Report EPA 542-R-98008

ESTCP (1999) Technology Status Review, In Situ Oxidation, Environmental Security Technology Certification Program.

Haber, F. and J. J. Weiss (1934). "The catalytic decomposition of hydrogen peroxide by iron salts." Proceedings of the Royal Society of London 147: 332-351.

Hsu, M. I. Y. and S. J. Masten (1997). "Kinetics of the reaction of ozone with phenanthrene in unsaturated soils.” Environmental Engineering Science 14: 207-218.

Huang, K. C., G. E. Hoag, et al. (1999). "Kinetic study of oxidation of trichloroethylene by potassium permanganate." Environmental Engineering Science 16(4): 265-274.

Kitajima, N., Fukuzumi, S. and Ono, Y. (1978). Formation of superoxide ion during the decomposition of hydrogen peroxide on supported metal oxides. The Journal of Physical Chemistry 82: 1505-1509.

Lowe, D.F., Oubre, C.L., and C.H. Ward (Editors), 1999. Surfactants and Cosolvents for NAPL Remediation: A Technology Practices Manual. Lewis Publishers, Boca Raton, FL.

Masten, S. J. (1991). "Ozonation of VOC's in the Presence of Humic Acids and Soils." Ozone: Science and Engineering OSZEDS 13(3): 287-312.

Masten, S. J. and S. H. R. Davies (1997). "Efficacy of in situ ozonation for the remediation of PAH contaminated soils." Journal of Contaminant Hydrology 28: 327-335.

Ohlenbusch, G., S. Hesse, et al.. (1998). "Effects of ozone treatment on the soil organic matter on contaminated sites." Chemosphere, October, 1557-1569.

Sales, T.C., and D.B. McWhorter, 2001. Steady-state mass transfer from single-component dense non-aqueous phase liquids in uniform flow fields. Water Resour. Res., 37:393-404.

Schnarr, M., C. Truax, et al.. (1998). "Laboratory and controlled field experiments using potassium permanganate to remediate trichloroethylene and perchloroethylene DNAPLs in porous media." Journal of Contaminant Hydrology 29(3): 205-224.

Siegrist, R. L., Lowe, K.S., Murdoch, LC., Case, T. L., Pickering, D. A. (1999). "In situ oxidation by fracture emplaced reactive solids." Journal of Environmental Engineering, 125(5), 429-440. 
Walling, C. 1975. "Fenton's Reagent Revisted". Accounts of Chemical Research . 8:125-131.

Watts, R. J., B. C. Bottenberg, et al.. (1999). "Role of reductants in the enhanced desorption and transformation of chloroaliphatic compounds by modified Fenton's reactions." Environmental Science \& Technology 33(19): 3432-3437.

Watts, R. J., M. D. Udell, et al.. (1999). "Fenton-like soil remediation catalyzed by naturally occurring iron minerals." Environmental Engineering Science 16(1): 93-103.

Weinstein, J. and Bielski, B.H. (1979). "Kinetics of the Interaction of $\mathrm{HO}_{2}$ and $\mathrm{O}_{2}{ }^{-}$Radicals with Hydrogen Peroxide. The Haber-Weiss Reaction". Journal of the American Chemical Society 101:58-62.

Wood, A.L., and C.G. Enfield, 2000. In Situ Enhanced Source Removal. http://hillafb.hgl.com/ Yin, Y. and Allen, H. E., (1999). "In Situ Chemical Treatment." Technology Evaluation Report TE -99-01, Groundwater Remediation Technologies Analysis Center (GWRTAC) E Series, pp. 74. 


\section{Chapter 2. Fenton Oxidation of Benzene, Toluene, Ethylbenzene, Xylene (BTEX) in Soil}

Slurry Systems

Namgoo Kang and Inez Hua

\subsection{Abstract}

In-situ Fenton's oxidation of benzene, toluene, ethylbenzene, and xylene (BTEX) was investigated in soil slurry batch reactors. The purpose of the investigation was to determine optimal combinations of catalyst (Fe(II) or Fe(III)), catalyst concentration (2, 5, and $10 \mathrm{mM}$ ), metal chelating agents (L-ascorbic acid, gallic acid, or $N$-(2-hydroxyethyl)iminodiacetic acid), and hydrogen peroxide concentration $(30,150,300 \mathrm{mM})$ for destroying BTEX compounds at near-neutral pH conditions. Initial concentrations of BTEX correspond were in the range of 20.3$36.1 \mathrm{mg} / \mathrm{kg}$, and the mass ratios of iron catalyst to hydrogen peroxide were 1:18, 1:37, and 1:92. Rapid contaminant mass reduction ( $97.7 \%$ over a period of $3 \mathrm{~h}$ ) occurred in the presence of 300 $\mathrm{mM}$ hydrogen peroxide and $10 \mathrm{mM} F($ III). Other conditions under which rapid mass reduction was observed included the application of $\mathrm{Fe}$ (III) and $\mathrm{N}$-(2-hydroxyethyl)iminodiacetic acid combined with $300 \mathrm{mM}$ hydrogen peroxide (95.5\% reduction over a period of $3 \mathrm{~h}$ ). A soluble iron catalyst was necessary for the most effective oxidation of contaminants in the soil slurry and $\mathrm{Fe}(\mathrm{II})$ generally exhibited higher catalytic activity than Fe(III). Thus, sufficient amounts of soluble iron must be maintained by amendment and/or addition of effective chelating agents. The influence of non-specific oxidant losses (primarily soil organic matter and iron oxyhydroxides) is also estimated and the observed BTEX oxidation rate constants are compared to estimated rate constants.

\subsection{Introduction}

Fenton's reagent (hydrogen peroxide + ferrous iron) has been applied to oxidize a diverse collection of contaminants. Its utility as an oxidizing system relies on the formation of hydroxyl radical $\left({ }^{\circ} \mathrm{OH}\right)$ from hydrogen peroxide, through a series of reactions involving the oxidation and reduction of iron. The reaction rate constants for ${ }^{\bullet} \mathrm{OH}$ attack on many organic contaminants are on the order of $10^{9} \mathrm{M}^{-1} \mathrm{~s}^{-1}$ and thus, when sufficient quantities of ${ }^{\bullet} \mathrm{OH}$ are generated, Fenton's reagent is a potential method for rapidly destroying the contaminants. However, a number of other free-radical oxidants can be formed, and Fenton's chemistry involves a complex collection of reaction pathways. 
Researchers have investigated the use of Fenton's reagent for in-situ chemical oxidation (ISCO) under a variety of conditions, and Fenton-type reagents are widely applied (e.g., 37 sites among a total of 42 ISCO sites for soils and groundwater) [1-3]. Several modifications of Fenton's reagent for groundwater and soil remediation have been investigated. In soils where the native iron is either unavailable or insufficient to destroy target contaminants by Fenton reaction, iron amendment is required. An increase in soluble iron can enhance rates of contaminant degradation because iron addition can enhance the formation of hydroxyl radical [4]. It has been reported that certain ferrous and ferric iron chelators retain an ability to promote Fenton-like oxidations of metalochlor in soil at near-neutral $\mathrm{pH}$ values [5-7]. Investigations of Fenton's reagent in soil or mineral systems have been reported for petroleum contaminants and aliphatic alcohols [8-10].

In this analysis, we describe the Fenton oxidation of benzene, toluene, ethylbenzene, and o-xylene (BTEX) in soil slurries over a period of $24 \mathrm{~h}$. A characterized soil from Warsaw, IN was spiked with BTEX compounds, and the performance of Fenton treatment was evaluated at near-neutral $\mathrm{pH}(\mathrm{pH}=5-7)$. Since toluene exhibits intermediate physical and chemical characteristics (relative to the other components of BTEX; Table 1), it was used as a representative compound for most Fenton oxidation experiments. However, experiments were conducted with all BTEX compounds. The primary goals of the study were to determine optimal concentrations of iron catalyst (Fe(II) or Fe(III); 2, 5, and $10 \mathrm{mM}$ ), metal chelating reagents (Lascorbic acid, gallic acid, or $N$-(2-hydroxyethyl)iminodiacetic acid; $2 \mathrm{mM}$ ) and hydrogen peroxide for the destruction of BTEX compounds in contaminated soil and groundwater systems. Furthermore, a kinetic model is developed that includes many of the heterogeneous and homogeneous free-radical reactions. With this model, non-specific oxidant losses during Fenton oxidation are quantified and compared to oxidant consumption by the target contaminants.

In-situ Fenton's oxidation of benzene, toluene, ethylbenzene, and xylene (BTEX) was investigated in soil slurry batch reactors. The purpose of the investigation was to determine optimal combinations of catalyst (Fe(II) or Fe(III)), catalyst concentration (2, 5, and $10 \mathrm{mM}$ ), metal chelating agents (L-ascorbic acid, gallic acid, or $N$-(2-hydroxyethyl)iminodiacetic acid), and hydrogen peroxide concentration $(30,150,300 \mathrm{mM})$ for destroying BTEX compounds at near-neutral $\mathrm{pH}$ conditions. Rapid contaminant mass reduction $(97.7 \%$ over a period of $3 \mathrm{~h})$ occurred in the presence of $300 \mathrm{mM}$ hydrogen peroxide and $10 \mathrm{mM} \mathrm{Fe}(\mathrm{III})$. Other conditions 
under which rapid mass reduction was observed included the application of Fe(III) and $\mathrm{N}$-(2hydroxyethyl)iminodiacetic acid combined with $300 \mathrm{mM}$ hydrogen peroxide $(95.5 \%$ reduction over a period of $3 \mathrm{~h}$ ). A soluble iron catalyst was necessary for the most effective oxidation of contaminants in the soil slurry and Fe(II) generally exhibited higher catalytic activity than Fe(III). Thus, sufficient amounts of soluble iron must be maintained by amendment and/or addition of effective chelating agents. The influence of non-specific oxidant losses (primarily soil organic matter and iron oxyhydroxides) is also estimated and the observed BTEX oxidation rate constants are compared to estimated rate constants.

\subsection{Methodology}

Benzene, toluene, ethylbenzene, and $o$-xylene (BTEX), stabilized hydrogen peroxide $\left(\mathrm{H}_{2} \mathrm{O}_{2}, 30\right.$ wt \%), L-ascorbic acid (ASC), and humic acid (sodium salts, in technical grade) were obtained from Aldrich. Ferrous sulfate $\left(\mathrm{Fe}(\mathrm{II}) \mathrm{SO}_{4} 7 \mathrm{H}_{2} \mathrm{O}\right)$, gallic acid (GAL), and decane were purchased from Sigma-Aldrich. Ferric sulfate $\left(\mathrm{Fe}(\mathrm{III})_{2}\left(\mathrm{SO}_{4}\right)_{3}\right)$ was obtained from Sigma and $N$ (2-hydroxyethyl)iminodiacetic acid (HEIDA) was from Fluka. Sodium hydroxide was purchased from Mallinckrodt. Sulfuric acid, hydrochloric acid, hydroxylamine hydrochloride, ammonium acetate, and sodium metaphosphate were purchased from Fisher Scientific. Most chemicals were of $>99 \%$ purity and all were used as received. All aqueous solutions were prepared with reagent grade water purified by reverse osmosis and a Barnstead ${ }^{\circledR}$ NANOpure II deionizing system $(\mathrm{R}=$ $\left.18.0 \mathrm{M} \Omega \mathrm{cm}^{-1}\right)$.

Soil samples were collected from an uncontaminated shallow subsurface $(\sim 2$ feet $)$ in Warsaw, IN. The soil was air-dried at room temperature for a month and the fraction that passed through a sieve of 10 US mesh $(2 \mathrm{~mm})$ was utilized in this study. The characteristics of the soil are presented in Table 2. The particle size distribution of the prepared soil was determined by a bouyoucos hydrometer method [1]. $5.0 \mathrm{~g}$ of soil was mixed with $5.0 \mathrm{~mL}$ reagent grade water and the $\mathrm{pH}$ was measured with a $\mathrm{pH}$ probe (Corning $\mathrm{pH}$ meter 320). Soil carbon content was quantified with a C/N analyzer (NA 1500 NC, Fisons Instruments). To determine total iron (Fe) and manganese $(\mathrm{Mn})$ content in the soil, an extraction procedure was employed [2]. And iron and manganese concentrations in the supernatent were determined by inductively coupled plasma atomic emission spectroscopy (AtomScan 16 spectrometer, Thermo Jarrell Ash) with an ultrasonic nebulizer (Cetac Technologies). 
Aqueous stock solutions of individual contaminants were prepared by adding $\sim 0.1 \mathrm{~mL}$ of substrate to $1.0 \mathrm{~L}$ of reagent grade water. The neck of the volumetric flask was sealed with Teflon tape to minimize volatilization of the contaminant. The aqueous stock solution was stirred for $24 \mathrm{~h}$ using a magnetic bar to ensure complete dissolution of the contaminant, and no significant volatilization loss was observed during this period. Stock solutions were prepared on a daily basis.

Soil slurry samples were prepared by placing $5.0 \mathrm{~g}$ of the Warsaw soil in an $11.2 \mathrm{~mL}$ borosilicate vial (VWR) with a Teflon-lined screw cap. $3.0 \mathrm{~mL}$ of contaminant stock solution was added to the vial, and the resulting soil slurry was vigorously mixed on a vortex for a few seconds. The soil slurry samples were equilibrated for $24 \mathrm{~h}$ to allow for sorption of the contaminant onto the soil. The initial concentration of each BTEX compound was $0.3( \pm 0.04)$ mmol contaminant / $\mathrm{kg}$ soil (20.3-36.1 mg contaminant/kg soil) for the oxidized soil samples and the slurry controls. When chelators were utilized during oxidation, three different solutions were prepared by mixing $\mathrm{Fe}(\mathrm{III})_{2}\left(\mathrm{SO}_{4}\right)_{3}$ and a ligand (L) in a molar ratio of $1: 1$ and adjusting the $\mathrm{pH}$ to pH 6.0.

Since toluene exhibits intermediate physical and chemical characteristics (relative to the other components of BTEX; Table 1), it was used as a representative compound for most Fenton oxidation experiments. However, experiments were conducted with all BTEX compounds. All Fenton-type oxidation experiments were conducted at $21-22^{\circ} \mathrm{C}$. The characterized soil samples were placed in $11.2 \mathrm{~mL}$ borosilicate vials with Teflon-lined caps. Each vial contained $5.0 \mathrm{~g}$ of soil and $5.0 \mathrm{~mL}$ of liquid. A range of $\mathrm{H}_{2} \mathrm{O}_{2}$ concentrations $(30,150$, and $300 \mathrm{mM}$ ) and catalysts $(0,2,5$, and $10 \mathrm{mM})$ were employed. The mass ratios of iron catalyst to hydrogen peroxide were 1:18, 1:37, and 1:92. Vials were vortexed after addition of catalyst solution $(1.0 \mathrm{~mL})$ and $\mathrm{H}_{2} \mathrm{O}_{2}$ solution $(1.0 \mathrm{~mL})$. The $\mathrm{pH}$ of the soil slurries prior to and after $\mathrm{H}_{2} \mathrm{O}_{2}$ addition was in the range of 5-7, depending on the catalyst concentration. During the course of oxidation, vials were placed on a reciprocating shaker at a speed of $200 \mathrm{rpm}$ for continuous agitation. Vials were sacrificed at $0,0.25,0.5,1,2,3$, and $24 \mathrm{~h}$ and the contaminant was extracted into decane $(2.5 \mathrm{~mL})$.

Two types of control experiments were conducted in parallel to the Fenton oxidation experiments. The purpose of the first set of controls was to determine contaminant mass recovery during the extraction procedure. These controls contained $3.0 \mathrm{~mL}$ of contaminated solution, $2.38 \mathrm{~mL}$ of reagent grade water (the corresponding volume for $5.0 \mathrm{~g}$ of soil) and $2.0 \mathrm{~mL}$ 
of reagent grade water. The purpose of the second control was to calculate the contaminant mass fraction remaining after Fenton oxidation; this set of controls consisted of $5.0 \mathrm{~g}$ of the soil, 3.0 $\mathrm{mL}$ of contaminated solution, and $2.0 \mathrm{~mL}$ of reagent grade water. All experiments were conducted in duplicate.

BTEX concentrations were determined with a Varian CP-3800 gas chromatograph (GC), fitted with a flame ionization detector (FID) and equipped with a DB-624 capillary column (30 $\mathrm{m} \times 0.53 \mathrm{~mm}$; film thickness of $3 \mathrm{~mm}$ ) from $\mathrm{J} \& \mathrm{~W}$ Scientific. The initial oven temperature $\left(40^{\circ} \mathrm{C}\right)$ was held at $1 \mathrm{~min}$, ramped at $3^{\circ} \mathrm{C} / \mathrm{min}$ to $80^{\circ} \mathrm{C}(1 \mathrm{~min})$ and ramped again at $100^{\circ} \mathrm{C} / \mathrm{min}$ to $250^{\circ} \mathrm{C}(1 \mathrm{~min})$. The injector and the detector temperatures were 230 and $250^{\circ} \mathrm{C}$. Under these conditions, the retention times for benzene, toluene, ethylbenzene, and $o$-xylene were 5.7, 9.9, 14.5 , and 16.3, respectively.

\subsection{Results and Discussion}

The mass recoveries (\%) for benzene (89.5-90.2), toluene (88.9-90.5), ethylbenzene (84.5-91.1), and $o$-xylene (91.1-94.8) were calculated as a ratio of the initial mass in the contaminated soil slurry control to the initial mass in the contaminant solution control. Experimental results for Fenton oxidation are summarized in Table 3. Although there is a complete kinetic data set for each experiment, for easier comparison of the kinetics, the percent mass reduction for BTEX compounds is shown for two representative reaction periods $(3 \mathrm{~h}$ and $24 \mathrm{~h}$ ). $38.7-97.7 \%$ of mass reduction in $3 \mathrm{~h}$ and 63.3-96.1\% in $24 \mathrm{~h}$ were achieved by Fenton processes when excess concentrations of $\mathrm{H}_{2} \mathrm{O}_{2}(150$ and $300 \mathrm{mM})$ were utilized in combination with $\mathrm{Fe}(\mathrm{II}), \mathrm{Fe}(\mathrm{III})$ or $\mathrm{Fe}(\mathrm{III})$-organic ligand complexes (2 and $5 \mathrm{mM}$ ). The standard deviation for BTEX destruction in duplicate samples at each reaction time point was within $\pm 7.0 \%$.

For the purpose of interpreting the experiment results, a series of relevant reactions, referred to by reaction number, are included in Table 4. The rate of mass reduction of toluene depends on the presence and oxidation state of iron in the soil slurry (Fig. 1). Mass reduction of toluene $\left(20 \%\right.$ after $2 \mathrm{~h}$ and $31 \%$ after $24 \mathrm{~h}$ ) occurs with the addition of $300 \mathrm{mM} \mathrm{H}_{2} \mathrm{O}_{2}$. These results suggested that toluene destruction may occur via a heterogeneous Fenton reaction (Reaction 25) due to the relatively high level (4.5 wt \%) of iron in the soil, in the absence of any added catalyst during the experiment [3]. However, in this case, the decomposition of $\mathrm{H}_{2} \mathrm{O}_{2}$ would not be sufficient for complete BTEX destruction or mineralization. Also, both soluble $\mathrm{Fe}(\mathrm{II})$ and $\mathrm{Fe}(\mathrm{III})$ can serve as catalysts in the Fenton destruction of BTEX [4]. Fe(II) catalysis 
results in a better mass reduction of toluene than $\mathrm{Fe}(\mathrm{III})$, suggesting that $\mathrm{Fe}(\mathrm{II})$ retains a higher catalytic activity than Fe(III) during the course of the experiment.

There are two primary reasons for these results. First, hydroxyl radicals $\left({ }^{\circ} \mathrm{OH}\right)$ are primarily responsible for contaminant destruction and are generated only by direct reaction of $\mathrm{H}_{2} \mathrm{O}_{2}$ and $\mathrm{Fe}(\mathrm{II})$ as shown in reaction 1 . In order to contribute to ${ }^{\circ} \mathrm{OH}$ production, $\mathrm{Fe}(\mathrm{III})$ must be reduced to $\mathrm{Fe}(\mathrm{II})$ via additional steps such as reactions 3 and 4 . Additionally, generation of ${ }^{\circ} \mathrm{OH}$ and the subsequent free-radical attack on target contaminants will proceed when soluble iron species are present. However, $\mathrm{Fe}(\mathrm{III})$ readily precipitates as $\mathrm{Fe}(\mathrm{OH})_{3(\mathrm{~s})}$ at near-neutral $\mathrm{pH}$ conditions.

We hypothesize that the rate of toluene mass reduction is limited by the availability of soluble iron under the experimental conditions employed. Selected experiments were performed to validate this hypothesis and the results are presented in Fig. 2. The mass reduction increases when amending with solutions of increasing iron concentrations (Fig. 2A). Toluene oxidation in the presence of $5 \mathrm{mM}$ and $10 \mathrm{mM} \mathrm{Fe}(\mathrm{III})$ is characterized by a very fast initial rate (at $\mathrm{t}<15 \mathrm{~min}$ ), and by a much slower rate at later times (Fig. 2B). Rapid degradation of toluene occurs initially because of an abundance of ${ }^{\bullet} \mathrm{OH}$ generated from hydrogen peroxide decomposition via reactions 1-2. However, as the total soluble iron decreases, in part because of the formation of $\mathrm{Fe}(\mathrm{OH})_{3(\mathrm{~s})}$, the catalytic cycles of soluble iron terminate and the observed Fenton reaction rate decreases. Hydroxyl radicals generated initially would be depleted by reaction with the target contaminant, and with other reduced compounds in the system. For the one-time injection of $5 \mathrm{mM} \mathrm{Fe}$ (III), toluene mass reduction slowed down such that the kinetics approached those observed in an "unamended" system (i.e., no iron added). When the concentration of soluble iron is renewed approximately half-way through the reaction period, the toluene rate rebounds. These findings supported the hypothesis that toluene mass reduction rates are iron catalyst-limited under the conditions of excess $\mathrm{H}_{2} \mathrm{O}_{2}$.

In the interest of retaining iron as dissolved species, the impact of chelating agents was investigated (Fig. 3). Fenton's oxidation of toluene is significantly enhanced in the presence of organic ligands. Especially in the presence of HEIDA, Fe(III) retained a much higher catalytic activity, as demonstrated by the greater reduction of toluene after 3 and $24 \mathrm{~h}$ (e.g., compare results from Test 11 to Test 15). These results are consistent with previous findings [5]. HEIDA does not facilitate oxidation of a target contaminant in the absence of iron amendments [6], 
suggesting that even strong chelating agents are incapable of solublizing sufficient amounts of iron from soil to participate in Fenton oxidation.

There are several reasons that HEIDA enhances Fenton oxidation. HEIDA is a multidentate ligand (L) and therefore, possesses a greater number of chelation sites for binding Fe(III) than gallic (GAL) and ascorbic (ASC) acids. There are 4, 3, and 2 chelation sites for HEIDA, GAL and ASC, respectively.

Although the values of the stability constants, $\mathrm{K}_{\mathrm{ST}}$, for the three $\mathrm{Fe}(\mathrm{III})$-ligand complexes are unavailable, an understanding of general relationship between chemical structure and free energy (and chemical reactivity) would be useful for describing difference in chelating activity. Complexation reactions could occur more favorably with a ligand having "more flexible structures" for the counterpart metal ion and thereby resulting in "lower free energy" of complexation products. HEIDA has more flexible, three-dimensional conformations for chelating metal ions, whereas GAL or ASC has a restricted structure because of its planar aromatic ring backbone. As a result, HEIDA may exhibit more effective chelating performance than GAL or ASC.

In addition to a ligand's stability constant, it's resistance to oxidation is also important. HEIDA (rate constant not available; $7.5 \times 10^{8} \mathrm{M}^{-1} \mathrm{~s}^{-1}$ at $\mathrm{pH} 4$ for nitrilotriacetic acid, NTA, with a similar chemical structure to HEIDA), an aminopolycarboxylate, is more stable against ${ }^{\circ} \mathrm{OH}$ attack compared to GAL (4.0x $10^{10} \mathrm{M}^{-1} \mathrm{~s}^{-1}$ at $\left.\mathrm{pH} 3\right)$ having an electrophilic aromatic ring and ASC (0.65-1.3 x10 ${ }^{10} \mathrm{M}^{-1} \mathrm{~s}^{-1}$ at $\mathrm{pH} 7$ ), a heterocyclic ester (rate constant data from [7]). Another possible explanation is offered by molecular orbital theory [8]. When compared to GAL or ASC, HEIDA is a p donor ligand which contains lone pairs of electrons that overlap with the $d$ orbitals of Fe(III). As a result, Fe(III) is better stabilized.

The role of humic acids (as a surrogate for organic matter) was also examined (Fig. 5). Toluene mass reduction in the presence of $50 \mathrm{mg} / \mathrm{L}$ of unfiltered Aldrich humic acid (HA) and 2 $\mathrm{mM} \mathrm{Fe}(\mathrm{III})$ was nearly identical to that for the soil slurry sample where $2 \mathrm{mM} \mathrm{Fe}(\mathrm{III})$ alone was amended. This result is further discussed in the context of ${ }^{\circ} \mathrm{OH}$ scavenging, in a later section of the paper.

Toluene mass reduction increases as iron concentration increases (Fig. 2). The influence of varying concentrations of Fe(II) and Fe(III) on the mass reduction of toluene is shown in Fig. 2(A). Amendment with $10 \mathrm{mM} \mathrm{Fe(III)} \mathrm{was} \mathrm{required} \mathrm{to} \mathrm{ensure} \mathrm{nearly} \mathrm{complete} \mathrm{reduction} \mathrm{of}$ 
toluene $(97.7 \%)$ after $3 \mathrm{~h}$. Also, while $5 \mathrm{mM} \mathrm{Fe}(\mathrm{II})$ resulted in significantly higher mass reduction than $5 \mathrm{mM} \mathrm{Fe(III),} 2 \mathrm{mM} \mathrm{Fe(II)} \mathrm{resulted} \mathrm{in} \mathrm{nearly} \mathrm{the} \mathrm{same} \mathrm{mass} \mathrm{reduction} \mathrm{as} 2 \mathrm{mM}$ $\mathrm{Fe}(\mathrm{III})$. These results suggest that difference in catalytic function between $\mathrm{Fe}(\mathrm{II})$ and $\mathrm{Fe}(\mathrm{III})$ would be more pronounced with increasing concentrations of iron catalyst $(>5 \mathrm{mM})$. It is therefore anticipated that $10 \mathrm{mM} \mathrm{Fe}(\mathrm{II})$ would result in at least the same extent of toluene mass reduction as $10 \mathrm{mM} \mathrm{Fe}(\mathrm{III})$.

Not surprisingly, toluene mass reduction generally increases with higher concentrations of $\mathrm{H}_{2} \mathrm{O}_{2}$ (Fig. 4). Toluene mass reduction after $3 \mathrm{~h}$ was nearly identical to that for $24 \mathrm{~h}$ in the presence of $30 \mathrm{mM} \mathrm{H}_{2} \mathrm{O}_{2}$ and $5 \mathrm{mM} \mathrm{Fe}$ (II) or $\mathrm{Fe}$ (III). When higher concentrations of $\mathrm{H}_{2} \mathrm{O}_{2}(150$ and $300 \mathrm{mM}$ ) were used, however, there were significant differences in the mass reduction of toluene after 3 and $24 \mathrm{~h}$. These results indicated that $30 \mathrm{mM} \mathrm{H}_{2} \mathrm{O}_{2}$ was rapidly depleted $(<15$ min) and there was no residual $\mathrm{H}_{2} \mathrm{O}_{2}$ available for subsequent slower phase reactions, even if there was sufficient soluble iron. Another observation is that the difference in toluene mass reduction in the presence of $\mathrm{Fe}(\mathrm{II})$ or $\mathrm{Fe}(\mathrm{III})$ is more pronounced at lower $\mathrm{H}_{2} \mathrm{O}_{2}$ concentrations. $\mathrm{Fe}(\mathrm{II})$ yields greater mass reduction of toluene than $\mathrm{Fe}(\mathrm{III})$, confirming that $\mathrm{Fe}(\mathrm{II})$ is a more effective catalyst than Fe(III) for Fenton reactions.

It is helpful to introduce a conceptual model that describes Fenton reactions in the aqueous phase of a soil slurry system. The net production rate of ${ }^{\circ} \mathrm{OH}$ is equal to the aggregate rates of ${ }^{\circ} \mathrm{OH}$ generation minus the aggregate rates of consumption ( Eqn. 1). The rate of ${ }^{\circ} \mathrm{OH}$ generation is determined by reactions 1 and 25 (Table 4). The rate of ${ }^{\circ} \mathrm{OH}$ consumption is dependent on its reactions with a target contaminant, $\mathrm{R}_{i}$, and with ${ }^{\circ} \mathrm{OH}$ scavengers, $\mathrm{S}_{j}$.

$$
\frac{d[\mathrm{OH} \bullet]}{d t}=\left\{k_{1}[\mathrm{Fe}(\mathrm{II})]+k_{25}\left[\mathrm{Fe}_{\mathrm{red}(\mathrm{s})}\right]\right\}\left[\mathrm{H}_{2} \mathrm{O}_{2}\right]-\left(\sum_{i} k_{\mathrm{OH} \cdot i}\left[\mathrm{R}_{i}\right]+\sum_{j} k_{\mathrm{OH} \cdot \mathrm{j}}\left[\mathrm{S}_{j}\right]\right)[\mathrm{OH} \bullet]
$$

where $k_{1}$ and $k_{25}$ are the second-order reaction rate constants for homogenous and heterogeneous Fenton reactions, respectively. $k_{\mathrm{OH} \cdot i}$ is the second-order rate constant $\left(\mathrm{M}^{-1} \mathrm{~S}^{-1}\right)$ for the reaction of an $i^{\text {th }}$ target contaminant such as BTEX compound with ${ }^{\bullet} \mathrm{OH}$ (Table 1), and $\sum k_{\mathrm{OH} \cdot j}\left[\mathrm{~S}_{j}\right]$ is a sum of the pseudo-first order rate constant $\left(\mathrm{s}^{-1}\right)$ for hydroxyl radical consumption by all the other constituents such as iron oxyhydroxide, soil organic carbon, or externally added scavengers such as organic chelating ligands and HA. Free-radical reactions are extremely rapid, and it is reasonable to assume that a steady state is achieved early in the reaction. 
Since $d[\mathrm{OH} \bullet] / d \mathrm{t}$ is zero at steady-state, the steady-state ${ }^{\bullet} \mathrm{OH}$ concentration, $[\mathrm{OH} \bullet]_{\mathrm{ss}}$, is

$$
[\mathrm{OH} \bullet]_{\mathrm{ss}}=\frac{\left\{k_{1}[\mathrm{Fe}(\mathrm{II})]+k_{25}\left[\mathrm{Fe}_{\mathrm{red}(\mathrm{s})}\right]\right\}\left[\mathrm{H}_{2} \mathrm{O}_{2}\right]}{\sum_{i} k_{\mathrm{OH} \cdot i}\left[\mathrm{R}_{i}\right]+\sum_{j} k_{\mathrm{OH} \cdot j}\left[\mathrm{~S}_{j}\right]}
$$

The reaction rate of a target contaminant, $\mathrm{R}_{i}$, can be described by pseudo-first order kinetics, with a first order rate constant, $k^{\prime}\left(\mathrm{s}^{-1}\right)$ provided that $[\mathrm{OH} \bullet]_{\mathrm{ss}}$ is constant (Eqn. 3).

$$
-\frac{d\left[\mathrm{R}_{i}\right]}{d t}=k_{16}[\mathrm{OH} \bullet]_{\mathrm{ss}}\left[\mathrm{R}_{i}\right]=k^{\prime}\left[\mathrm{R}_{i}\right]
$$

From the experimental data at a reaction time of $15 \mathrm{~min}$, the values for $k^{\prime}$ and $[\mathrm{OH} \bullet]_{\mathrm{ss}}$ were 3.6-7.8 $\times 10^{-4} \mathrm{~s}^{-1}$ and 7.1-15.2 $\times 10^{-14} \mathrm{M}$, respectively.

Theoretical values for $k^{\prime}$ can be obtained as a product of $k_{16}$ and $[\mathrm{OH} \bullet]_{\mathrm{Ss}}$. The steadystate concentrations of hydroxyl radical at the initial reaction time, $[\mathrm{OH} \bullet]_{\mathrm{ss}}$, ini, can be estimated using available rate constants of relevant reactions involving ${ }^{\circ} \mathrm{OH}$ and initial concentrations of various reactants (Eqn. 4):

$$
[\mathrm{OH} \bullet]_{s s, \text { ini }}=\frac{\left\{\mathrm{k}_{1}[\mathrm{Fe}(\mathrm{II})]_{0}+\mathrm{k}_{25}\left[\mathrm{Fe}_{\mathrm{red}(\mathrm{s})}\right]_{0}\right\}\left[\mathrm{H}_{2} \mathrm{O}_{2}\right]_{0}}{\mathrm{k}_{16}[\mathrm{R}]_{0}+\mathrm{k}_{3}\left[\mathrm{H}_{2} \mathrm{O}_{2}\right]_{0}+\mathrm{k}_{4}[\mathrm{Fe}(\mathrm{II})]_{0}+\mathrm{k}_{5}[\mathrm{OH} \bullet]_{0}+\mathrm{k}_{20}\left[\mathrm{HCO}_{3}^{-}\right]_{0}+\mathrm{k}_{24}\left[\mathrm{SOC}_{0}+\mathrm{k}_{25}\left[\mathrm{Fe}_{\mathrm{red}}(\mathrm{s})\right]_{0}\right.}
$$

Necessary assumptions were: the molecular weight of SOC is $1000 \mathrm{~g} \mathrm{~mol}^{-1} ; k_{24}$ is $1 \times 10^{10}$ $\mathrm{M}^{-1} \mathrm{~s}^{-1} ;\left[\mathrm{HCO}_{3}^{-}\right]_{0}=73.4 \mathrm{mM}$ (estimated when $\mathrm{CaCO}_{3}(\mathrm{~s})$ in excess is dissolved in groundwater that is open to atmosphere at $\mathrm{pH} 5.0[9]) ; \alpha$-geothite, $\mathrm{FeO}(\mathrm{OH})_{(\mathrm{s})}$, was used for the calculation of $\mathrm{Fe}_{\operatorname{red}(\mathrm{s})}$ concentration, $\left[\mathrm{Fe}_{\operatorname{red}(\mathrm{s})}\right]_{0}=1.6 \times\left(\right.$ total iron content) $=71756 \mathrm{mg} \mathrm{FeO}(\mathrm{OH})_{(\mathrm{s})} / \mathrm{kg} \mathrm{soil}$; other rate constants were used as reported. Accordingly, the estimated $[\mathrm{OH} \bullet]_{\mathrm{ss}}$, ini and $k^{\prime}$ were 7.8-19.5 x $10^{-13} \mathrm{M}$ and 3.98-9.94 $\times 10^{-3} \mathrm{~s}^{-1}$, respectively.

The values for $k^{\prime}$ and $[\mathrm{OH} \bullet]_{\mathrm{ss}}$ obtained from the experiments were approximately one order of magnitude lower than the predicted values of $k^{\prime}$ and $[\mathrm{OH} \bullet]_{\mathrm{ss}}$, ini. Given the very dynamic nature of the oxidation, and the number of assumptions that were made, there is reasonable agreement between the experimental and the predicted rate constants. Taking into account that the rates of toluene destruction must be at least faster at initial time than those at relatively longer time scale (15 $\mathrm{min}$ ), this comparison demonstrated that the model approach was relevant to the experimental data. In addition, a sensitivity analysis indicated that iron 
oxyhydroxide content and initial concentrations of $\mathrm{Fe}(\mathrm{II})$ and $\mathrm{H}_{2} \mathrm{O}_{2}$ were the most important variables in determining $[\mathrm{OH} \bullet]_{\mathrm{Ss}}$, ini .

Fenton treatment was also tested for benzene, ethylbenzene, and $o$-xylene (Fig. 5). Mass reductions of each contaminant by Fenton oxidation in a single contaminant system were very similar after $3 \mathrm{~h}$ and $24 \mathrm{~h}$ (Fig. 5(A)). Since the reaction conditions are basically the same for each contaminant, the mass reduction rate of a single BTEX contaminant in a soil slurry system would be a function of its second-order reaction rate constant with ${ }^{\bullet} \mathrm{OH}, k_{16}$. Since BTEX compounds exhibit rate constants of similar magnitude $\left(5.1-7.6 \times 10^{9} \mathrm{M}^{-1} \mathrm{~s}^{-1}\right)$, it is reasonable that their observed mass reduction rates are also similar. There are three xylene isomers (ortho, meta and para) and the total mass of the xylenes are of regulatory concern. The ortho isomer is representative of the others for several reaons. First, the rate constants of hydroxyl radical attack of the meta and para isomers $\left(7.0 \times 10^{9} \mathrm{~L} / \mathrm{mol}-\mathrm{sec}\right.$ and $7.5 \times 10^{9} \mathrm{~L} / \mathrm{mol}-\mathrm{sec}$, respectively) are nearly the same as that of the ortho isomer $\left(6.7 \times 10^{9} \mathrm{~L} / \mathrm{mol}-\mathrm{sec}\right)$. These rate constants are important indicators of degradation by Fenton oxidation because hydroxyl radical is the primary oxidant under these conditions. Also, most other physico-chemical characteristics such as aqueous solubility, vapor pressure, Henry's law constant, and the sorption coefficient for organic carbon are basically same within these isomers. It is therefore anticipated that the degradation effectiveness for all three isomers will be similar.

Comparison of Fig. 5(A) with Fig. 5(B) indicates that mass reduction of individual BTEX compounds by Fenton oxidation is quite similar to that for each compound in a BTEX mixture. Competition of scavengers for ${ }^{\circ} \mathrm{OH}$ may be the key to interpreting these results. Since the consumption of ${ }^{\circ} \mathrm{OH}$ by other scavengers is much faster than consumption by target contaminants (i.e., $\sum k_{\mathrm{OH} \cdot i}\left[\mathrm{R}_{i}\right]=8.1 \times 10{ }^{6} \mathrm{~s}^{-1}<<\sum k_{\mathrm{OH} \cdot{ }_{j}}\left[\mathrm{~S}_{j}\right]=5.8 \times 10{ }^{10} \mathrm{~s}^{-1}$ ) under the experimental conditions for the data presented in Fig. 5(B), ${ }^{\bullet} \mathrm{OH}$ concentration at steady-state is virtually independent of the total concentration of target contaminants (Eqn. 5):

$$
[\mathrm{OH} \bullet]_{\mathrm{ss}} \approx \frac{\left\{k_{1}[\mathrm{Fe}(\mathrm{II})]+k_{25}\left[\mathrm{Fe}_{\mathrm{red}(\mathrm{s})}\right]\right\}\left[\mathrm{H}_{2} \mathrm{O}_{2}\right]}{\sum_{j} k_{\mathrm{OH} \cdot j}\left[\mathrm{~S}_{j}\right]}
$$

Since the oxidant demand from organic carbon (100 mg C / $\mathrm{kg}$ soil) provided by $1.2 \mathrm{mmol}$ total BTEX / kg soil is considerably less than the demand from naturally occurring organic carbon 
(4300 $\mathrm{mg} \mathrm{C} \mathrm{/} \mathrm{kg}$ soil) and iron oxyhydroxides ( $45000 \mathrm{mg}$ as Fe / $\mathrm{kg}$ soil), mass reduction of a single contaminant in the same soil slurry system remains unaffected by the presence of the other three contaminants. In this slurry system, the competition of BTEX compounds with each other for hydroxyl radicals is negligible compared to competition with other scavengers.

For the same reasons, the mass reduction of toluene remains unchanged in the presence of $50 \mathrm{mg} / \mathrm{L}$ of HA (Fig. 3) because HA does not substantially affect hydroxyl radical consumption in the soil slurry (i.e., $\sum k_{\mathrm{OH} \cdot j}\left[\mathrm{~S}_{j}\right]$ remains constant).

\subsection{Conclusions}

Fenton-type treatment of BTEX-contaminated soil slurry using a liquid to soil ratio of 1.0 $\mathrm{mL} / \mathrm{g}$ was investigated in batch experiments. A characterized soil (Warsaw, IN) was spiked with BTEX compounds, and the performance of Fenton treatment was evaluated using a matrix of $\mathrm{H}_{2} \mathrm{O}_{2}$ concentrations and iron catalysts ( $\mathrm{Fe}(\mathrm{II}), \mathrm{Fe}(\mathrm{III})$, and $\mathrm{Fe}(\mathrm{III})$-organic ligand complexes) in the range of near-neutral $\mathrm{pH}$. The results indicate that for initial concentrations of BTEX (0.26$0.34 \mathrm{mmol} / \mathrm{kg}$ soil), 38.7-97.7 \% of mass reduction in $3 \mathrm{~h}$ and $63.3-96.1 \%$ in $24 \mathrm{~h}$ were achieved by Fenton processes where $\mathrm{H}_{2} \mathrm{O}_{2}(150$ and $300 \mathrm{mM}$ ) with combinations of $\mathrm{Fe}$ (II) or $\mathrm{Fe}(\mathrm{III})$ or Fe(III)-organic ligand complexes (2 and $5 \mathrm{mM}$ ) were utilized.

Soluble iron catalyst was considered one of the key parameters for effective performance in Fenton oxidation of contaminated soil slurry systems. Fe(II) generally showed higher catalytic activity than $\mathrm{Fe}(\mathrm{III})$. In addition, Fenton treatment of toluene could be significantly enhanced in the presence of HEIDA, an organic chelating agent for Fe(III). Amendment of 10 $\mathrm{mM} \mathrm{Fe}(\mathrm{III})$ or $2 \mathrm{mM} \mathrm{Fe}(\mathrm{III})$-HEIDA (molar ratio of 1:1 ) was required to attain over $95 \%$ mass reduction of toluene in $3 \mathrm{~h}$ reaction period. It is anticipated that as long as a sufficient amount of soluble iron is augmented or effective chelating agents are employed, Fenton processes could be effectively utilized for remediation of gasoline-contaminated soils and groundwater within a fairly short clean-up time scale (hours to days). 


\subsection{Tables}

Table 2-1: Selected physical and chemical characteristics of BTEX compounds

\begin{tabular}{|l|l|l|l|l|}
\hline Attribute (units) & Benzene & Toluene & Ethylbenzene & o-Xylene \\
\hline Chemical Formula & $\mathrm{C}_{6} \mathrm{H}_{6}$ & $\mathrm{C}_{6} \mathrm{H}_{5}\left(\mathrm{CH}_{3}\right)$ & $\mathrm{C}_{6} \mathrm{H}_{5}\left(\mathrm{C}_{2} \mathrm{H}_{5}\right)$ & $\mathrm{C}_{6} \mathrm{H}_{4}\left(\mathrm{CH}_{3}\right)_{2}$ \\
\hline $\mathrm{MW}\left(\mathrm{g} \mathrm{mol}^{-1}\right)$ & 78.1 & 92.1 & 106.2 & 106.2 \\
\hline $\mathrm{P}^{\mathrm{o}}(\mathrm{atm})$ & 0.125 & 0.037 & 0.013 & 0.009 \\
\hline $\mathrm{S}_{\mathrm{w}}(\mathrm{mol} \mathrm{L}$ & & $5.81 \times 10^{-3}$ & $1.43 \times 10^{-3}$ & $1.65 \times 10^{-3}$ \\
\hline $\mathrm{K}_{\mathrm{H}}\left(\mathrm{atm} \mathrm{m}^{3} \mathrm{~mol}^{-1}\right)$ & $5.59 \times 10^{-3}$ & $6.37 \times 10^{-3}$ & $9.00 \times 10^{-3}$ & $5.10 \times 10^{-3}$ \\
\hline $\mathrm{K}_{\mathrm{oc}}\left(\mathrm{L} \mathrm{kg}^{-1}\right)$ & 83 & 300 & 1100 & 830 \\
\hline$k_{\mathrm{OH}}\left(\mathrm{M}^{-1} \mathrm{~s}^{-1}\right)$ & $7.6 \times 10^{9}$ & $5.1 \times 10^{9}$ & $7.5 \times 10^{9}$ & $6.7 \times 10^{9}$ \\
\hline
\end{tabular}

From reference [10]: $\mathrm{MW}=$ molecular weight; $\mathrm{P}^{\mathrm{o}}=$ vapor pressure; $\mathrm{S}_{\mathrm{W}}=$ aqueous solubility; $\mathrm{K}_{\mathrm{H}}$ = Henry's law constant. $\mathrm{K}_{\mathrm{oc}}=$ sorption coefficient for organic carbon [11]; $k_{\mathrm{OH}}=$ second-order reaction rate constant for hydroxyl radical [7].

\section{Table 2-2: Characteristics of soil (Warsaw, IN)}

\begin{tabular}{|l|l|l|}
\hline Characteristic & Units & Value \\
\hline Sand $(0.05-2.0 \mathrm{~mm})$ & dry wt \% & 80.0 \\
\hline Silt $(0.002-0.05 \mathrm{~mm})$ & dry wt \% & 7.7 \\
\hline Clay $(<0.002 \mathrm{~mm})$ & dry wt \% & 12.3 \\
\hline Soil pH (in reagent grade water) & - & 7.5 \\
\hline Carbon content: & & \\
\hline \multicolumn{1}{|c|}{ Total carbon } & $\mathrm{mg} / \mathrm{kg}$ & $7,000( \pm 410)$ \\
\hline Total organic carbon & $\mathrm{mg} / \mathrm{kg}$ & $4,300( \pm 260)$ \\
\hline Total iron & $\mathrm{mg} / \mathrm{kg}$ & 45,000 \\
\hline
\end{tabular}


Table 2-3: Summarized results for Fenton oxidation of BTEX in soil slurries

\begin{tabular}{|c|c|c|c|c|c|c|c|}
\hline $\begin{array}{l}\text { Experiment } \\
\text { No. }\end{array}$ & $\mathrm{R}$ & $\begin{array}{l}\mathrm{C}_{\mathrm{o}} \\
(\mathrm{mmol} \\
\mathrm{kg})\end{array}$ & $\begin{array}{l}\mathrm{H}_{2} \mathrm{O}_{2} \\
(\mathrm{mM})\end{array}$ & Catalyst & $\begin{array}{l}\text { Catalyst } \\
(\mathrm{mM})\end{array}$ & $\begin{array}{l}\% \operatorname{Red}^{1} \\
(\mathrm{t}=3 \mathrm{~h})\end{array}$ & $\begin{array}{l}\% \operatorname{Red}^{1} \\
(\mathrm{t}=24 \mathrm{~h})\end{array}$ \\
\hline 1 & $\mathrm{~T}$ & 0.28 & 30 & None & - & 7.8 & 11.0 \\
\hline 2 & $\mathrm{~T}$ & 0.28 & 30 & $\mathrm{Fe}(\mathrm{III})$ & 5 & 20.0 & 23.6 \\
\hline 3 & $\mathrm{~T}$ & 0.28 & 30 & $\mathrm{Fe}(\mathrm{II})$ & 5 & 55.7 & 56.3 \\
\hline 4 & $\mathrm{~T}$ & 0.29 & 150 & None & - & 8.2 & 10.0 \\
\hline 5 & $\mathrm{~T}$ & 0.29 & 150 & $\mathrm{Fe}(\mathrm{III})$ & 5 & 38.7 & 63.3 \\
\hline 6 & $\mathrm{~T}$ & 0.29 & 150 & $\mathrm{Fe}(\mathrm{II})$ & 5 & 59.1 & 76.9 \\
\hline 7 & B & 0.34 & 150 & $\mathrm{Fe}(\mathrm{II})$ & 5 & 53.4 & 67.0 \\
\hline 8 & $\mathrm{E}$ & 0.30 & 150 & $\mathrm{Fe}(\mathrm{II})$ & 5 & 58.8 & 71.5 \\
\hline 9 & $\mathrm{X}$ & 0.32 & 150 & $\mathrm{Fe}(\mathrm{II})$ & 5 & 61.1 & 76.6 \\
\hline 10 & $\mathrm{~T}$ & 0.34 & 300 & None & - & 19.7 & 31.4 \\
\hline 11 & $\mathrm{~T}$ & 0.33 & 300 & $\mathrm{Fe}(\mathrm{III})$ & 2 & 51.8 & 61.0 \\
\hline 12 & $\mathrm{~T}$ & 0.33 & 300 & $\mathrm{Fe}(\mathrm{II})$ & 2 & 54.0 & 57.8 \\
\hline 13 & $\mathrm{~T}$ & 0.33 & 300 & Fe(III)-ASC & $2+2$ & 62.6 & 73.5 \\
\hline 14 & $\mathrm{~T}$ & 0.33 & 300 & Fe(III)-GAL & $2+2$ & 63.8 & 74.9 \\
\hline 15 & $\mathrm{~T}$ & 0.33 & 300 & $\begin{array}{l}\text { Fe(III)- } \\
\text { HEIDA }\end{array}$ & $2+2$ & 95.5 & 96.1 \\
\hline 16 & $\mathrm{~T}$ & 0.33 & 300 & $\mathrm{Fe}(\mathrm{III})$ & 5 & \begin{tabular}{|l|}
58.6 \\
$(54.7)^{3}$
\end{tabular} & 87.0 \\
\hline 17 & $\mathrm{~T}$ & 0.34 & 300 & $\mathrm{Fe}(\mathrm{II})$ & 5 & 71.7 & 90.9 \\
\hline 18 & $\mathrm{~T}$ & 0.32 & 300 & $\mathrm{Fe}(\mathrm{III})$ & 10 & \begin{tabular}{|l|}
97.7 \\
$(95.8)^{3}$
\end{tabular} & NT \\
\hline 19 & $\mathrm{~T}$ & 0.33 & 300 & $\mathrm{Fe}(\mathrm{III})$ & $5(\mathrm{x} 2)^{2}$ & $(95.3)^{3}$ & NT \\
\hline 20 & $\mathrm{~T}$ & 0.32 & 300 & Fe(III)-HA & $\begin{array}{l}5+50 \\
\mathrm{mg} / \mathrm{L}\end{array}$ & 48.6 & 56.5 \\
\hline \multirow{4}{*}{$21^{4}$} & $\mathrm{~B}$ & 0.32 & \multirow{4}{*}{150} & \multirow{4}{*}{$\mathrm{Fe}(\mathrm{II})$} & \multirow{4}{*}{5} & 69.4 & 74.1 \\
\hline & $\mathrm{T}$ & 0.26 & & & & 68.1 & 77.7 \\
\hline & $\mathrm{E}$ & 0.27 & & & & 62.2 & 68.9 \\
\hline & $\mathrm{X}$ & 0.28 & & & & 64.5 & 72.1 \\
\hline
\end{tabular}

Abbreviations: $\mathrm{R}=$ target contaminant, $\mathrm{C}_{\mathrm{o}}=$ initial concentration of contaminant in soil slurry, $\mathrm{Fe}(\mathrm{II})=\mathrm{FeSO}_{4} 7 \mathrm{H}_{2} \mathrm{O}, \mathrm{Fe}(\mathrm{III})=\mathrm{Fe}_{2}\left(\mathrm{SO}_{4}\right)_{3}, \mathrm{~B}=$ benzene, $\mathrm{T}=$ toluene, $\mathrm{E}=$ ethylbenzene, $\mathrm{X}=o$ xylene, $\mathrm{ASC}=\mathrm{L}$-ascorbic acid, $\mathrm{GAL}=$ gallic acid, $\mathrm{HA}=$ unfiltered Aldrich humic acid, $\mathrm{NT}=$ not tested.

Notes: $1 . \%$ mass reduction at time $\mathrm{t}=[$ (initial mass of contaminant - mass at time $\mathrm{t}) /$ initial mass of contaminant] x 100. 2. Addition of Fe(III) at reaction times $t=0$ and 65 min. 3 . Measured at 2 h. 4. Mixture of benzene, toluene, ethylbenzene, and $o$-xylene. 
Table 2-4: Proposed reactions for BTEX destruction by Fenton oxidation in soil slurries

\begin{tabular}{|c|c|c|c|}
\hline No. & Reaction & Rate constant $\left(\mathrm{M}^{-1} \mathrm{~s}^{-1}\right)$ at $20-25^{0} \mathrm{C}$ & Ref. \\
\hline \multicolumn{4}{|c|}{ Group 1. Principle Fenton reaction and related radical reactions in the aqueous phase } \\
\hline $1 *$ & $\mathrm{Fe}(\mathrm{II})+\mathrm{H}_{2} \mathrm{O}_{2} \rightarrow \mathrm{Fe}(\mathrm{III})+\mathrm{OH} \bullet$ & $\mathrm{Fe}^{2+}: 76$ & {$[12]$} \\
\hline $2 \mathrm{a}$ & $\mathrm{Fe}(\mathrm{III})+\mathrm{H}_{2} \mathrm{O}_{2} \leftrightarrow \mathrm{Fe}-\mathrm{OOH}(\mathrm{II})+\mathrm{H}^{+}$ & $\mathrm{Fe}^{3+}: \mathrm{pK}_{\mathrm{a}}=2.44$ & [13] \\
\hline $2 b$ & $\mathrm{Fe}-\mathrm{OOH}(\mathrm{II}) \rightarrow \mathrm{Fe}(\mathrm{II})+\mathrm{HO}_{2}^{\bullet}$ & $\mathrm{Fe}^{3+}: 0.002-0.011 \mathrm{~s}^{-1}(\mathrm{pH}<3)$ & [13] \\
\hline $3 *$ & $\mathrm{OH} \bullet+\mathrm{H}_{2} \mathrm{O}_{2} \rightarrow \mathrm{O}_{2} \bullet+\mathrm{H}_{2} \mathrm{O}$ & $2.7 \times 10^{7}(\mathrm{pH} 7)$ & [7] \\
\hline $4^{*}$ & $\mathrm{OH} \bullet+\mathrm{Fe}(\mathrm{II}) \rightarrow \mathrm{Fe}(\mathrm{III})+\mathrm{OH}^{-}$ & $\mathrm{Fe}^{2+}: 3.2-3.5 \times 10^{8}(\mathrm{pH} 4.5-7)$ & [14] \\
\hline $5^{*}$ & $2 \mathrm{OH} \bullet \rightarrow \mathrm{H}_{2} \mathrm{O}_{2}$ & $5.2-6.2 \times 10^{9}(\mathrm{pH} 3,7)$ & [7] \\
\hline 6 & $\mathrm{HO}_{2} \bullet \leftrightarrow \mathrm{O}_{2} \bullet+\mathrm{H}^{+}$ & $\mathrm{pK}_{\mathrm{a}}=4.8$ & [9] \\
\hline 7 & $\mathrm{HO}_{2} \bullet+\mathrm{Fe}(\mathrm{II}) \rightarrow \mathrm{H}_{2} \mathrm{O}_{2}+\mathrm{Fe}(\mathrm{III})$ & $\mathrm{Fe}^{2+}: 1.2 \times 10^{6}(\mathrm{pH} 1-7)$ & [7] \\
\hline 10 & $\mathrm{O}_{2} \cdot \bullet+\mathrm{Fe}(\mathrm{II}) \rightarrow \mathrm{H}_{2} \mathrm{O}_{2}+\mathrm{Fe}(\mathrm{III})$ & $\mathrm{Fe}^{2+}: 1 \times 10^{7}(\mathrm{pH} \mathrm{1-7})$ & [7] \\
\hline 11 & $\mathrm{O}_{2} \cdot \bullet+\mathrm{Fe}(\mathrm{III}) \rightarrow \mathrm{Fe}(\mathrm{II})+\mathrm{O}_{2}$ & $\mathrm{FeOH}^{2+}: 1.5 \times 10^{8}(\mathrm{pH} 7)$ & [7] \\
\hline 12 & $\mathrm{HO}_{2} \bullet+\mathrm{O}_{2}^{-} \bullet \rightarrow \mathrm{H}_{2} \mathrm{O}_{2}+\mathrm{O}_{2}+\mathrm{OH}^{-}$ & $9.7 \times 10^{7}$ & [7] \\
\hline 13 & $\mathrm{OH} \bullet+\mathrm{HO}_{2} \bullet \rightarrow \mathrm{H}_{2} \mathrm{O}+\mathrm{O}_{2}$ & $6.6 \times 10^{9}(\mathrm{pH} 0.5-6.75)$ & [7] \\
\hline 14 & $\mathrm{OH} \bullet+\mathrm{O}_{2}^{-} \bullet \rightarrow \mathrm{OH}^{-}+\mathrm{O}_{2}$ & $0.7-1 \times 10^{10}(\mathrm{pH} 2.7-8.5)$ & [7] \\
\hline 15 & $\mathrm{Fe}(\mathrm{II})+\mathrm{O}_{2}+\mathrm{OH}^{-} \rightarrow \mathrm{Fe}(\mathrm{III})$ & $\mathrm{r}=k[\mathrm{Fe}(\mathrm{II})]\left[\mathrm{O}_{2(\mathrm{aq})}\right] /\left[\mathrm{H}^{+}\right]^{2} ; k=5 \times 10^{-14} \mathrm{Ms}^{-1}$ & [9] \\
\hline \multicolumn{4}{|c|}{ Group 2. Reactions associated with BTEX (R) and its break-down intermediates and/or products } \\
\hline $16^{*}$ & $\mathrm{OH} \bullet+\mathrm{R} \rightarrow \mathrm{ROH} \bullet$ & $5.1-7.6 \times 10^{9}$ & [7] \\
\hline 17 & $\begin{array}{l}\mathrm{ROH} \bullet+\mathrm{O}_{2}\left[\leftrightarrow \mathrm{R}(\mathrm{OH}) \mathrm{O}_{2} \bullet\right] \rightarrow \mathrm{ROH}+\mathrm{HO}_{2} \bullet \text { or } \\
\rightarrow \rightarrow \text { ring-opened products }\end{array}$ & $10^{8}-10^{9}$ & {$[15,16]$} \\
\hline 18 & $\mathrm{ROH} \bullet+\mathrm{Fe}(\mathrm{III}) \rightarrow \mathrm{ROH}+\mathrm{Fe}(\mathrm{II})$ & 7000 & [15] \\
\hline \multicolumn{4}{|c|}{ Group 3. Reactions associated with carbonate species } \\
\hline $19 \mathrm{a}$ & $\mathrm{CO}_{2(\mathrm{~g})}+\mathrm{H}_{2} \mathrm{O} \leftrightarrow \mathrm{H}_{2} \mathrm{CO}_{3(\mathrm{aq})}$ & $\mathrm{pK}_{\mathrm{a}}=1.47$ & [9] \\
\hline $19 \mathrm{~b}$ & $\mathrm{H}_{2} \mathrm{CO}_{3(\mathrm{aq})} \leftrightarrow \mathrm{HCO}_{3}^{-}+\mathrm{H}^{+}$ & $\mathrm{pK}_{\mathrm{a}}=6.35$ & [9] \\
\hline $20^{*}$ & $\mathrm{HCO}_{3}^{-}+\mathrm{OH}^{\bullet} \rightarrow \mathrm{CO}_{3}^{-} \bullet+\mathrm{OH}^{-}$ & $1 \times 10^{7}(\mathrm{pH} 6.5)$ & [7] \\
\hline 21 & $\mathrm{CO}_{3}^{-} \bullet+\mathrm{H}_{2} \mathrm{O}_{2} \rightarrow \mathrm{HO}_{2}^{\bullet}+\mathrm{HCO}_{3}^{-}$ & $8 \times 10^{5}$ & [3] \\
\hline 22 & $2 \mathrm{CO}_{3} \cdot \bullet \rightarrow$ products & $2.2 \times 10^{6}$ & [3] \\
\hline 23 & $\mathrm{CaCO}_{3(\mathrm{~s})}+\mathrm{H}^{+} \leftrightarrow \mathrm{Ca}^{2+}+\mathrm{HCO}_{3}^{-}$ & $\mathrm{K}=269$ & [9] \\
\hline \multicolumn{4}{|c|}{ Group 4. Reaction associated with soil organic carbon (SOC) } \\
\hline $24^{*}$ & $\mathrm{SOC}+\mathrm{OH} \bullet \rightarrow$ products & $10^{7}-10^{10}$ & [17] \\
\hline \multicolumn{4}{|c|}{ Group 5. Soil mineral surface catalyzed reactions } \\
\hline $25^{*}$ & $\mathrm{Fe}_{\mathrm{red}(\mathrm{s})}+\mathrm{H}_{2} \mathrm{O}_{2} \rightarrow \mathrm{Fe}_{\text {ox (s) }}+\mathrm{OH} \bullet$ & 0.00167 & [3] \\
\hline 26 & $\mathrm{Fe}_{\mathrm{ox}(\mathrm{s})}+\mathrm{H}_{2} \mathrm{O}_{2} \rightarrow \mathrm{Fe}_{\mathrm{red}(\mathrm{s})}+\mathrm{HO}_{2} \bullet$ & 0.000167 & [3] \\
\hline $27 *$ & $\mathrm{Fe}_{\mathrm{red}(\mathrm{s})}+\mathrm{OH} \bullet \rightarrow \mathrm{Fe}_{\mathrm{ox}(\mathrm{s})}+\mathrm{OH}^{-}$ & $8 \times 10^{11}$ & [3] \\
\hline 28 & $\mathrm{Fe}_{\mathrm{red}(\mathrm{s})}+\mathrm{HO}_{2} \bullet \rightarrow \mathrm{Fe}_{\mathrm{ox}(\mathrm{s})}+\mathrm{H}_{2} \mathrm{O}_{2}$ & $2 \times 10^{7}$ & [3] \\
\hline 29 & $\mathrm{Fe}_{\mathrm{ox}(\mathrm{s})}+\mathrm{O}_{2} \cdot \bullet \rightarrow \mathrm{Fe}_{\text {red (s) }}+\mathrm{O}_{2}$ & $1.42-4.17$ & {$[3]$} \\
\hline
\end{tabular}

Notes: *Denotes key reactions involving hydroxyl radical. 1. $\mathrm{Fe}_{\mathrm{red}(\mathrm{s})}$ and $\mathrm{Fe}_{\mathrm{ox}(\mathrm{s})}$ are reduced and oxidized iron oxyhydroxide surface sites. 2. The values for the second order rate constants ( $g$ $\mathrm{sand} / \mathrm{mL}$ liquid $)^{-1} \mathrm{~s}^{-1}$ for reactions 25 through 29 are mineral specific and were estimated for autoclaved Iowa River alluvial sand [3]. 


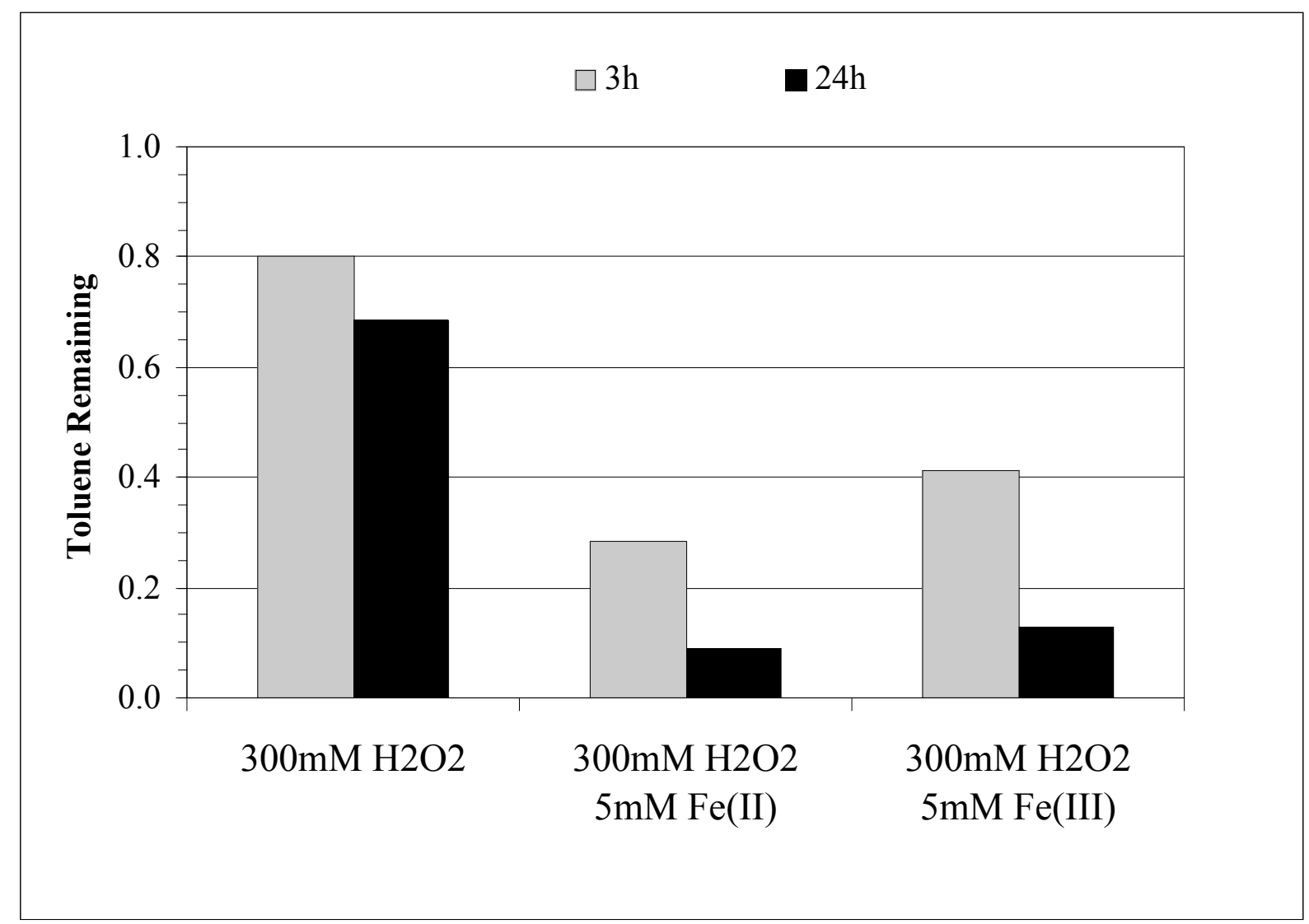

Fig. 2-1. Effects of different catalysts on toluene destruction at near-neutral pH (Expts. 10, 16, 17). 

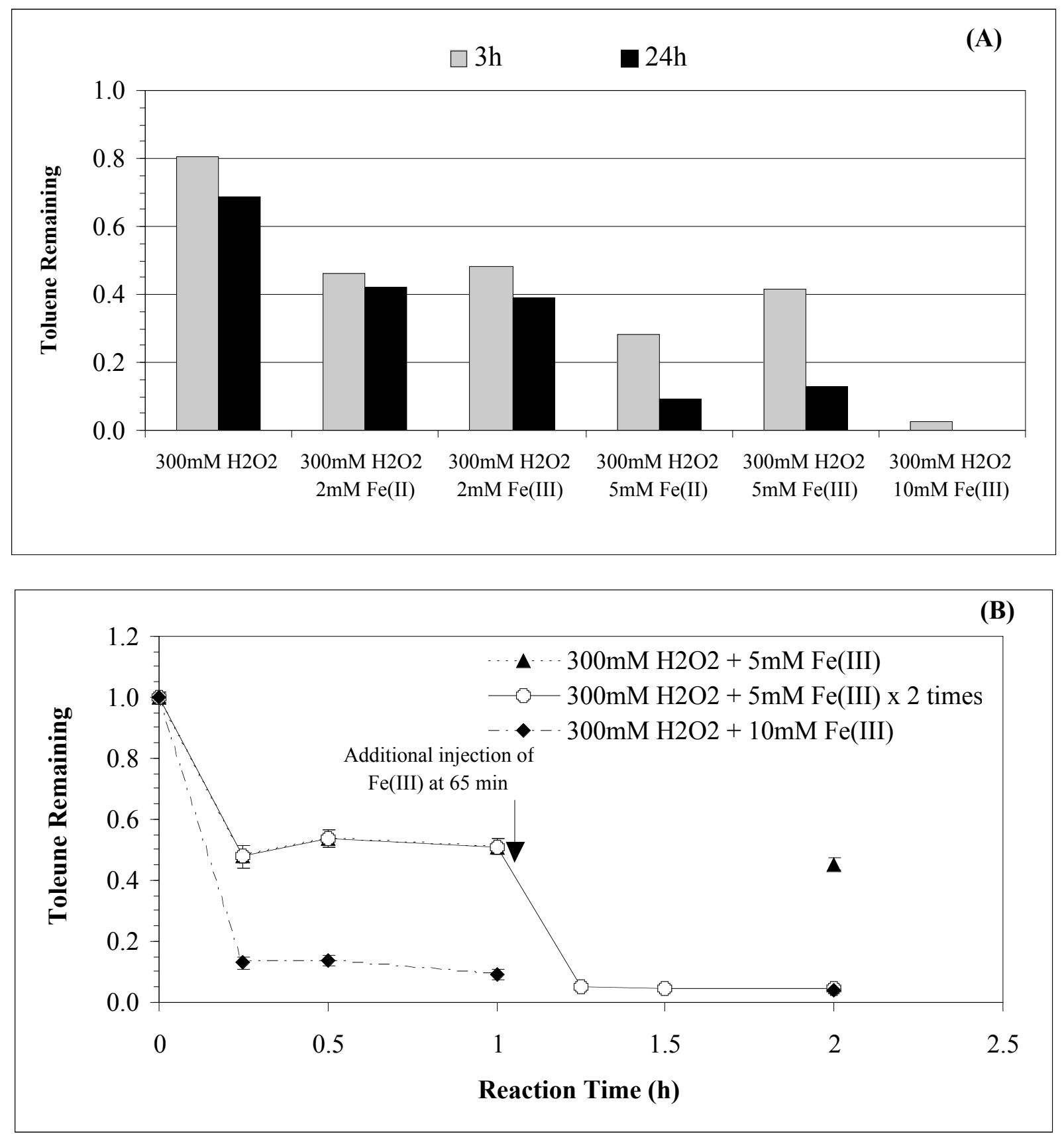

Fig. 2-2. (A) Influence of soluble iron concentrations on Fenton oxidation of toluene at nearneutral $\mathrm{pH}$ (Expts. 10-12, 16-18); (B) Soluble iron catalyst-limited condition for toluene destruction (Expts. 16, 18, 19). $\left[\mathrm{H}_{2} \mathrm{O}_{2}\right]_{0}=300 \mathrm{mM}$; [soluble iron $]_{0}=2-10 \mathrm{mM}$; $[\text { toluene }]_{0}=0.3 \mathrm{mmol} / \mathrm{kg} ; \mathrm{pH} 5-7$. 


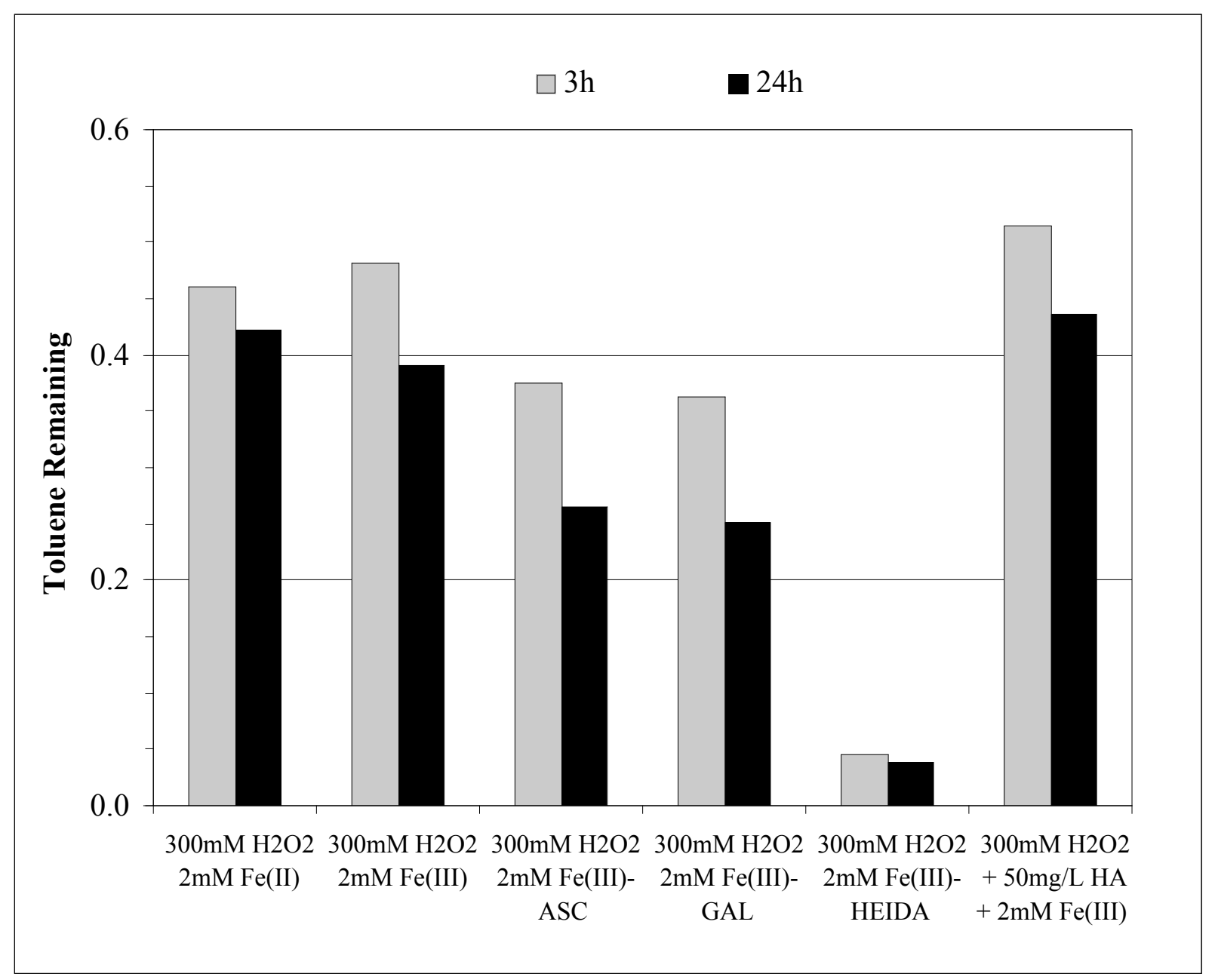

Fig 2-3. Effects of organic chelating agents on mass reduction of toluene by Fenton oxidation at near-neutral pH (Expts. 11-15, 20). 


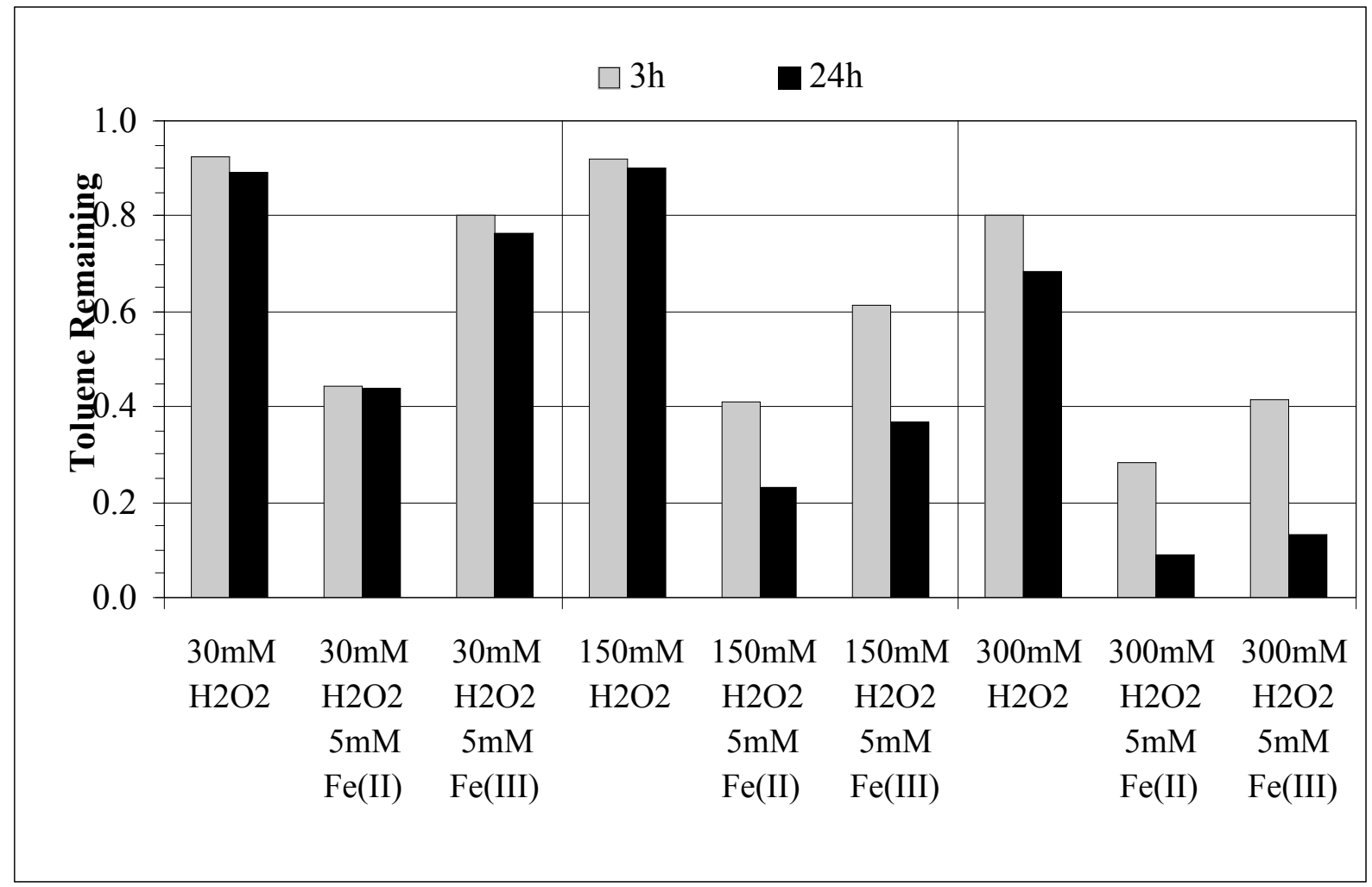

Fig. 2-4. Influence of $\mathrm{H}_{2} \mathrm{O}_{2}$ concentrations on Fenton degradation of toluene at near-neutral $\mathrm{pH}$ (Expts. 1-6, 10, 16, 17). 

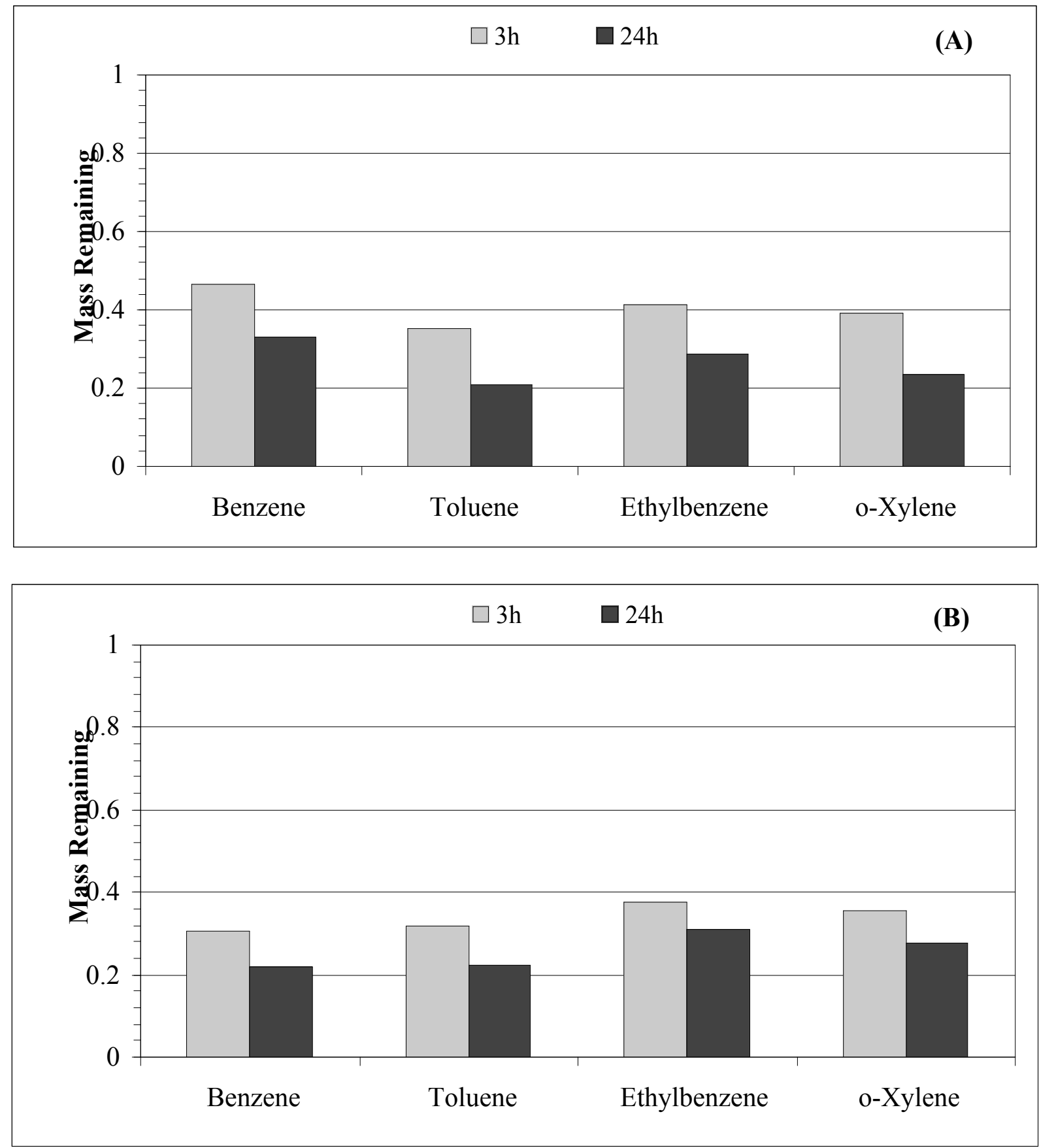

Fig. 2-5. Comparison of Fenton degradation of BTEX compounds (A) As single contaminants (Expts. 6-9) (B) In a contaminant mixture (Expt. 21). 


\section{References}

[1] Thien SJ, Graveel JG. Laboratory manual for soil science: agricultural and environmental principles, 7th ed: McGraw-Hill Inc., 1997.

[2] Ravikumar JX, Gurol MD. Chemical oxidation of chlorinated organics by hydrogen peroxide in the presence of sand. Envion Sci Technol 1994;28:394-402.

[3] Miller CM, Valentine RL. Mechanistic studies of surface catalyzed $\mathrm{H}_{2} \mathrm{O}_{2}$ decomposition and contaminant degradation in the presence of sand. Water Res 1999;33:2805-16.

[4] Lou JC, Lee SS. Chemical oxidation of BTX using Fenton's reagent. Haz Waste Haz Mater 1995;12:185-93.

[5] Pignatello JJ, Baehr K. Ferric complexes as catalysts for "Fenton" degradation of 2,4-D and metolachlor in soil. J Environ Qual 1994;23:365-70.

[6] Pignatello J, Day M. Mineralization of methyl parathion insecticide in soil by hydrogen peroxide activated with iron(III)-NTA or -HEIDA complexes. Haz Waste Haz Mater 1996;13:237-44.

[7] Buxton GV, Greenstock CL, Helman WP, Ross AB. Critical review of rate constants for reactions of hydrated electrons, hydrogen atoms and hydroxyl radicals $\left(\begin{array}{l}- \\ -\end{array}\right.$ aqueous solution. J Phys Chem Ref Data 1988;17:513-886.

[8] Morel FMM, Hering JG. Principles and applications of aquatic chemistry. New York, NY: Wiley-Interscience, 1993.

[9] Stumm W, Morgan JJ. Aquatic chemistry: chemical equilibria and rates in natural waters, 3rd ed. New York, NY: Wiley-Interscience, 1996.

[10] Charbeneau RJ. Groundwater hydraulics and pollutant transport. Upper Saddle River, NJ: Prentice Hall Inc., 2000.

[11] Bedient PB, Rifai HS, Newell CJ. Groundwater contamination: transport and remediation, 2nd ed. Upper Saddle River, NJ: Prentice Hall Inc., 1999.

[12] Walling C. Fenton's reagent revisited. Acc Chem Res 1975;8:125-31.

[13] Walling C, Goosen A. Mechanism of the ferric ion catalyzed decomposition of hydrogen peroxide. Effect of organic substrates. J Am Chem Soc 1973;95:2981-91. 
[14] Farhataziz T, Ross AB. Selected specific rates of reactions of transients in water and aqueous media III. Hydroxyl radical and their radical ions. National standard reference data series (US National Bureau of Standards) 1977;59.

[15] Metelitsa DI. Mechanisms of the hydroxylation of aromatic compounds. Russian Chem Rev 1971;40:563-80.

[16] Pignatello JJ, Chen R. Role of quinone intermediates as electron shuttles in Fenton and photoassisted Fenton oxidations of aromatic compounds. Envion Sci Technol 1997;31:2399-406.

[17] Hoigne J, Faust BC, Haag WR, Scully FEJ, Zepp RG. Aquatic humic substances as sources and sinks of photochemically produced transient reactants. In: Suffet IH, MacCarthy P, eds. The 193rd National Meeting of the American Chemical Society. Denver, Colorado: American Chemical Society, 1989:363-81. 
Chapter 3: Characterization and Controlled Release of Encapsulated Potassium Permanganate By Namgoo Kang, Inez Hua, and P. Suresh C. Rao

\subsection{Abstract}

Potassium permanganate $\left(\mathrm{KMnO}_{4}\right)$ has been widely applied as an oxidant for in-situ remediation of groundwater and soil. Paraffin-wax coated particulate $\mathrm{KMnO}_{4}$, was produced and investigated for minimizing non-specific oxidant losses during in-situ application. Paraffin wax is biodegradable and insoluble in water, but soluble in most hydrophobic contaminants, including chlorinated solvents such as perchloroethylene (PCE). Multinuclear particulate $\mathrm{KMnO}_{4}$ with a mean equivalent spherical diameter of $15( \pm 8.6) \mu \mathrm{m}$ was incorporated into a paraffin wax matrix and then pulverized, resulting in completely or partially encapsulated particles with a mean equivalent spherical diameter of $874( \pm 377) \mu \mathrm{m}$. The release kinetics of $\mathrm{KMnO}_{4}$ from the encapsulated particles into reagent grade water were characterized by a rapid initial phase due to the fast dissolution of $\mathrm{KMnO}_{4}$ near the surface of the wax carrier, followed by a significantly sustained, diffusion-limited rate in the later phase. The release in later stages exhibited zerothorder kinetics. The release rates were $0.32 \times 10^{-3}, 1.07 \times 10^{-3}$, and $3.34 \times 10^{-3} \mathrm{~g} \mathrm{day}^{-1}$ and extrapolated times for $90 \%$ release were 1.6 months (1:1 W:P), 19.3 years $(2: 1 \mathrm{~W}: \mathrm{P})$, and 472 years $(5: 1 \mathrm{~W}: \mathrm{P})$.

\subsection{Introduction}

Controlled release techniques have attracted attention in diverse fields such as pharmaceutical and agrochemical technologies. ${ }^{1-3}$ However, controlled release of an oxidant into a subsurface environment is an emerging concept relevant to environmental engineering. In particular, the controlled release of oxidants during the application of in-situ oxidation merits investigation.

There are numerous reports of in-situ chemical oxidation (ISCO) of chlorinated dense non-aqueous phase liquids (DNAPLs) by potassium permanganate $\left(\mathrm{KMnO}_{4}\right){ }^{4-7}$ One drawback 
of ISCO, regardless of the specific oxidizing agent, is that excess oxidant (with respect to the target contaminant) is often required for rapid destruction. For example, it has been reported that the mass ratio of $\mathrm{KMnO}_{4}$ (concentration=10 $\mathrm{g} \mathrm{L}^{-1}$; total flow rate, $100 \mathrm{~L} \mathrm{day}^{-1}$ ) to trichloroethylene (TCE, 1.0 L) was $20: 1$ to achieve complete destruction within 120 days ${ }^{4}$ in 3D flow tank studies. In another study, the mass ratio of $\mathrm{KMnO}_{4}$ (concentration= $19.2 \mathrm{~g} \mathrm{~L}^{-1} ; 51 \mathrm{~L}$ day $^{-1}$ ) to perchloroethylene (PCE, $0.576 \mathrm{~L}$ ) was $73: 1$ to destroy $\sim 41 \%$ of the total mass of DNAPL over 63 days in 1-D column experiment. ${ }^{6}$

Excess oxidant is necessary because of non-specific oxidant losses incurred during the ISCO process. The target contaminant competes for the oxidant with natural organic matter, inorganic soil constituents and other reduced compounds, and thus only a small fraction of the applied oxidant actually reaches and oxidizes the target compound. Therefore, it is advantageous to develop delivery methods that minimize non-specific oxidant losses, and thereby decrease the amount of oxidant needed for a particular clean-up.

The remediation performance of ISCO strongly depends on how $\mathrm{KMnO}_{4}$ is delivered into the contaminated zone. Currently, delivery system configurations include vertical or horizontal soil mixing, direct injection, oxidant re-circulation, and hydraulic fracturing. ${ }^{8-10}$ However, few studies on controlled (sustained) oxidant delivery systems have been conducted, particularly for $\mathrm{KMnO}_{4} \cdot{ }^{10-12}$ It has been documented that solid oxidant particle mixtures (OPMs) with a grain size of less than $\sim 5 \mathrm{~mm}$ were generated in which $\mathrm{KMnO}_{4}$ granules were suspended in clay or cement plus water as a carrier fluid. ${ }^{11}$ This patent proposed a treatment zone approach, suggesting that once the granular OPMs are injected into the subsurface soil and groundwater contaminated with TCE or PCE, they would release $\mathrm{KMnO}_{4}$ slowly (over a period of months to years). ${ }^{11}$ 
Especially for source zone remediation, controlled release of $\mathrm{KMnO}_{4}$ may be achieved by completely or partially coating the water-soluble solid $\mathrm{KMnO}_{4}$ core with a water-insoluble matrix. The purpose of the coating would be to prevent contact between the aqueous solution and the oxidant and thus control the dissolution rates of $\mathrm{KMnO}_{4} \cdot{ }^{9} \mathrm{~A}$ coating material should therefore possess several essential characteristics. The material should be a solid at ambient temperature, and it should be water insoluble, soluble in the target organic contaminant, chemically compatible and mutually immiscible with $\mathrm{KMnO}_{4}$, and environmentally benign.

The objectives of the present study were to generate and characterize encapsulated $\mathrm{KMnO}_{4}$ particles potentially applicable to the oxidation of hydrophobic organic contaminants, and to probe the release characteristics from the coated $\mathrm{KMnO}_{4}$ particles into aqueous solutions and an organic solvent such as PCE. Commercially available paraffin wax was selected as a coating material and matrix for particulate $\mathrm{KMnO}_{4}$.

\subsection{Experimental Materials and Methods}

Materials. $\mathrm{KMnO}_{4}$ (particle size, -325 US mesh; purity, 97\%) was purchased from Aldrich. Paraffin wax with a melting (congealing) range of $50-55^{\circ} \mathrm{C}$ was obtained from Fluka. Reagent grade water was prepared from distilled water purified by reverse osmosis and a Barnstead ${ }^{\circledR}$ NANOpure II de-ionizing system $\left(\mathrm{W}=18.0 \mathrm{M} \Omega \mathrm{cm}^{-1}\right)$.

Particle Size Reduction. The particle sizes of uncoated $\mathrm{KMnO}_{4}$ particles (UPPs) or encapsulated $\mathrm{KMnO}_{4}$ granules (EPGs) were reduced by processing each material with a laboratory mill (IKA A1 Basic Mill). The working principle of this mill is based on impact milling and the process type is batch. Preliminary tests revealed that continuous high-speed rotation (a maximum of $28,000 \mathrm{rpm}$ when unloaded) of the stainless steel blade raised the temperature sufficiently such that particle agglomeration occurred. To minimize this agglomeration, a stepwise milling process was employed; each step included power-on (milling) 
for $5 \mathrm{~min}$ and a subsequent power-off $(>6 \mathrm{~h})$ until the mill temperature returned to ambient. Since milling performance leveled off after $20 \mathrm{~min}$, UPPs were milled for $20 \mathrm{~min}$ to produce uncoated, milled $\mathrm{KMnO}_{4}$ (UMPPs) which were then employed as the core material for encapsulation.

Encapsulation. A molten suspension and cooling (MSC) method, modified from a meltdispersion technique ${ }^{13,14}$ was employed for the encapsulation of $\mathrm{KMnO}_{4}$ (the oxidant) with a paraffin wax as the coating material (matrix). Solid paraffin wax (10.0 g) was introduced into a $100 \mathrm{~mL}$ Pyrex beaker, which was placed on a hot plate-sitter (Cimarec top stirring hotplate). The temperature of the wax was maintained at $80-85^{\circ} \mathrm{C}$ and stirred at $300 \mathrm{rpm}$ with a glass magnetic bar $(2.0 \mathrm{~cm})$. UMPPs $(2-10 \mathrm{~g})$ were gradually added to the molten wax while continuously mixing (15 min) to ensure uniform dispersion of the $\mathrm{KMnO}_{4}$ in the wax phase. Approximately $0.5 \mathrm{~mL}$ of the molten suspension was rapidly transferred into reagent grade water. The molten suspension drops solidified into encapsulated $\mathrm{KMnO}_{4}$ granules (EPGs). The EPGs were collected after vacuum filtration and dessication for $24 \mathrm{~h}$. The encapsulated $\mathrm{KMnO}_{4}$ particles (EPPs) were generated by pulverizing the EPGs in the laboratory mill for $3 \mathrm{~min}$.

Microscopic Evaluation. The shape and surface characteristics of the UPPs, UMPPs, and EPPs were observed using visual imaging instruments. An optical microscope (AxioCam optical microscope system, Zeiss), a scanning electron microscope (SEM, JSM-35CF, Jeol) and an environmental SEM (ESEM, system 2020, ElectroScan) were utilized to gather information on the particles during various stages of processing.

Particle Size Analysis. Particle size distribution and mean particle sizes were determined using a laser light diffraction particle size analyzer (Beckman Coulter LS 230) equipped with a Small Volume Module Plus and Coulter LS Particle Characterization Software Version 2.11a. Approximately $0.15 \mathrm{~g}$ of the test material was introduced into the sample vessel containing $\sim 20$ 
$\mathrm{mL}$ of toluene (for UPPs) or isopropyl alcohol (for EPPs) as the suspension fluids. To prevent agglomeration, the sample was sonicated in a water bath (Branson 5210) at $45 \mathrm{~W}$ for $5 \mathrm{~min}$. The suspension fluid and dispersed particles flowed through the sample cell and hoses in a closedloop system. Light passed through a diffraction sample cell during measurement. The obscuration level (extent of attenuation of incident beam intensity due to presence of particles) ${ }^{15}$ was calculated to be nearly $45 \%$. The Fraunhofer diffraction solution was employed as the optical model for particle size estimation because it is applicable when particles are coarser than $\sim 2 \mu \mathrm{m}$ and because it is independent of any properties (e.g., refractive index) of the particles being tested. ${ }^{15}$ The particle size distribution results were expressed as a function of the equivalent spherical diameter on a volume basis. The equivalent spherical diameter is defined as the diameter of a regular, homogeneous sphere that has the same volume as the particle being measured and represents three-dimensional properties of the real particle. ${ }^{15}$

Thermal Analysis. Thermal properties of selected samples were measured with differential scanning calorimetry (DSC 2920 System, TA Instruments). The purge gas was nitrogen (flow rate, $35 \mathrm{~mL} \mathrm{~min}^{-1}$ ). The initial temperature was $20{ }^{\circ} \mathrm{C}$ and ramped at $10{ }^{\circ} \mathrm{C} \mathrm{min}{ }^{-1}$ to $140{ }^{\circ} \mathrm{C}$. Aluminum sample pans were utilized.

Determination of Mass Recovery. An extraction procedure was employed to determine the actual mass of $\mathrm{KMnO}_{4}$ within the paraffin wax matrix and the mass recovery of $\mathrm{KMnO}_{4}$ loaded in the EPPs. The EPPs $(0.20 \mathrm{~g})$ were introduced into a $25 \mathrm{~mL}$ volumetric flask containing $20 \mathrm{~mL}$ of cyclohexane. The flask was tightly capped, vortexed and placed on a rotary wheel shaker for $24 \mathrm{~h}$ to ensure complete dissolution of the paraffin wax. The suspension was transferred to a $1.0 \mathrm{~L}$ volumetric flask and reagent grade water was added in order to extract the $\mathrm{KMnO}_{4}$. The aqueous and organic phases were vigorously mixed for $1 \mathrm{~h}$ and maintained in contact for another $1 \mathrm{~h}$. The organic phase was separated from the aqueous phase. The concentration of permanganate ion in the aqueous phase was determined by measuring the 
absorption at $\lambda=552 \mathrm{~nm}$ with a UV-Visible spectrophotometer (Perkin-Elmer Lamda 3) and by measuring manganese $(\mathrm{Mn})$ content with an atomic absorption spectrophotometer (AAS, Varian SpectrAA-20 Plus) equipped with a graphite tube atomizer (Varian GTA-96). The molar absorptivity, $\varepsilon_{522}$, for permanganate ion was $2221 \mathrm{M}^{-1} \mathrm{~cm}^{-1}$.

Release experiments. The EPPs $(0.30,0.15$, and $0.10 \mathrm{~g}$ for $5: 1,2: 1$ and $1: 1 \mathrm{~W}: \mathrm{P}$, respectively) were introduced into $1.0 \mathrm{~L}$ of reagent grade water at room temperature under constant mixing $(200 \mathrm{rpm}$ ) with a mechanical stirrer (Arrow 6000) to ensure a well-mixed solution. With a special care to prevent the uptake of the particles, samples $(4.0 \mathrm{~mL})$ of the aqueous solution were withdrawn at 1,2, 3, 4, 5, 10, 20, 30, 60, 120, 800, and 1200 min using a glass syringe (Micro-mate Interchangeable) equipped with a stainless steel needle $(30 \mathrm{~cm}$ in length). The samples were transferred to $7 \mathrm{~mL}$ glass vials. The concentration of permanganate ion in the aqueous phase was determined by measuring the absorption at $\lambda=552 \mathrm{~nm}$ with a UVVisible spectrophotometer (Perkin-Elmer Lamda 3). The release of $\mathrm{KMnO}_{4}$ from the UMPPs (milled for $20 \mathrm{~min}$ ) into reagent grade water was also measured as the control experiment.

\subsection{Results and Discussion}

Both elemental and UV-Vis spectrophotometric analyses confirmed that the recovery of $\mathrm{KMnO}_{4}$ after dissolution of the paraffin wax coating in cyclohexane approached $100 \%$.

SEM images and the size distribution of UPPs are presented in Figure 1. UPPs are characterized by sharp edges and very irregular shapes including elliptic or bar-type with varying size distributions. The comparison of the two images before and after milling suggests that milling resulted in significant size reduction of UPPs. Particle size distribution analyses demonstrate that mean particle size ( \pm standard deviation) decreased from $152( \pm 222) \mu \mathrm{m}$ to 15(士9) $\mu \mathrm{m}$ after milling for $20 \mathrm{~min}$. However, it was observed from both SEM (Figure 1A) and the particle size distribution (Figure 1B) that much smaller particles than the mean diameter were 
present in each batch.

Encapsulated $\mathrm{KMnO}_{4}$ granules (EPGs) with a size of 0.5 to $5 \mathrm{~mm}$ were milled to produce smaller sized particles (Figure 2). ESEM images demonstrate that multi-nuclear, micronized $\mathrm{KMnO}_{4}$ particles were randomly entrapped in the paraffin wax matrix. The particle distribution of EPPs for 2:1 ratio paraffin wax to $\mathrm{KMnO}_{4}$ followed a bimodal curve with a mean diameter of $874( \pm 377) \mu \mathrm{m}$. Figure 2B suggests that some of the EPPs formed aggregates. The paraffin wax matrix is very cohesive, resulting in the second peak at a particle diameter of $1700 \mu \mathrm{m}$. EPPs with a higher mass fraction of $\mathrm{KMnO}_{4}(50 \%$ for $1: 1 \mathrm{~W}: \mathrm{P})$ contained more $\mathrm{KMnO}_{4}$ particles embedded on the surface and thus a rougher surface than those with a lower mass fraction of $\mathrm{KMnO}_{4}(33.3 \%$ for $2: 1 \mathrm{~W}: \mathrm{P})$. There was no significant difference in the mean diameter for different $\mathrm{W}: \mathrm{P}$ ratios.

DSC data indicate the melting behavior of the paraffin wax before and after the modified MSC process. $\mathrm{KMnO}_{4}$ particles and paraffin wax are inert towards each other over a range of temperatures (Figure 3). Endothermic peaks in a differential scanning thermogram usually represent melting temperatures and energies of the tested materials. The two characteristic melting ranges with the smaller peak at 30 to $50{ }^{\circ} \mathrm{C}$ and the bigger one at 50 to $70{ }^{\circ} \mathrm{C}$ were observed for the paraffin wax. Since most paraffin waxes retain residual oil $(\sim 0.5 \%)$, paraffin waxes do not exhibit sharp melting points. ${ }^{16}$ There was no significant difference between melting ranges of the wax in the presence and in the absence of $\mathrm{KMnO}_{4}$ particles and no additional peaks were detected. It is therefore likely that the solid $\mathrm{KMnO}_{4}$ particles do not significantly interact with the paraffin wax over the temperature range in which the MSC process was conducted. These results are consistent with previous reports that significant oxidation of paraffin wax exposed to oxidants does not occur until the temperature reaches $93{ }^{\circ} \mathrm{C}$ and requires at least three 
days at $121{ }^{\circ} \mathrm{C} .{ }^{16}$ The paraffin wax, therefore, will not contribute to non-specific losses of the $\mathrm{KMnO}_{4}$ during delivery and transport of the particles.

Figure 4 shows release profiles of $\mathrm{KMnO}_{4}$ from EPPs into reagent grade water. Dissolution of the UPPs was immediate $(<1 \mathrm{~min})$ while that of the EPPs was significantly retarded: $10-30 \%$ of the $\mathrm{KMnO}_{4}$ was released in a week. The release of the oxidant from the particles into reagent grade water was biphasic and characterized by an initial rapid release $(<2$ h) followed by a relatively steady release. The initial fast release is due to dissolution of $\mathrm{KMnO}_{4}$ particles embedded into or near the surface of the EPPs, which are readily accessible to water. The depletion of $\mathrm{KMnO}_{4}$ at the surface of the particles is shown in Figure 5. After four days of continuous contact with reagent grade water, empty crevices appeared on the surface of the paraffin wax medium (Figure 5).

These results are in good agreement with previous findings that a highly water soluble core material such as potassium chloride can exhibit biphasic release patterns. ${ }^{17}$ The rapidly stirred reactors represent very turbulent conditions, and therefore the measured release rates into water should be considered an upper limit. The release rates of the EPPs would be slower under less turbulent flow conditions such as groundwater flow.

The sustained release of $\mathrm{KMnO}_{4}$ at later stages probably results from dissolution of $\mathrm{KMnO}_{4}$ located further within the paraffin wax matrix. To further elucidate the release mechanism, several models including zero-order kinetics, the Sinclair and Peppas equation ${ }^{18}$, modified first-order kinetics ${ }^{19}$, and a modified hyperbola model ${ }^{20}$ were tested to fit to the experimental data sets. Among them, the simplified empirical equation (Eq 1) proposed by Sinclair and Peppas best simulated $\left(\mathrm{r}^{2}>0.974\right)$ the release kinetics for the experimental data sets while curve-fitting results were not as good $\left(\mathrm{r}^{2}<0.900\right)$ with the other models. 


$$
Q=k t^{n}
$$

where $\mathrm{Q}$ is the fraction of the active agent released at time $t, k$ is a constant incorporating the characteristics of the active agent $\left(\mathrm{KMnO}_{4}\right)$ and matrix (paraffin wax) system and has a unit of $t^{-}$ ${ }^{n}$, and $n$ is the diffusional exponent. This equation suggests that the release process is non-Fickian diffusion with constant pseudo-convection due to the stress within the wax matrix. ${ }^{18}$ Figure 5 demonstrates that fast dissolution of $\mathrm{KMnO}_{4}$ particles on the wax surface, leaving crevices and pores. It is hypothesized that these pores may possibly generate inter-particular openings or channels within the wax matrix. Consequently, aqueous solution may be allowed to diffuse in and contact the remaining $\mathrm{KMnO}_{4}$. These findings indirectly support that the transport mechanism of aqueous solution into the wax matrix may be governed by a diffusion-related process. This hypothesis could be supported in part by a report that release of water soluble agents from water-insoluble matrices (matrix-type formulations) was controlled by diffusion. ${ }^{2}$

The values of $n$ and $k$ are usually obtained by linearizing Eq. 1 in logarithmic form (Eq 2), plotting the experimental data, and determining the slope and the intercept on the axis of log $\mathrm{Q}$, respectively:

$$
\log Q_{t}=\log k+n \log t
$$

However, even if the square of the correlation coefficient for the fitting of experimental data to a linearized model (Eq 2) is highly acceptable (e.g., $\left.r^{2}=0.99\right)$, the estimated values do not necessarily simulate non-linear release kinetics with accuracy. ${ }^{18}$ For this reason, the parameters were estimated in this study by an optimization method which can minimize the sum of square of errors (SSE) between the experimental (after $5 \mathrm{~min}$ ) and calculated data:

$$
\mathrm{SSE}=\sum_{t}\left(Q_{t, \exp }-Q_{t, \text { calc }}\right)^{2}
$$


Accordingly, the time required for $90 \%$ release of the oxidant $(Q=0.9), t_{0.9}$, can be estimated using:

$$
t_{0.9}=\left(\frac{0.9}{k}\right)^{1 / n}
$$

For the EPPs with varying ratios of W:P, presented in Table 1 are the estimated values of $r^{2}$ obtained from Eq 2; $n, k$, and SSQ from Eq 3; and $\mathrm{t}_{0.9}$ from Eq 4. Table 2 indicates that the model fits were in good agreement with the experimental data sets, suggesting that the model could adequately describe the release kinetics of $\mathrm{KMnO} 4$ from the wax matrix. The estimated values of $n(0.187,0.200$, and 0.282$)$ were consistent with a reported range $(0.173$ to 0.261$)$ obtained from Eq 2 fitted to release data sets of various fertilizers such as monoammonium phosphate and diammonium phosphate from a paraffin wax (congealing point, $57-60{ }^{\circ} \mathrm{C}$; Winlab, U.K.) in deionized water in the absence of stirring. ${ }^{20}$ This comparison suggests that release characteristics from paraffin wax matrices would be similar to each other regardless of system agitation.

The model prediction results indicate that time scale for $90 \%$ release ranged from over a month (1.7 mo for $1: 1 \mathrm{~W}: \mathrm{P})$ to years in the absence of a target organic contaminant such as PCE. This estimation clearly suggests that the fraction of $\mathrm{KMnO}_{4}$ which is well-sequestered in the wax matrix, which is promising for reducing the non-specific losses of the oxidant.

A primary factor that controls $\mathrm{KMnO}_{4}$ release is the ratio of $\mathrm{KMnO}_{4}$ to paraffin wax. The results from Figure 4 and Table 2 clearly indicate that the mass fraction of $\mathrm{KMnO}_{4}$ released into water at a given time is closely related to the mass fraction of UPPs utilized in the modified MSC process. The release rate is proportional to the mass fraction of UPPs and inversely proportional to the mass fraction of the paraffin wax. 
Selected experiments were conducted to examine the dissolution of the paraffin wax coating in PCE, a representative DNAPL. EPPs $(0.10 \mathrm{~g})$ of varying W:P ratios were introduced into pure PCE $(5 \mathrm{~mL})$ and agitated for $1 \mathrm{~min}$ on an orbit shaker at $200 \mathrm{rpm}$ at room temperature. Not surprisingly, encapsulated $\mathrm{KMnO}_{4}$ particles with a higher mass fraction of the paraffin wax $(83 \% ; \mathrm{W}: \mathrm{P}=5: 1)$ dissolved more slowly than those with paraffin mass fractions of $66.7 \%$ (W:P $=2: 1)$ and $50 \%(\mathrm{~W}: \mathrm{P}=1: 1)$. However, for all $\mathrm{W}: \mathrm{P}$ ratios, complete dissolution of the paraffin wax coating occurred within 3 min of contact with PCE. Rapid release of the oxidant from the encapsulation matrix is an essential aspect of delivery via a controlled release approach.

Figure 6 demonstrates how the EPPs behave in the presence of PCE droplets in reagent grade water before and after the suspension is agitated. The EPPs preferentially agglomerate at the interface of the free-phase PCE due to the affinity of the paraffin wax for PCE. The fact that the EPPs collected at the interface of free-phase PCE and water represents a local enhancement of oxidant concentration relative to the bulk solution.

The modified MSC method has many advantages over other encapsulation techniques because it does not require specialized equipment, and is easily scaled up to produce larger quantities of particles. Furthermore, the method does not require organic solvents; and the encapsulation efficiency of a core material, defined as the ratio of the actual mass of the core material loaded in coated particles to a mass of the core material initially used in the encapsulation process, ${ }^{20}$ is close to $100 \%$ for the $\mathrm{KMnO}_{4}$ paraffin wax system.

Paraffin wax meets the criteria set forth in the introduction for a suitable coating material. Paraffin wax is a solid at room temperature and consists mostly $(80-90 \% \mathrm{w} / \mathrm{w})$ of straight chain hydrocarbons (20 to 30 carbon atoms per chain). ${ }^{16}$ Paraffin wax is also extremely soluble in many organic contaminants including chlorinated compounds (e.g., TCE and PCE) as 
summarized in Table $2 .{ }^{16}$ However, it is practically insoluble in water. ${ }^{16,21}$ Saturated hydrocarbons, such as paraffin waxes, are relatively inert to $\mathrm{KMnO}_{4}$ oxidation. Finally, paraffin wax is fully biodegradable. ${ }^{22,23}$ For example, hydrocarbon-oxidizing bacteria including Pseudomonas, Mycobaterum, Nocardia, Corynebacterium, and Micrococus are known to degrade petroleum fractions rich in paraffin $(>80 \%) .{ }^{22}$ It has been documented that nearly $60 \%$ and $40 \%$ of initial mass of linear and branched paraffin waxes were biodegraded over three months in a soil system. ${ }^{23}$

\subsection{Conclusions}

Paraffin wax was applied as an environmentally benign and inert matrix for protecting solid $\mathrm{KMnO}_{4}$ particles from rapid dissolution and undesirable reactions in moist conditions. Multinuclear EPGs with a size range of about 0.5 to $5 \mathrm{~mm}$ were generated using a modified MSC process. The release of $\mathrm{KMnO}_{4}$ from the EPPs into reagent grade water was characterized by a relatively fast initial rate due to fast dissolution of partly coated $\mathrm{KMnO}_{4}$ near the surface of the paraffin wax matrix, followed by a significantly slower rate in the later phase due probably to reduced mass of $\mathrm{KMnO}_{4}$ that remained in the paraffin wax matrix. For environmental applications, EPPs may be potentially utilized as packing material for reactive permeable barriers (PRBs) to treat contaminant plumes containing chlorinated ethenes such as TCE or PCE in a similar manner as a previous patent documented. ${ }^{11}$ When transported with ground water flow, organic contaminants such as TCE and PCE dissolved in aqueous phase would preferentially partition into the paraffin wax coating due to their significant solubilities in the paraffin wax. Consequently, enhanced contact may occur between the contaminant and the locally high concentrations of $\mathrm{KMnO}_{4}$ released into the interfacial region of EPPs and the aqueous phase. The 
$\mathrm{KMnO}_{4}$ concentration in the vicinity of the EPPs will be close to its maximum aqueous solubility. 
Table 3-1. Estimated values of the model parameters fitted to experimental data sets for release tests in reagent grade water.

\begin{tabular}{|c|l|l|l|l|l|}
\hline $\begin{array}{c}\text { Paraffin wax }: \mathrm{KMnO}_{4} \\
\text { (by mass) }\end{array}$ & $\boldsymbol{r}^{\mathbf{2}}$ & $\boldsymbol{n}$ & $\boldsymbol{k}\left(\boldsymbol{t}^{-\boldsymbol{n}}\right)$ & $\mathbf{S S Q}$ & $\boldsymbol{t}_{\mathbf{0 . 9}}$ \\
\hline $\mathbf{1 : 1}$ & 0.987 & 0.282 & 0.122 & $5.04 \times 10^{-3}$ & $1.7 \mathrm{mo}$ \\
\hline $\mathbf{2 : 1}$ & 0.974 & 0.200 & 0.081 & $1.64 \times 10^{-3}$ & $19.3 \mathrm{yr}$ \\
\hline $\mathbf{5 : 1}$ & 0.993 & 0.187 & 0.052 & $1.7 \times 10^{-4}$ & $472 \mathrm{yr}$ \\
\hline
\end{tabular}

Table 3-2. Solubility of paraffin wax (melting point of $51.4-53{ }^{\circ} \mathrm{C}$ ) in various organic solvents. ${ }^{17}$

\begin{tabular}{|l|l|}
\hline Solvent & Solubility at $\mathbf{2 0}^{\mathbf{0}} \mathbf{C}(\mathbf{g} / \mathbf{m L})$ \\
\hline Carbon tetrachloride & 0.317 \\
\hline Benzene & 0.285 \\
\hline Chloroform & 0.246 \\
\hline Tetrachloroethylene (PCE) & $\sim 0.20\left(22^{\circ} \mathrm{C}\right)^{\mathrm{a}}$ \\
\hline Hexane & 0.0831 \\
\hline Cyclohexane & $0.0776\left(16.7^{\circ} \mathrm{C}\right)$ \\
\hline Trichloroethylene $(\mathrm{TCE})$ & $0.0286\left(15^{\circ} \mathrm{C}\right)$ \\
\hline
\end{tabular}

${ }^{a}$ measured value in this work. 

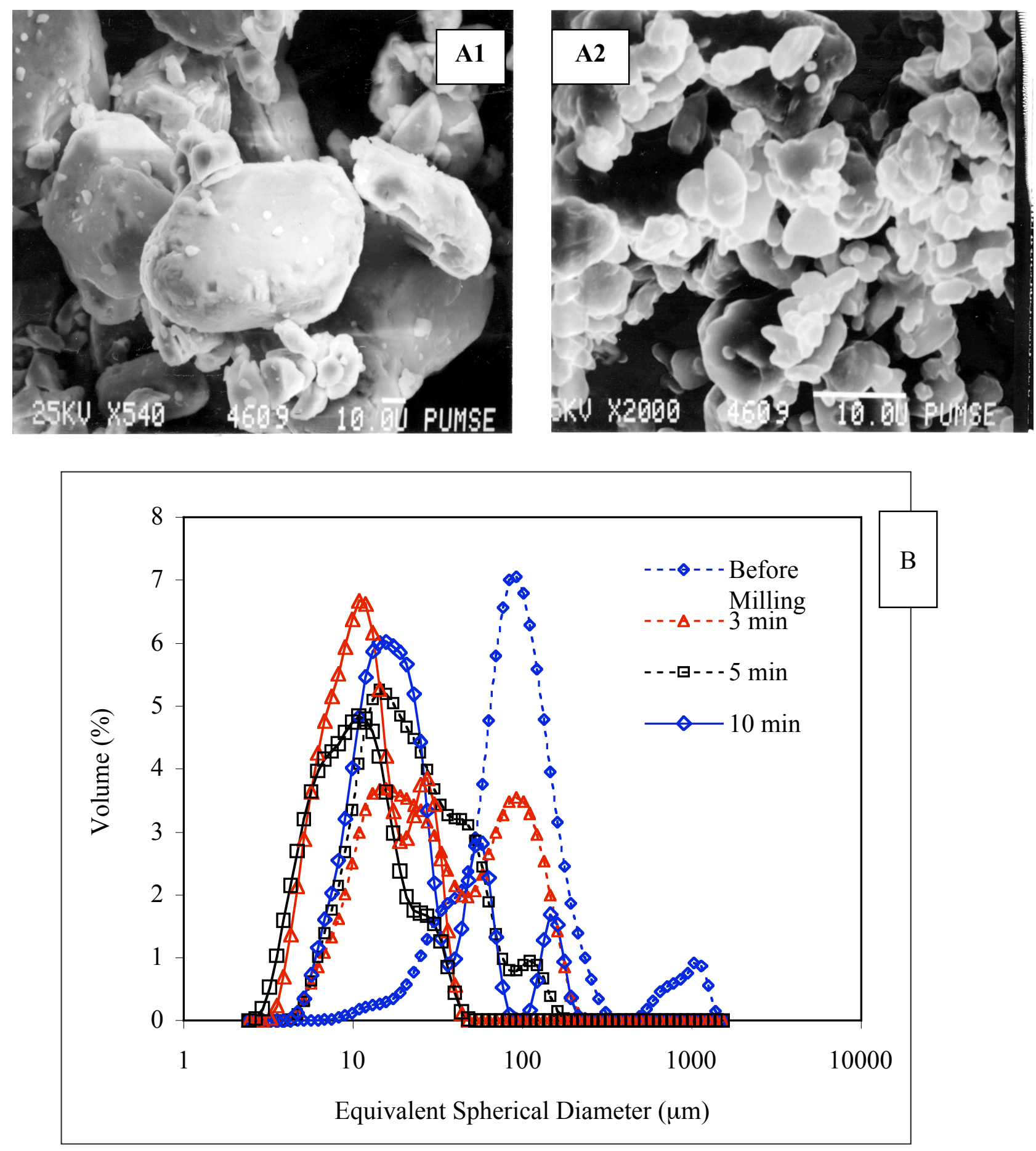

Figure 3-1. Characterization of uncoated $\mathrm{KMnO}_{4}$ particles. (A1) SEM image before milling (scale bar, $10 \mu \mathrm{m})(\mathrm{A} 2)$; SEM image after milling for $20 \mathrm{~min}$ (scale bar, $10 \mu \mathrm{m}$ ); (B) particle size reduction as a function of milling time. 


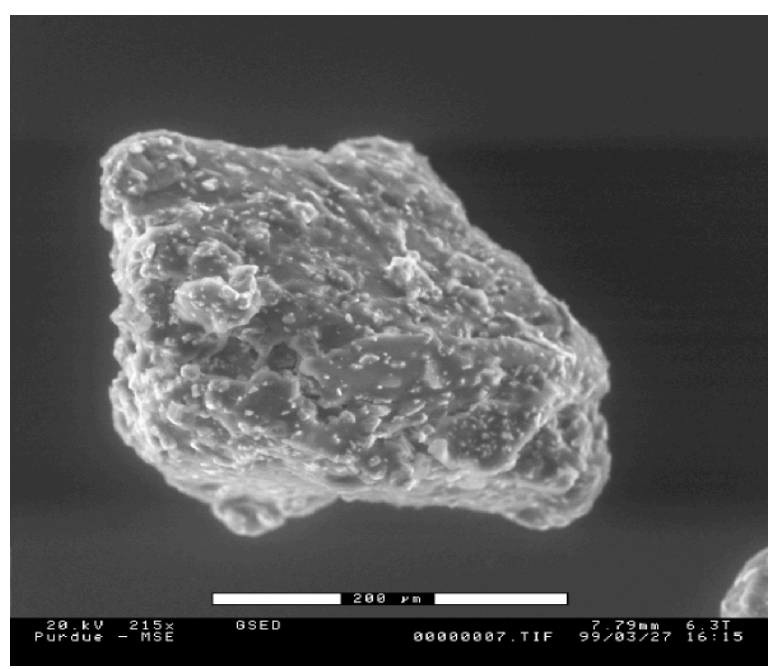

(A1)

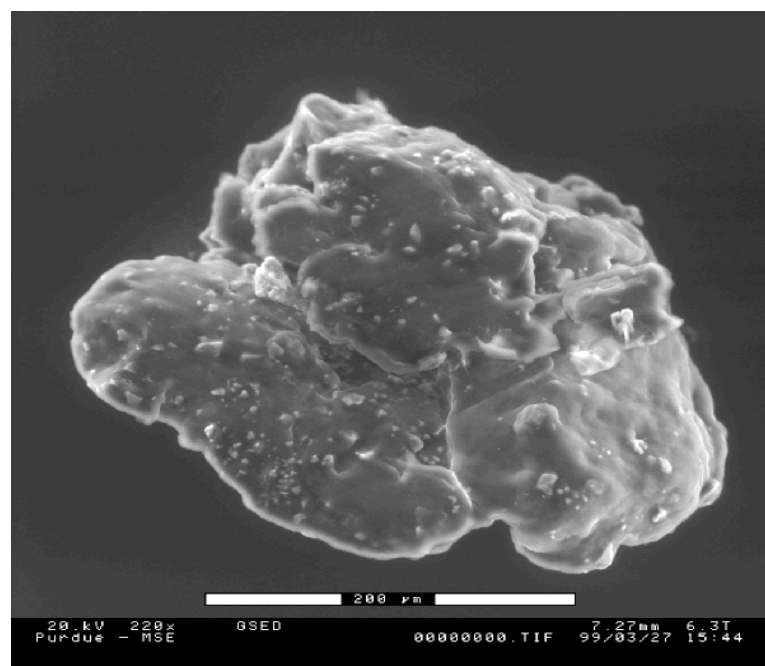

(A2)

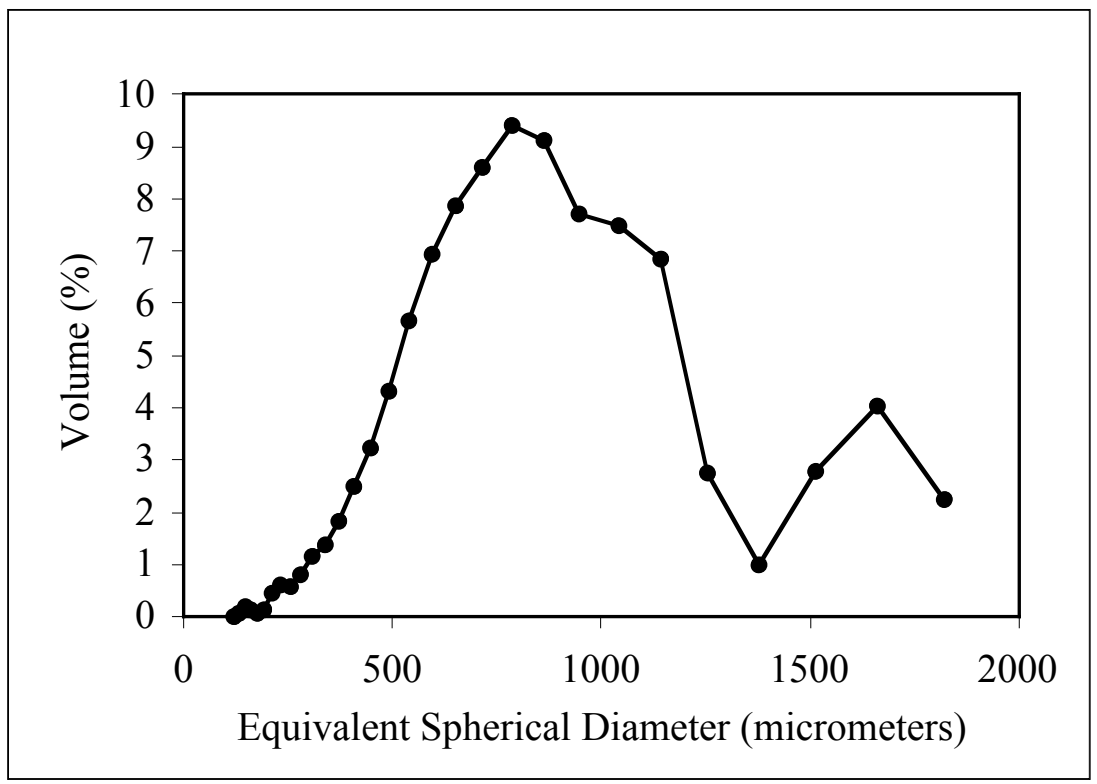

(B)

Figure 3-2. Pulverized encapsulated $\mathrm{KMnO}_{4}$ particles. ESEM images (scale bar, $200 \mu \mathrm{m}$ ) for 1:1 $\mathrm{W}: \mathrm{P}(\mathrm{A} 1)$ and 2:1 W:P (A2); (B) particle size distribution as volume percent for 2:1 W:P. 


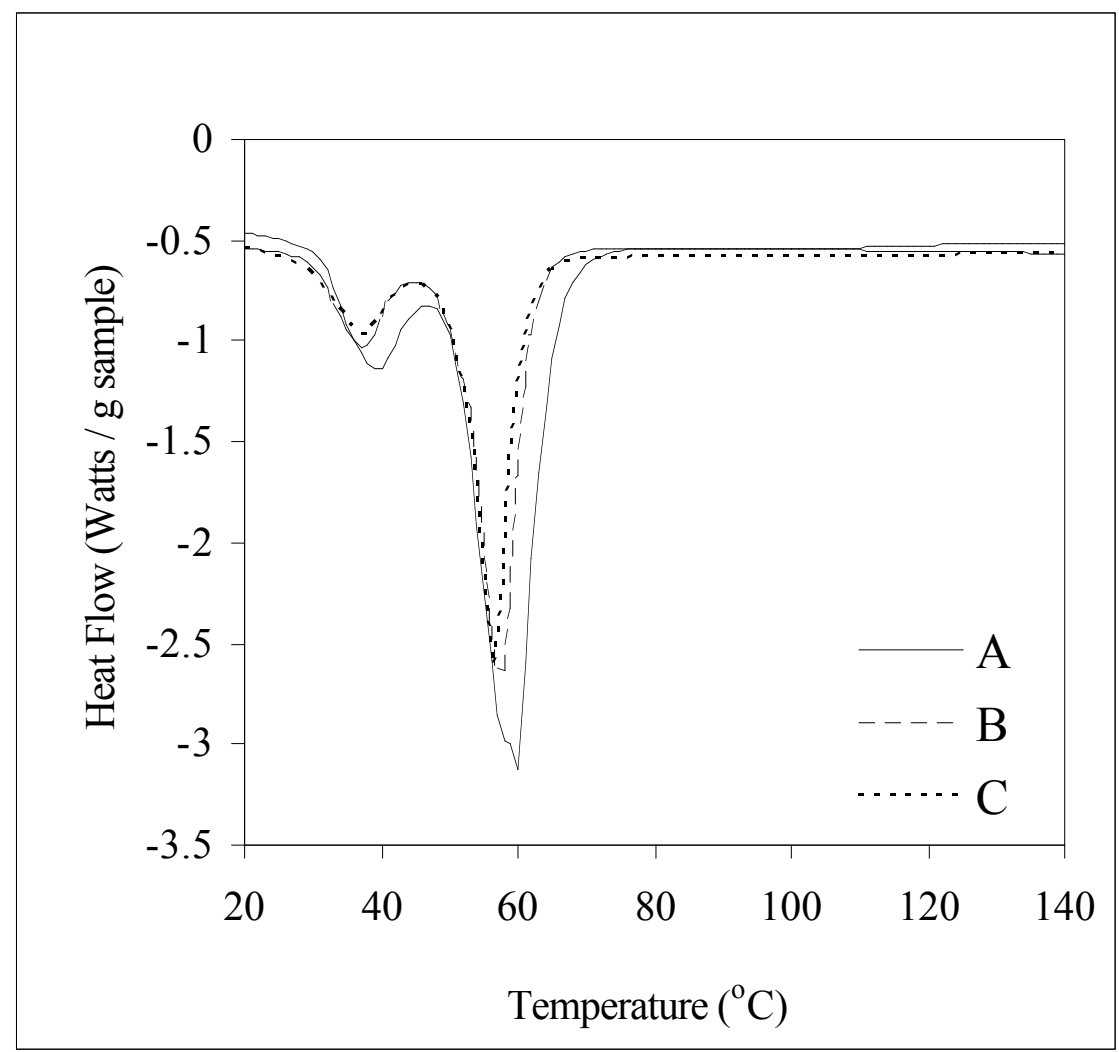

Figure 3-3. Differential scanning thermograms. (A) paraffin wax; (B) physical mixture of paraffin wax and uncoated $\mathrm{KMnO}_{4}$ particles; and (C) encapsulated $\mathrm{KMnO}_{4}$ particles $(1: 1 \mathrm{~W}: \mathrm{P})$. 

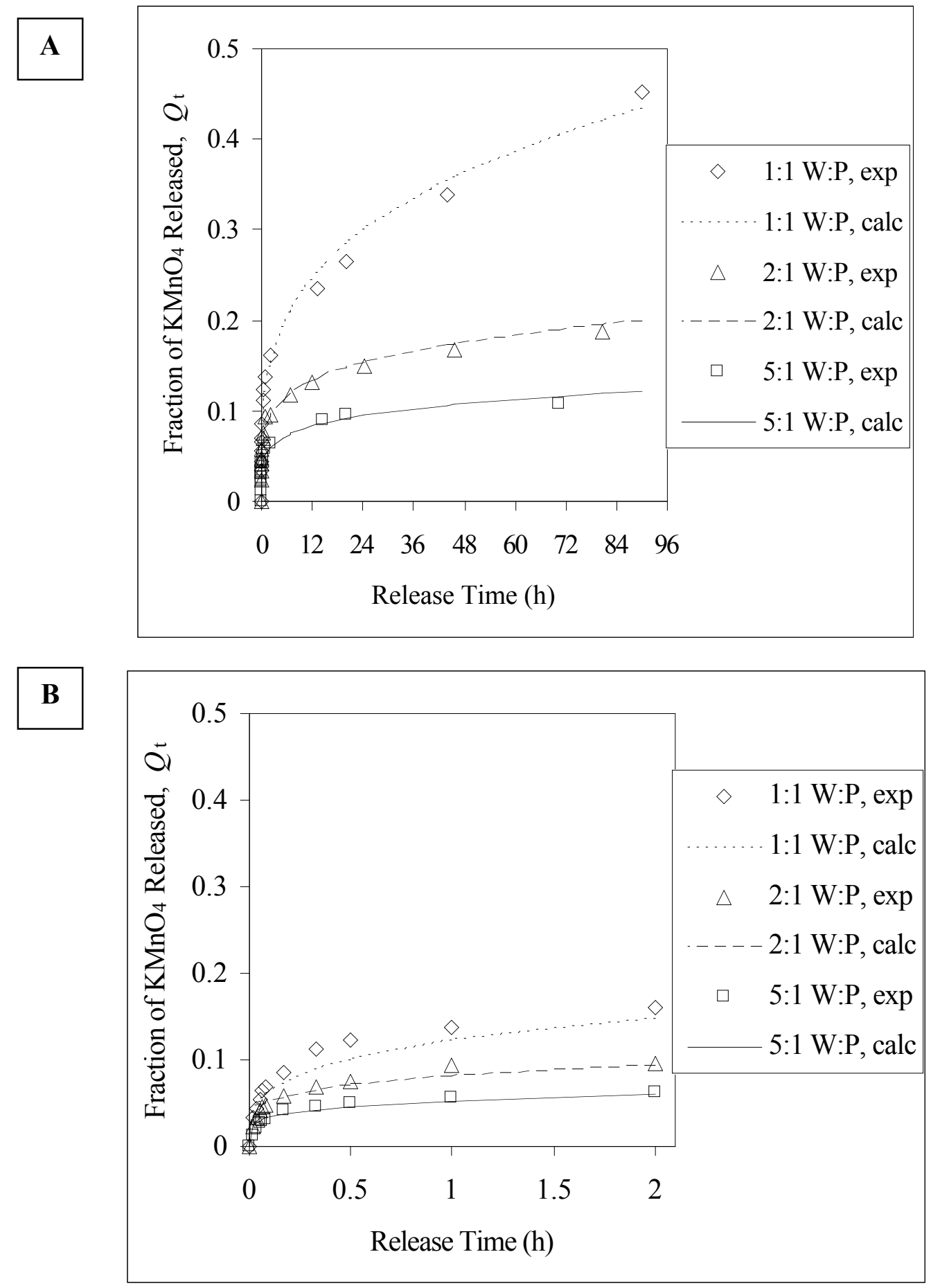

Figure 3-4. Experimental data and calculated values by $\mathrm{Eq} 1$ for $\mathrm{KMnO}_{4}$ released over time from the paraffin wax matrix into reagent grade water. (A) overall plots; (B) data points near $t=0$. 


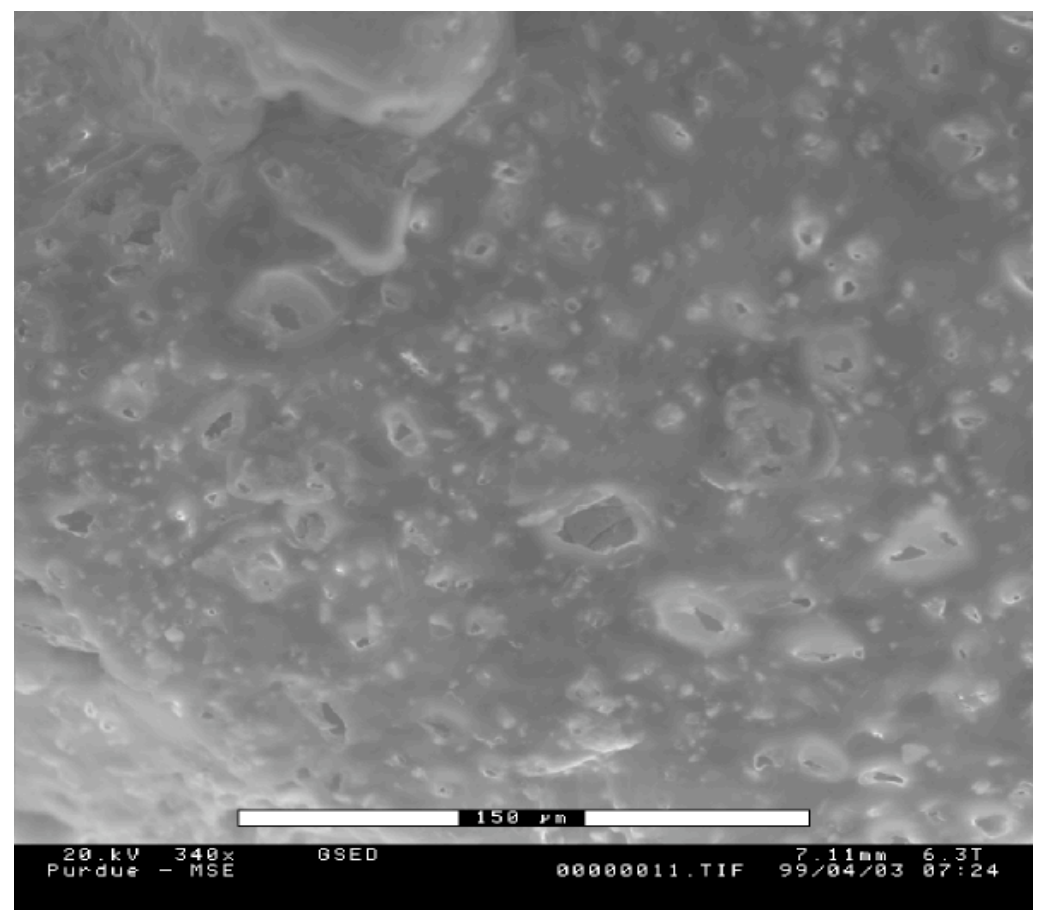

Figure 3-5. ESEM image of the surface of an encapsulated $\mathrm{KMnO}_{4}$ particle $(1: 1 \mathrm{~W}: \mathrm{P}$; scale bar, $150 \mu \mathrm{m})$ after 4 days of stirring in reagent grade water. Note crevices which remain after the $\mathrm{KMnO}_{4}$ has dissolved. 

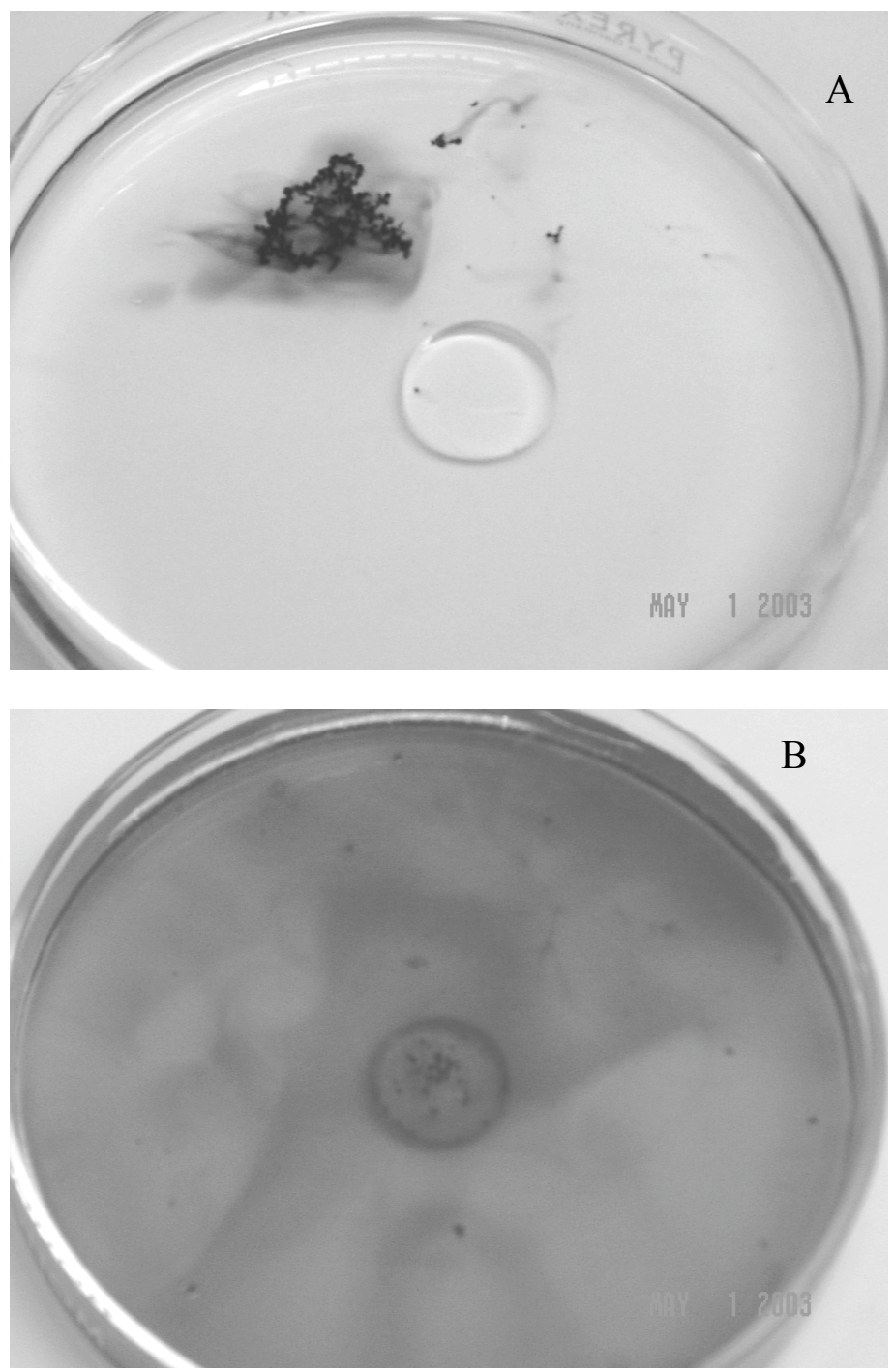

Figure 3-6. Accumulation of pulverized encapsulated $\mathrm{KMnO}_{4}$ particles $(0.05 \mathrm{~g}, 2: 1 \mathrm{~W}: \mathrm{P})$ at the surface of a PCE droplet $(0.7 \mathrm{~mL})$ in reagent grade water. (A) Before agitation; (B) $10 \mathrm{~min}$ after the system was agitated for $1 \mathrm{~min}$. 


\subsection{References}

(1) Harris, M. S. Preparation and release characteristics of potassium chloride microcapsules. J. Pharmaceutical Sci. 1981, 70, 391.

(2) Kakoulides, E. P.; Valkanas, G. N. Modified rosin-paraffin wax resins as controlled delivery systems for fertilizer. Fabrication parameters governing fertilizer release in water. Ind. Eng. Chem. Res. 1994, 33, 1623.

(3) Quaglia, F.; Barbato, F.; De Rosa, G.; Granata, E.; Miro, A. et al. Reduction of the environmental impact of pesticides: Waxy microspheres encapsulating the insecticide carbaryl. J. Agri. Food. Chem. 2001, 49, 4808.

(4) Lee, E. S.; Seol, Y.; Fang, Y. C.; Schwartz, F. W. Destruction efficiencies and dynamics of reaction fronts associated with the permanganate oxidation of trichloroethylene. Environ. Sci. Technol. 2003, 37, 2540.

(5) Nelson, M. D.; Parker, B. L.; Al, T. A.; Cherry, J. A.; Loomer, D. Geochemical reactions resulting from in situ oxidation of PCE-DNAPL by $\mathrm{KMnO}_{4}$ in a sandy aquifer. Environ. Sci. Technol. 2001, 35, 1266.

(6) Schnarr, M.; Truax, C.; Farquhar, G.; Hood, E.; Gonullu, T. et al. Laboratory and controlled field experiments using potassium permanganate to remediate trichloroethylene and perchloroethylene DNAPLs in porous media. J. Contaminant Hydrology 1998, 29, 205.

(7) Thomson, N. R.; MacKinnon, L. K. Laboratory-scale in situ chemical oxidation of a perchloroethylene pool using permanganate. J. Contaminant Hydrology 2002, 56, 49.

(8) ITRC Dense non-aqueous phase liquids (DNAPLs): review of emerging characterization and remediation technologies, 2000.

(9) Siegriest, R. L.; Urynowicz, M. A.; West, O. R.; Crimi, M. L.; Lowe, K. S. Principles and practices of in-situ chemical oxidation using permanganate, Battele Press, 2001.

(10) Siegriest, R. L.; Lowe, K. S.; Murdoch, L. C.; Case, T. L.; Pickering, D. A. In situ oxidation by fractured emplaced reactive solids. J. Environ. Eng. 1999, 125, 429. 
(11) Siegriest, R. L.; Murdoch, L. C. Oxidative particle mixtures for groundwater treatment. United States Patent 6,102,621, 2000.

(12) Klatte, F. Chemically impregnated zeolite and method for chemcally impregnationg and coating zeolite. U.S. Patent 5,278,112, 1994.

(13) Herbig, J. A. Process for making capsules. U.S. Patent 3,161,602, 1964.

(14) Kondo, A. Microcapsule processing and technology, Marcel Dekker, Inc., New York, 1979.

(15) Jillavenkatesa, A.; Dapkunas, S. J.; Lum, L. H. Particle size characterization: NIST recommended practice guide, National Institute of Standards and Technology, 2001.

(16) Bennet, H. Industrial waxes, Volume 1. Natural and synthetic waxes, Chemical Publishing Company, Inc., New York, 1965.

(17) Becirevic, M.; Begic, V. Controlled release formulations of potassium chloride produced by fluidized bed film coating and spray-drying technique. Pharmazie 1994, 49, 339.

(18) Cussler, E. L. Diffusion: mass transfer in fluid systems; 2nd ed., Cambridge University Press, New York, 1997.

(19) Weast, R. C. Handbook of chemistry and physics; 54th ed., CRC Press, Cleveland, OH, 1973.

(20) Lee, T. H.; Wang, J.; Wang, C.-H. Double-walled microspheres for the sustained release of a highly water soluble drug: characterization and irradiation studies. J. Controlled Release 2002, 83, 437.

(21) Budavari, S.; O'Neil, M. J.; Smith, A.; Heckelman, P. E.; Kinneary, J. F. The merck index: an encyclopedia of chemicals, drugs, and biologicals; 12th ed., Merck and Co., Inc., Whitehouse Station, NJ, 1996.

(22) Johnson, M. J. Growth of microbial cells on hydrocarbons. Science 1967, 155, 1515.

(23) Valkanas, G. N. Controlled release fertilizer. U.S. Patent 5,137,563, 1992. 


\section{Chapter 4. Co-solvent Enhanced Chemical Oxidation of Perchloroethylene by Potassium Permanganate}

Xihong Zhai, Inez Hua, P. Suresh C. Rao, Linda S. Lee

\subsection{Batch and 1-D Experiments}

\subsubsection{Abstract}

Various aspects of cosolvent enhanced oxidation of perchloroethylene (PCE) by potassium permanganate $\left(\mathrm{KMnO}_{4}\right)$ were studied. From 18 cosolvent candidates screened for cosolvency power and non-reactivity toward $\mathrm{KMnO}_{4}$, tertiary butyl alcohol (TBA) and acetone were selected as the two most suitable cosolvents. They were tested and compared with respect to their efficiencies in enhancing PCE oxidation rates, and their mobilization potentials of a dense non-aqueous phase liquid (DNAPL). The environmental degradability of the cosolvents themselves was also considered.

Step-wise, isocratic flushing with different volume fractions of cosolvent indicated that a volume fraction of less than $20 \%$ does not mobilize residual PCE in a sandy soil (hydraulic conductivity $2.48 \ldots 10^{-7} \mathrm{~m} / \mathrm{s}$, sampled from a former INDOT site in Warsaw, IN). TBA at 20\% enhances PCE solubility four fold. Acetone exhibits similar cosolvency power as TBA, but does not induce PCE mobility at volume fractions $\leq 50 \%$.

Batch experiments indicated that in the presence of free-phase PCE, the rate of chloride production from $\mathrm{PCE}$ oxidation by $\mathrm{KMnO}_{4}$ in a $20 \%$ acetone system was as much as twice that in the absence of co-solvent in the same period with same initial concentration of $\mathrm{KMnO}_{4}$. The presence of free-phase PCE mimics solubility conditions in the source zone.

However, in the absence of free-phase PCE, the second order rate constant for PCE oxidation by potassium permanganate was $0.043 \pm 0.002 \mathrm{M}^{-1} \mathrm{~s}^{-1}$ in the absence of co-solvent. This number decreased to $0.036 \pm 0.003 \mathrm{M}^{-1} \mathrm{~s}^{-1}$ with $20 \% \mathrm{TBA}$, and $0.031 \pm 0.002 \mathrm{M}^{-1} \mathrm{~s}^{-1}$ for $20 \%$ 
acetone. The chlorine atoms contained in PCE were recovered as chloride ion in the absence of co-solvent, whereas $70 \sim 90 \%$ of it recovered as chloride when $20 \%$ TBA or $20 \%$ acetone was present.

\subsubsection{Introduction}

Among the subsurface contaminants in soils and groundwater, hydrophobic organic compounds are a common class. These hydrophobic organic compounds can be immiscible with water, and are often referred to as non-aqueous phase liquids (NAPLs). NAPLs are classified according to their densities relative to water as dense non-aqueous phase liquids (DNAPLs) and light non-aqueous phase liquids (LNAPLs). The work reported in this chapter focuses on perchloroethylene (PCE) as a model DNAPL.

PCE has adverse effects on human health. The U. S. EPA's drinking water standard for PCE is $5 \_\mathrm{g} / \mathrm{L}$, which is five orders of magnitude lower than its aqueous solubility, $150 \mathrm{mg} / \mathrm{L}$ (0.90mM) (USEPA, 2002). However, this solubility is relatively low and it presents a long-term contaminant source to groundwater. Once spilled, PCE will penetrate the water table and form discontinuous "pools" on top of layers with low permeability. It can enter small fractures and pore spaces easily because of the low interfacial tension between PCE and water, which increases the difficulty of clean-up. PCE is also recalcitrant to biological degradation or abiotic chemical reactions (Pankow et al., 1996). Thus, PCE exhibits a long half-life in the subsurface and new methods should be developed for in-situ destruction in source zones.

Chemical oxidation has been used traditionally in the municipal and industrial water and waste treatment industry. Several chemical oxidant systems, most notably Fenton's reagent, ozone, and permanganate, are commonly applied. Research efforts have directed towards exploring the application of chemical oxidation to remediate subsurface environments (Barbeni 
et al., 1987; Berry and Boyd, 1985; Bier et al., 1999; Bowers et al., 1989; Chen et al., 1999; Kubarewicz and Pfeffer, 1985; Schnarr et al., 1998; Siegrist, R. L. et al., 1999; USEPA, 1998; Watts, R. J. et al., 1999b; Watts, Richard J. et al., 1999). In the case of cosolvent enhanced oxidation of chlorinated ethylenes, permanganate is preferred over the other two oxidants because of its ease in handling, strong oxidation capacity, and selectivity toward PCE.

Permanganate ion, $\mathrm{MnO}_{4}{ }^{-}$, has recently been applied for in situ oxidation of trichloroethylene (TCE) and PCE in laboratory and field studies (Schnarr et al., 1998; Siegrist, R. L. et al., 1999; USEPA, 1998). Complete oxidation to chloride and carbon dioxide was observed. The exact mechanisms and kinetics involved are not well established, but the reactions probably occur primarily in the aqueous phase (Huang et al., 1999; Huang et al., 2002) and to a lesser extent in the organic phase. The success of permanganate at oxidizing TCE and PCE results from the fact that they are alkenes, which are generally reactive towards permanganate. Several kinetic studies regarding permanganate oxidation of chlorinated ethylenes have been accomplished (Hood et al., 2000; Huang et al., 2001; Seol and Schwartz, 2000; Yan and Schwartz, 1999, 2000). These researchers concluded that PCE oxidation by potassium permanganate is pseudo-first order with respect to PCE and permanganate, respectively, and second order overall $\left(\mathrm{k} \cong 0.05 \mathrm{M}^{-1} \mathrm{~s}^{-1}\right)$. Because the oxidant concentration can be very high in field applications, PCE oxidation by potassium permanganate can be fairly fast compared to the mass transfer by NAPL dissolution. Thus, enhancing the dissolution mass transfer rate can be an effective approach to increase the efficiency of in situ chemical oxidation technology in remediation of PCE-contaminated sites.

One method of enhancing the mass transfer rate is to increase the solubility of PCE by adding a cosolvent. A solvent must meet three criteria to be considered as a candidate cosolvent 
during ISCO: large cosolvency power, miscibility with water, and recalcitrance to oxidation by permanganate. The cosolvent effect of alcohols on the aqueous solubility of PCE has been studied (Ladaa et al., 2001) and tertiary butyl alcohol (TBA) exhibits strong cosolvency power on PCE. Also, cosolvent-enhanced oxidation as "co-oxidation" has been patented (Cowdery et al., 2002), where TBA served as the cosolvent to enhance the PCE oxidation by permanganate.

The cosolvent enhanced solubility is exponentially correlated to the volume fraction of the cosolvent in a mixture by the cosolvency power (Banerjee and Yalkowsky 1988; Schwarzenbach et al. 2002; Yalkowsky et al. 1972a; Yalkowsky et al. 1972b; Yalkowsky and Roseman 1981) as

$$
\mathrm{C}_{\mathrm{m}}^{\mathrm{sat}}=\mathrm{C}_{\mathrm{w}}^{\mathrm{sat}} \cdot 10^{\text {of }}
$$

$\mathrm{C}_{\mathrm{m}}{ }^{\text {sat }}=$ cosolvent-enhanced solubility, $\mathrm{M} / \mathrm{L}^{3}$;

$\mathrm{C}_{\mathrm{w}}{ }^{\text {sat }}=$ the initial aqueous solubility, $\mathrm{M} / \mathrm{L}^{3}$;

$\sigma=$ the cosolvency power, dimensionless;

$\mathrm{f}=$ the volume fraction of the cosolvent in the mixture, $\mathrm{L}^{3} / \mathrm{L}^{3}$.

The objective of this study was fulfilled through the following tasks: 1) select a suitable cosolvent by screening the reactivity of numerous cosolvents (which are miscible with water and exert cosolvency power over PCE) towards potassium permanganate; 2) determine PCE solubility enhancement by adding the cosolvents; 3) conduct bench-scale experiment to determine the reaction kinetics of the cosolvent-enhanced chemical oxidation; and 4) perform batch experiments in the presence of free phase PCE to evaluate the effectiveness of cosolventenhanced PCE oxidation by potassium permanganate.

\subsubsection{Materials and Methods}

Reagent grade water $\left(\mathrm{R}=18 \mathrm{M} \Omega \mathrm{cm}^{-1}\right)$ was obtained through a Barnstead NANOpure Ultrapure water system. Reagent grade sodium thiosulfate (Aldrich), potassium permanganate 
(Aldrich), tetrachloroethylene (PCE) (Aldrich), ethylbenzene (Aldrich), acetone (Aldrich), tertiary-butyl alcohol (TBA, Fisher Scientific), and methanol (Fisher Scientific) were used as received.

Selection of cosolvents: Water was mixed with co-solvent candidates at a volume fraction of $20 \% . \mathrm{KMnO}_{4}$ was added to these mixtures (initial concentration $=2 \mathrm{mM}$ ). The time required for the $\mathrm{KMnO}_{4}$ concentration to decrease below detectible levels was recorded as a measure of the recalcitrance of the co-solvent to the attack by the oxidant. The co-solvents selected from this screening step were then used in following studies.

Interfacial tension (IFT) measurements: The interfacial tension between PCE and the co-solvent/water mixtures (volume fractions $=0,20 \%, 25 \%, 30 \%, 35 \%, 40 \%$, and $50 \%$ ) was measured at room temperature using a tensiometer ring (DoNouY).

Solubility enhancement: Five $\mathrm{mL}$ of co-solvent/water mixtures (volume fraction of 0 , $10 \%, 15 \%, 20 \%, 25 \%, 30 \%$ ) as solvent matrices were placed in $5 \mathrm{~mL}$ Teflon capped vials. To minimize the partitioning of cosolvent into PCE, the volume of PCE injected into each vial was calculated based on the approximated solubility tested in the preliminary experiment given a safety factor of two, which was in the range of 1 to $50 \mu \mathrm{L}$. Two gas tight Hamilton syringes (10 $\mu \mathrm{L}$ and $50 \mu \mathrm{L}$ ) were used to inject PCE. The vials were then rotated gently on circular rotator (Glas-Col ${ }^{\circledR}, 20 \mathrm{rpm}$ ) for 5 hours at room temperature, and the resulting PCE concentration was measured using gas chromatograph equipped with a flame ionization detector (GC-FID).

Column flushing: It was expected that as the volume fraction of cosolvent increases in the water/cosolvent mixture, its potential to mobilize DNAPL would also increase. To find out the maximum volume fraction of cosolvent that can be applied without causing DNAPL mobilization, isocratic flushing of residual DNAPL with step-wise increasing of cosolvent 
content was performed in one-dimensional (1-D) soil-packed column. Soil samples were taken from an Indiana Department of Transportation (INDOT) site in Warsaw, Indiana. The soil was air dried at room temperature $\left(\sim 22^{\circ} \mathrm{C}\right)$ and sieved (30-mesh). The soil had a bulk density of 1.36 $\mathrm{g} / \mathrm{cm}^{3}$ (gravimetric method), organic matter content of $1.21 \%$ (oven digestion at $500^{\circ} \mathrm{C}$ ), porosity of 0.27 (gravimetric method), and saturated hydraulic conductivity of $2.41 \times 10^{-7} \mathrm{~m} / \mathrm{s}$ (constanthead permeameter method). A borosilicate glass column (Western Analytical, $2.5 \mathrm{~cm}$ i.d., $10 \mathrm{~cm}$ long) was packed (to $7 \mathrm{~cm}$ bed length) with dry soil with frequent vibration during the packing. Helium degassed water was then delivered with a dual-motor syringe pump (Harvard 55-3333) with an upward flow of $0.05 \mathrm{~mL} / \mathrm{min}$ to saturate the column. The column pore volume was approximately $10 \mathrm{ml}$. The packed column was loaded with PCE pumped in an upward flow of $0.02 \mathrm{ml} / \mathrm{min}$ for 3 hours. After turning the column upside down, it was flushed with water (downward) at $0.05 \mathrm{~mL} / \mathrm{min}$ until no DNAPL phase was observed in the column effluent. Cosolvent/water mixtures, with increasing cosolvent volume fractions, were used to flush the residual saturated PCE from the column. Each solvent mixture was pumped at the rate of 0.05 $\mathrm{mL} / \mathrm{min}$ for 200 minutes, resulting in about one pore volume being displaced.

Kinetic studies: Batch experiments were conducted in several sets of $5 \mathrm{~mL}$ vials with Teflon-lined open-top cap (VWR). The temperature was maintained at $25^{\circ} \mathrm{C}$ by placing the vials in a water bath. For comparison purposes, stock solutions of PCE were prepared in three matrices: water, water/TBA ( $80 \%: 20 \%)$, and water/acetone (80\%:20\%). The PCE concentration level was targeted to the aqueous solubility (about $1.21 \mathrm{mM}$ or $200 \mathrm{mg} / \mathrm{L}$ ) for all matrices. The $\mathrm{pH}$ was adjusted to 7 using a buffer solution of $\mathrm{Na}_{2} \mathrm{HPO}_{4}$ and $\mathrm{NaH}_{2} \mathrm{PO}_{4}$. To facilitate the interfacial area between PCE and water, the stock solution with water as a solvent matrix was first prepared in sets of $25 \mathrm{~mL}$ vials. Twenty-five $\mathrm{mL}$ of each $\mathrm{pH}$ buffered solvent matrix was 
added to each vial followed by injection of $4 \mu \mathrm{L}$ of pure PCE with a $10 \mu \mathrm{L}$ syringe (Hamilton). These vials were then rotated gently overnight and mixed together in a $50-\mathrm{mL}$ bottle. Due to the salt effect from buffers, the solubility of PCE in buffered solution decreased to $0.84 \mathrm{mM}$ (140 $\mathrm{mg} / \mathrm{L}$ ). This concentration was then used to make the solution in water/TBA and water/acetone. Since the solubilities in these two solvent matrices are much larger than the targeted concentration, pre-dissolution in smaller vials was not necessary and these solutions were prepared in $100 \mathrm{~mL}$ volumetric flasks immediately preceding the experiments.

$\mathrm{KMnO}_{4}$ stock solution was made by dissolving excess $\mathrm{KMnO}_{4}$ solid in $\mathrm{pH}$ buffered water such that the solution was saturated with $\mathrm{KMnO}_{4}$ (about $400 \mathrm{mM}$ ). The oxidation reaction was initiated by mixing $4.8 \mathrm{~mL}$ PCE stock solution and $0.2 \mathrm{~mL} \mathrm{KMnO}_{4}$ stock solution in a set of 5 $\mathrm{mL}$ vials. The headspace was minimized as much as possible in the vials. This resulted in about $0.81 \mathrm{mM}$ PCE and $16 \mathrm{mM} \mathrm{KMnO}_{4}$ initially in the vials so that the reaction was pseudo-first order $\left(\left[\mathrm{KMnO}_{4}\right]_{0} \approx 10[\mathrm{PCE}]_{0}\right)$. At pre-determined time intervals the reaction in two of the vials was quenched by addition of $0.2 \mathrm{~mL} 1 \mathrm{~N} \mathrm{Na}_{2} \mathrm{~S}_{2} \mathrm{O}_{3}$ solution after $0.2 \mathrm{~mL}$ aliquot was withdrawn. Two $\mathrm{mL}$ of the reacted solution was extracted with $3 \mathrm{~mL}$ of pentane for PCE analysis (the extracts were rotated on circular rotator at $70 \%$ speed $(50 \mathrm{rpm})$ for 45 minutes $)$, and the rest was set aside until the $\mathrm{MnO}_{2}$ precipitate settled and the supernatant was sampled for $\mathrm{Cl}^{-}$analysis by ion chromatography (IC).

Most often, PCE exists as DNAPL in the source zone of the contaminated sites. To mimic this situation in a batch system, an excess amount of pure PCE was added to the reactor. As the dissolved PCE is oxidized by permanganate, the excess PCE present as DNAPL dissolves and serves as continuous supply into the aqueous phase. The two solvent matrices, water and water/acetone ( $80 \%: 20 \%)$, were compared. PCE oxidation was monitored by measuring the rate 
of Cl-production. A $250 \mathrm{~mL}$ glass reactor with Teflon lined septum and open-top closure was placed in $25^{\circ} \mathrm{C}$ water jacket on a stirring plate; $238 \mathrm{~mL}$ of solvent matrix pre-saturated with PCE, $2 \mathrm{~mL}$ of pure PCE, and $10 \mathrm{~mL}$ of $\mathrm{KMnO}_{4}$ stock solution were added to the reactor in sequence. $\mathrm{pH}$ was not adjusted in this experiment. A small stirring bar and a low stirring speed were used to prevent the formation of an emulsion. At pre-determined time intervals, $2 \mathrm{~mL}$ sample of the aliquot were taken out of the reactor with needle syringe, of which part was diluted for $\mathrm{KMnO}_{4}$ measurement and the rest was quenched by $200 \mu \mathrm{L}$ of $\mathrm{Na}_{2} \mathrm{~S}_{2} \mathrm{O}_{3}$ for PCE and $\mathrm{Cl}$ - analysis. A smaller reactor $(25 \mathrm{~mL})$ was filled with the same volume ratio of PCE saturated solvent matrix and $\mathrm{KMnO}_{4}$; solution was withdrawn from this smaller reactor at the corresponding time intervals, and transferred to the larger reactor to compensate for volume loss due to sampling in the larger reactor.

Instrumental analysis: PCE was analyzed with a Varian 3800 GC equipped with flame ionization detector (FID), CombiPAL auto-sampler, and DB 624 column (30 m long, $0.53 \mathrm{~mm}$ ID, $3 \mu \mathrm{m}$ of film thickness). Injection port and detector temperatures were $150 \quad{ }^{\circ} \mathrm{C}$ and $250{ }^{\circ} \mathrm{C}$, respectively. The gas flow rate was $9.0 \mathrm{~mL} / \mathrm{min}$. The oven temperature was programmed as initially $60^{\circ} \mathrm{C}$ for 2 minutes, and then increased at $10^{\circ} \mathrm{C}$ per minute for 6 minutes, followed by $120^{\circ} \mathrm{C}$ for 1 minute. The injection volume was $1 \mu \mathrm{L}$. PCE retention time was 5.6 minutes with this program. $\mathrm{KMnO}_{4}$ was analyzed using a UV-Vis spectrophotometer (Perkin-Elmer, Lambda 3) at $522 \mathrm{~nm}$. The extinction coefficient was $2.2214 / \mathrm{M} \mathrm{KMnO}_{4}$. Chloride ion was quantified using a Dionex Ion Chromatograph equipped with a Dionex AS11 column. The flow-rate of the mobile phase $\left(2 \mathrm{mM} \mathrm{NaHCO}\right.$ and $\mathrm{Na}_{2} \mathrm{CO}_{3}$ ) was $2 \mathrm{~mL} / \mathrm{min}$. The retention time for $\mathrm{Cl}^{-}$was 1.6 minutes with this system. 


\subsubsection{Results and Discussion}

Shorter-chain organics and lower molecular weight compounds are more easily oxidized by permanganate than branched-chain and higher molecular weight species (Table 1). However, no obvious, direct relationship can be discerned regarding the recalcitrance of an organic species to permanganate oxidation and its chemical structure. The most stable compound in the presence of permanganate was tertiary butyl alcohol (TBA), which was stable for more than 3 days. The recalcitrance of TBA lies in its tertiary structure. The three methyl groups attached to alcohol functional group makes the whole molecule bulky, and protects the alcohol group from the attack of $\mathrm{KMnO}_{4}$.

Acetone is not as recalcitrant to $\mathrm{KMnO}_{4}$ oxidation as TBA; the half-life of $\mathrm{KMnO}_{4}$ in $30 \%$ acetone is about 10 hours. But, it is expected that $\mathrm{KMnO}_{4}$ will oxidize most of the accessible PCE within 10 hours. Further more, both TBA and acetone are readily biodegradable (Bradley et al., 2002; Piveteau et al., 2001; Platen and Schink, 1987, 1989; Platen et al., 1990), which means that microbial degradation can be facilitated afterwards to reduce the cosolvent concentrations. Both TBA and acetone were used as cosolvent in the following experiments to test their effectiveness in cosolvent-enhanced chemical oxidation of PCE.

\section{Solubility enhancement}

The aqueous solubility of PCE in reagent-grade water measured in this experiment ranged from 196 to $232 \mathrm{mg} / \mathrm{L}$, consistent with a value of $242 \mathrm{mg} / \mathrm{L}$ at $24^{\circ} \mathrm{C}$ reported by (Broholm et al., 1992). Both TBA and acetone showed strong cosolvency power for PCE, as seen in equations 5 and 6, and Figure 1.

For TBA:

$\log \mathrm{C}_{\mathrm{m}}{ }^{\text {sat }}=3.85 \mathrm{f}+\log \mathrm{C}_{\mathrm{w}}{ }^{\text {sat }} ; \mathrm{r}^{2}=0.96$

For acetone:

$$
\log \mathrm{C}_{\mathrm{m}}{ }^{\text {sat }}=3.22 \mathrm{f}+\log \mathrm{C}_{\mathrm{w}}{ }^{\text {sat }} ; \mathrm{r}^{2}=0.96
$$


TBA was reported to be a powerful cosolvent for PCE. Ladaa et al (2001) reported a PCE solubility of $4000 \mathrm{mg} / \mathrm{L}$ in $28 \% \mathrm{TBA}$, which is close to the observation in this study (4076 mg/L in $30 \%$ TBA). The cosolvency power of acetone was also calculated from a model (Morris et al., 1988) based on the octanol-water partitioning coefficient of the solute $\left(\mathrm{k}_{\mathrm{ow}}\right)$,

$$
\sigma=\log k_{\text {ow }}+0.48
$$

Given the value of $\log k_{\text {ow }}$ for PCE of 2.88 (Schwarzenbach 2002), cosolvency power of acetone was 3.36, which is comparable to the result in this study. Siegrist et al. (Siegrist, Robert L. et al., 2001) proposed for PCE dissolution the steady-state diffusion across a stagnant film:

$$
\mathrm{J}=-\mathrm{k}\left(\mathrm{C}_{\mathrm{s}}-\mathrm{C}\right)
$$

Where $\mathrm{J}=$ mass flux of solute $\mathrm{M} / \mathrm{L}^{2} / \mathrm{T}$;

$\mathrm{k}=$ mass transfer coefficient, $\mathrm{L} / \mathrm{T}$;

$\mathrm{C}_{\mathrm{s}}=$ effective aqueous solubility, $\mathrm{M} / \mathrm{L}^{3}$, and

$\mathrm{C}=$ actual aqueous concentration.

The measured $\mathrm{k}$ value for PCE dissolution into water was reported to be $0.14 \mathrm{~cm} / \mathrm{min}$ (Johnson et al., 1999). The major driving force for mass transfer, the difference between saturated concentration and the actual concentration $\left(\mathrm{C}_{\mathrm{s}}-\mathrm{C}\right)$ is not very high considering the low aqueous solubility of PCE. If PCE solubility is increased by a factor of four or more, this driving force will significantly increase and therefore enhance the mass transfer rate. Besides increasing the magnitude of $\mathrm{C}_{\mathrm{s}}$, a cosolvent is also expected to increase the value of $\mathrm{k}$ by changing the interfacial tension and other characteristics related to mass transfer kinetics (Heyse et al., 2002; Jawitz et al., 2003).

Interfacial tension and DNAPL mobilization 
Since PCE solubility increases exponentially with $f_{c}$, it is reasonable to conclude that the more cosolvent used, the more efficient will be in-situ flushing. However, the upper limit of $f_{c}$ is determined by the mobilization of PCE. A possible side effect of in-situ flushing with a cosolvent is that the interfacial tension between the DNAPL and fluid can drop, and cause the mobilization of NAPL. The total trapping number theory was utilized to quantify the tendency of NAPL to migrate in a subsurface environment (Pennell et al., 1996). The total trapping number, $\mathrm{N}_{\mathrm{T}}$, is calculated from Capillary Number, $\mathrm{N}_{\mathrm{Ca}}$, and Bond Number, $\mathrm{N}_{\mathrm{B}}$, as follows,

$$
\begin{gathered}
N_{c a}=\frac{q_{w} \mu_{w}}{\sigma_{o w}} \\
N_{B}=\frac{\Delta \rho g k k_{r w}}{\sigma_{o w}} \\
N_{T}=\sqrt{N_{C a}^{2}+2 N_{C a} N_{B} \sin \alpha+N_{B}^{2}}
\end{gathered}
$$

where $\mathrm{q}_{\mathrm{w}}=\operatorname{Darcian}$ velocity $(\mathrm{cm} / \mathrm{s}) ; \mu_{\mathrm{w}}=$ volume averaged fluid viscosity, dyne $\mathrm{s} / \mathrm{cm} ; \sigma_{\mathrm{ow}}=$ the interfacial tension between the DNAPL and fluid, dyne/cm; $\Delta \rho=$ density difference between the fluid and PCE, $\mathrm{g} / \mathrm{cm}^{3} ; \mathrm{g}=$ gravity, $980.6 \mathrm{~cm} / \mathrm{s}^{2} ; \mathrm{k}=$ intrinsic permeability, $\mathrm{cm}^{-2} ; \mathrm{k}_{\mathrm{rw}}=$ relative permeability, unitless, assumed to be $1 ; \alpha=$ the angle of the flow makes with the horizontal direction to the right (counter clockwise).

In the case of vertical upward flow, $\sin \alpha=1$, and the relationship between $\mathrm{N}_{\mathrm{T}}, \mathrm{N}_{\mathrm{Ca}}$, and $\mathrm{N}_{\mathrm{B}}$ simplifies to:

$$
\mathrm{N}_{\mathrm{T}}=\left|\mathrm{N}_{\mathrm{Ca}}+\mathrm{N}_{\mathrm{B}}\right|
$$

The critical value of $\mathrm{N}_{\mathrm{T}}$ required to initiate residual PCE mobilization is within the range of 2 $\times 10^{-5}$ to $5 \times 10^{-5}$ (Pennell et al., 1996). 
The measured interfacial tension (IFT) between water and PCE was in the range of 46-48 dynes/cm (Figure 2), close to the literature value of 44.4 dynes/cm (Mercer and Cohen, 1990), with the slight deviation probably due to temperature differences. For both TBA and acetone, the IFT drops rapidly as the volume fraction of cosolvent increased, but the decrease in acetone/water solvent is not as much as that in TBA/water solvent. Thus, PCE mobilization is more likely with TBA addition than with acetone.

In step-wise, isocratic flushing at $0.05 \mathrm{ml} / \mathrm{min}$ in an upward flow mode, a negligible amount of PCE was flushed out with 20\% TBA. However, as the TBA fraction exceeded this threshold, it could be visually seen that the red colored PCE as NAPL appear in the outlet tubing intermittently. More and more residual PCE was mobilized as the TBA volume fraction increased. For acetone volume fractions of $10 \%, 20 \%, 30 \%, 40 \%$ and even $50 \%$, very little of the residual phase PCE was displaced from the column. For various TBA and acetone volume fractions, the $\mathrm{N}_{\mathrm{T}}$ values were calculated based on the soil properties and hydrodynamic condition used in flushing, and the measured IFT values. The normalized residual saturation (Sn') was plotted against the corresponding calculated total trapping number $\left(\mathrm{N}_{\mathrm{T}}\right)$ for various volume fractions of TBA and acetone in Figure 3. It indicated that PCE was mobilized when the $\mathrm{N}_{\mathrm{T}}$ value reached $3 \times 10^{-7}$ with $20 \% \mathrm{TBA}$, namely $20 \% \mathrm{TBA}$ is the maximum volume fraction usable without causing the mobilization of residual PCE. The critical $\mathrm{N}_{\mathrm{T}}$ value resulted from this study was two orders of magnitude lower than the range of $2 \times 10^{-5}$ to $5 \times 10^{-5}$ given by Pennel et al. (1996). The same phenomenon was observed by Padgett and Hayden (1999) when they mix sand with clay. Their explanation is that the mixed media soil favored the formation of multipore ganglia which can be more easily mobilized. The same reasoning can be applied here considering the large range of the soil particle size in this study. 

dissolved PCE are found in the source zone, but just dissolved PCE in the plume. In the absence of free phase PCE, the amount of PCE reduced can be tracked conveniently; therefore, chlorine mass balance can be computed based on PCE loss and increase in chloride ion concentration. Oxidation experiments were performed in the presence and absence of PCE.

\section{Dissolved PCE only:}

The concentrations of $\mathrm{KMnO}_{4}$ in the vials were measured soon after the reaction was initiated ( 2 minutes) and at the end of the experiment course (60 minutes). Their difference was even less than the error associated in dilution process and the random error of instrument. Therefore pseudo-first order reaction was a reasonable assumption. The change of PCE concentrations with all three solvent matrices falls in the pseudo-first order model quite well with the coefficient of determination $\left(\mathrm{R}^{2}\right)$ higher than 0.99 (Figure 4). The second order rate constant without cosolvent is $0.043 \pm 0.005 \mathrm{M}^{-1} \mathrm{~s}^{-1}$ as calculated from the data in this work, which is close to the results from other research groups with similar condition (Yan and Schwartz, 1999; Hood et al., 2000; and Huang et al. 2002) (Table 2). Chlorine mass balance based on PCE and chloride concentration ranged from $95 \%$ to $104 \%$ when the solvent matrix was water (Figure 5), indicating that all the chlorine contained in PCE was released as chloride upon oxidation in water-based solvent system.

However, when cosolvent was used, the reaction kinetics decreased (Figure 4 and Table 2), and the chlorine mass balances were less complete (60 90\%, Figure 5). Various efforts were taken to account for the un-recovered chlorine mass, including dissolving the reaction precipitate and analyzing for chloride, and looking for possible chlorine-containing organic intermediates with Gas Chromatograpy/Mass Spectrosocopy (GC/MS). It is possible that both lower reaction 
kinetics and poor chlorine recovery in the presence of cosolvent are due to local heterogeneity of the system. On the micro-scale if PCE molecules are more surrounded by TBA or acetone and $\mathrm{KMnO}_{4}$ molecules are more surrounded by water, then probably $\mathrm{KMnO}_{4}$ is not as available to PCE as in the system without cosolvent. According to the reaction pathway proposed by Huang et al. (2002), some chlorine containing intermediates, such as oxylyl chloride, are produced from the reaction, but they are not stable in water system and soon transformed to water and hydrochloric acid. It is suspected that these intermediates can be more stable in the microenvironment around PCE where there is less water and more cosolvent molecules, and that they were lost during the sample processing and therefore weren't detected.

With free phase PCE:

To simulate the performance of cosolvent-enhanced chemical oxidation of PCE in the source zone, an excess amount of PCE was injected into $20 \%$ acetone so that there was free phase PCE in the system. It was expected that cosolvent would increase the mass transfer rate between DNAPL and aqueous phase and thus lead to faster destruction of PCE. Our experimental results with free phase PCE supports this hypothesis as seen in Figure 6 and 7. The concentrations of PCE were also measured for these experiments. The results were much higher than the solubility limits both in the case of no cosolvent and $20 \%$ acetone (data not shown), indicating that some of the free phase PCE probably adsorbed to the surface of precipitate formed from reaction between $\mathrm{PCE}$ and $\mathrm{KMnO}_{4}$. The adsorbed PCE was extracted by pentane and resulted in a very high measured concentration of PCE. Based on this it is reasonable to assume that PCE dissolution is instantaneous and PCE concentrations remains at the solubility level through the course of the reaction, given the high surface area of the DNAPL. 
With this assumption, the reaction between PCE and $\mathrm{KMnO}_{4}$ can be approximated as first order with respect to $\mathrm{KMnO}_{4}$. Using the reaction rate constant obtained above, the change in concentration of $\mathrm{KMnO}_{4}$ and chloride can be modeled, assuming three moles of chloride will be produced for each mole of $\mathrm{KMnO}_{4}$ consumed. The modeled values were plotted together with the actual measured values in Figure 6 and 7. The chloride concentration in the $20 \%$ acetone case was corrected based on $70 \%$ mass balance obtained before. It can be seen that the model predicted the reaction very well when there was no cosolvent in the system, which verified the kinetic rate constant obtained in this study. However, there was a gap between the modelpredicted values and the actual data in the case of $20 \%$ acetone, with actual less chloride and less $\mathrm{KMnO}_{4}$ than predicted. Note that acetone can be oxidized by $\mathrm{KMnO}_{4}$ slowly. This gap can be due to the $\mathrm{KMnO}_{4}$ consumed by acetone, possibly also by intermediate from PCE oxidation. More chloride was produced in $20 \%$ acetone system than in the no-cosolvent system throughout the course of the experiment (Figure 6), indicating that cosolvent increased the time-efficiency of permanganate in oxidation of PCE. Chloride production in $20 \%$ acetone reached a plateau gradually after 120 minutes of reaction because of the significant drop in $\mathrm{KMnO}_{4}$ concentration (Figure 7).

\subsubsection{Conclusions}

The cosolvent-enhanced chemical oxidation of PCE by KMnO4 appears to be an effective DNAPL source-zone remediation method. The major findings from this work are summarized as follows:

- Both TBA and acetone are sufficiently recalcitrant to the oxidation by $\mathrm{KMnO}_{4}$ to be used as cosolvent. The half-life of $\mathrm{KMnO}_{4}$ in $20 \%$ TBA is more than 3 days, and that of 
acetone is 10 hours; thus, they are present at high enough concentration to solubilize more PCE which is in turn, oxidized by $\mathrm{KMnO}_{4}$.

- TBA and acetone can increase the solubility of PCE significantly. The cosolvency power of TBA for PCE is 3.47 , and that of acetone is 2.76 . Considering the decrease in $\mathrm{PCE} /$ water interfacial tension with cosolvent addition, $20 \% \mathrm{TBA}$ is the maximum volume fraction at which PCE mobilization can be avoided, whereas acetone exhibits a much lower mobilization tendency and 50\% acetone does not mobilize PCE.

- In the absence of free-phase PCE, the reaction kinetics between PCE and $\mathrm{KMnO}_{4}$ was reduced by approximately $25 \%$ when $20 \%$ TBA or acetone was used, probably due to the micro-scale heterogeneity in the cosolvent system. A full chlorine mass balance can be obtained in the absence of co-solvent, based on PCE and chloride concentrations. However, chloride recovered from the solution accounts for $70 \sim 80 \%$ of chlorine contained in PCE with 20\% TBA, and with $20 \%$ acetone.

- The chloride production from PCE oxidation with $\mathrm{KMnO}_{4}$ in $20 \%$ acetone system was about twice as much as that in the absence of co-solvent, indicating the former system has a higher time-efficiency in utilizing $\mathrm{KMnO}_{4}$. 


\subsubsection{References}

Barbeni, M., Mineero, C., and Pelizzetti, E., 1987. "Chemical degradation of chlorophenols with Fenton's Reagent". Chemosphere, 16, 2225-2237.

Berry, D. F., and Boyd, S. A., 1985. "Decontamination of soil through enhanced formation of bound residues". Environmental Science \& Technology, 19, 1132-1133.

Bier, E. L., Singh, J., and al., e., 1999. "Remediating hexahydro-1,3,5-trinitro-1,2,5-trazinecontaminated water and soil by fenton oxidation". Environmental Toxicology and Chemistry, $18(10), 2400-2400$.

Bowers, A. R., Gaddipati, P., and al., e., 1989. "Treatment of toxic or refractory wastewaters with hydrogen-peroxide". Water Science and Technology, 21(6-7), 477-486.

Bradley, P. M., Landmeyer, J. E., and Chapelle, F. H., 2002. "TBA biodegradation in surfacewater sediments under aerobic and anaerobic conditions". Environmental Science \& Technology, 36(19), 4087-4090. $\leq$ Go to ISI $>: / / 000178351800026$

Broholm , K., Cherry, J. A., and Feenstra, S. (1992). "Dissolution of heterogeneously distributed solvents residuals". Paper presented at the Subsurface Restoration Conference, Third International Conference On Groundwater Quality Research, Dallas, Texas.

Chen, S. T., Stevens, D. K., and al., e., 1999. "Pentachlorophenol and crystal violet degradation in water and soils using heme and hydrogen peroxide". Water Research, 33(17), 3657-3665. Cowdery, R. C., Warner, K. M., and Applegate, J. L. (2002). "Co-oxidation method and cooxidation reagent for decontamination groundwater and soil." Patent.

Heyse, E., Augustijn, D., Rao, P. S. C., and Delfino, J. J., 2002. "Nonaqueous phase liquid dissolution and soil organic matter sorption in porous media: review of system similarity". Environmental Science \& Technology, 32(4), 337-397. 
Hood, E. D., Thomson, N. R., Grossi, D., and Farquhar, G. J., 2000. "Experimental determination of kinetic rate law for the oxidation of perchloroethylene by potassium permanganate". Chemosphere(40), 1383-1388.

Huang, K.-C., Hoag, G. E., and al., e., 1999. "Kinetic study of oxidation of trichloroethylene by potassium permanganate". Environmental Engineering and Science, 16(4), 265-274.

Huang, K.-C., Hoag, G. E., Chheda, P., Woody, B. A., and Dobbs, G. M., 2001. "Oxidation of chlorinated ethenes by potassium permanganate: a kinetic study". Journal of hazardous materials, B87, 155-169.

Huang, K.-C., Hoag, G. E., Chheda, P., Woody, B. A., and Dobbs, G. M., 2002. "Kinetics and mechanism of oxidation of tertrachloroethylene with permanganate". Chemosphere, 46, 815-825. Jawitz, J. W., Dai, D., Rao, P. S. C., Annable, M. D., and Rhue, R. D., 2003. "Rate-limited Solubilization of Multi-component Nonaqueous Phase Liquids by Flushing with Cosolvents and Surfactants: Modeling Data from Laboratory and Field Experiments (in press)". Accepted by Environmental Science \& Technology.

Johnson, J. C., Sun, S. B., and Jaffe, P. R., 1999. "Surfactant enhanced perchloroethylene dissolution in porous media: The effect on mass transfer rate coefficients". Environmental Science \& Technology, 33(8), 1286-1292. $\leq$ Go to ISI $>$ ://000079974600023

Kubarewicz, J. W., and Pfeffer, J. L., 1985. "Task 4 of desensitization of explosives laden soil/sediments: phase II, laboratory studies".

Ladaa, T. I., Lee, C. M., Coates, J. T., and Falta, R. W. J., 2001. "Cosolvent effects of alcohols on the Henry's law constant and aqeous solubility of tetrachloroethylene (PCE)". Chemosphere, 44, 1137-1143. 
Mercer, J. W., and Cohen, R. M., 1990. "A review of immiscible fluids in the subsurface:

Properties, models, characterization and remediation".

Pankow, J. F., Freestra, S., Cherry, J. A., and Ryan, M. C. (1996). "Dense chlorinated solvents and other DNAPLs in Groundwater: background and history of the problem". In J. A. Cherry (Ed.), Dense chlorinated solvents and other DNAPLs in Groundwater: History, behavior, and remediation (pp. 3-28). Portland, Oregon: Waterloo Press.

Pennell, K. D., Pope, G. A., and Abriola, L. M., 1996. "Influence of viscous and buoyancy forces on the mobilization of residual tetrachloroethylene during surfactant flushing". Environmental Science \& Technology, 30(4), 1328-1335. < Go to ISI >://A1996UC41300058 Piveteau, P., Fayolle, F., Vandecasteele, J. P., and Monot, F., 2001. "Biodegradation of tertbutyl alcohol and related xenobiotics by a methylotrophic bacterial isolate". Applied Microbiology and Biotechnology, 55(3), 369-373. $\leq$ Go to ISI $>$ ://000168388600016

Platen, H., and Schink, B., 1987. "Methanogenic Degradation of Acetone by an Enrichment Culture". Archives of Microbiology, 149(2), 136-141. $\leq$ Go to ISI>://A1987L221500009

Platen, H., and Schink, B., 1989. "Anaerobic Degradation of Acetone and Higher Ketones Via Carboxylation by Newly Isolated Denitrifying Bacteria". Journal of General Microbiology, 135, 883-891. $\leq$ Go to ISI $>: / / A 1989 U 302100017$

Platen, H., Temmes, A., and Schink, B., 1990. "Anaerobic Degradation of Acetone by Desulfococcus-Biacutus Spec Nov". Archives of Microbiology, 154(4), 355-361. $\leq$ Go to $\underline{\text { ISI }>: / / A 1990 D Z 98300008}$

Schnarr, M., Truax, C., Farquhar, G., Hood, E., Gonullu, T., and Stickney, B., 1998. "Laboratory and controlled field experiment using potassium permanganate to remediate 
trichloroethylene and perchloroethylene DNAPLs in porous media". Journal of contaminant hydrology(29), 205-224.

Schwarzenbach, R. P., Gschwend, P. M., and Imboden, D. M., 2002. " Environmental Organic Chemistry" (2nd ed.): Wiley, John \& Sons, Incorporated.

Seol, Y., and Schwartz, F. W., 2000. "Phase-transfer catalysis applied to the oxidation of nonaqueous phase trichloroethylene by potassium permanganate". Journal of contaminant hydrology(44), 185-201.

Siegrist, R. L., Lowe, K. S., Murdoch, L. C., Case, T. L., and Picering, D. A., 1999. "In situ oxidation by fracture emplaced reactive solids". Journal of Environmental Engineering, 125(5), $429-440$.

Siegrist, R. L., Urynowicz, M. A., West, O. R., Crimi, M. L., and S., L. K., 2001. "Principles and Practices of in situ chemical oxidation using permanganate". Columbus, Ohio: Battelle press. USEPA. 1998. "Field applicaiton of in situ remediation technologies: chemical oxidation" (1996 ed.). Washington, DC.

USEPA. (2001, 2/25/2003). "Cleaning Up Underground Storage Tank System Releases" [Internet]. USEPA. Retrieved, from the World Wide Web: http://www.epa.gov/swerust1/cat/index.htm USEPA. (2002, 11/26/2002). " Technical Factsheet on:TETRACHLOROETHYLENE" [Internet]. USEPA. Retrieved, from the World Wide Web: http://www.epa.gov/OGWDW/dwh/tvoc/tetrachl.html

Watts, R. J., Bottenberg, B. C., and al., e., 1999b. "Role of reductant in the enhanced desorption and transformation of chloroaliphatic compounds by modified Fenton's reaction". Environmental Science and Engineering, 33(19), 3432-3437. 
Watts, R. J., Foget, M. K., Kong, S.-H., and Teel, A. L., 1999. "Hydrogen peroxide decomposition in model subsurface systems". Journal of Hazardous Material, 69(2), 229-243. Yan, Y. E., and Schwartz, F. W., 1999. "Oxidative degradation and kinetics of chlorinated ethylenes by potassium permanganate". Journal of contaminant hydrology(37), 343-365. Yan, Y. E., and Schwartz, F. W., 2000. "Kinetics and mechanisms for TCE oxidation by permanganate". Environmental science and technology(34), 2535-2541.

\subsection{Preliminary Two-Dimensional Studies}

Construction and Operation of the 2-D Flow System

A two-dimensional (2-D) flow system was constructed to investigate the reduction in mass flux of NAPL as a response to total mass reduction due to the cosolvent-enhanced chemical oxidation by $\mathrm{KMnO}_{4}$ in a heterogeneous medium. The flow field was contained in two rectangular glass plates $(62 \mathrm{~cm} \mathrm{x} 40 \mathrm{~cm})$. Square aluminum tubing $(1.3 \mathrm{~cm} \mathrm{x} 1.3 \mathrm{~cm})$ was used to close the three sides of the flow chamber. The inlet and outlet wells of the flow chamber were made by slotting the vertical section of the aluminum tubing with the slot width of $0.03 \mathrm{~cm}$ and a frequency of 4 slots per $\mathrm{cm}$. The top of the chamber was sealed by a thin layer $(3 \mathrm{~cm})$ of bentonite to simulate a confined aquifer. Steady state flow was established by maintaining constant head at both inlet and outlet ends. A random, spatially correlated, heterogeneous medium, generated using stochastic methods in the Hydrus-2D model, was used as the blueprint to pack the box. The matrix of the flow domain was coarse sand with a particle size of 20 to 30 mesh. Medium sand (40 to 50 mesh) and fine sand (50 to 60 mesh) were included within the coarse sand to generate a lenticular structure. Wet packing was used with intermittent vibration to ensure tight packing without air bubbles. Four DNAPL release points inside the chamber were composed of stainless steel tubing terminating at different depths, connected to a gas-tight 
syringe with a two-way Mininert ${ }^{\circledR}$ valve. The injection points were designed to generate a positive correlation between NAPL residual distribution and permeability.

Dye tracer test

The flow chamber was flushed with $0.005 \mathrm{~N} \mathrm{CaCl}_{2}$ to prevent the settling of clay particles and to simulate the electrolyte condition in groundwater. To visually delineate the hydrodynamic characteristic of the flow field and baseline flow pattern, $0.002 \mathrm{M} \mathrm{KMnO}_{4}$ was used to a run a dye tracer test and injected at $8.725 \mathrm{ml} / \mathrm{min}$ for 11 minutes, followed by flushing the $\mathrm{CaCl}_{2}$ solution at the same flow rate. The concentration of $\mathrm{KMnO}_{4}$ at the outlet end was measured with UV-Vis spectrophotometer. A digital camera was also used to capture the movement of the dye pulse at different times.

The breakthrough curve of $\mathrm{KMnO}_{4}$ (Figure 4-8) resulting from the dye tracer test shows clearly two peaks, indicating two distinct flow domains in the chamber. The first, sharp peak represents the high permeability zone consisting of coarse sand, and the second, broad peak represents the low permeability lenses. The pore volume determined from moment analysis of the tracer test data was $892.8 \pm 9.8 \mathrm{ml}$.

Figure 4-9 is a photograph taken after 40 minutes of tracer injection. The dark areas are the lenses with low permeability. The purple color is the $\mathrm{KMnO}_{4}$ pulse. It can be seen that the tracer pulse moves faster in the high permeability zone. 
Table 4-1. Solvent stability in the presence of permanganate

\begin{tabular}{|l|l|}
\hline Co-Solvent & Stability* \\
\hline Formaldehyde & 5 to 30 minutes \\
Acetaldehyde & \\
Ethyl lactate & \\
\hline Tetrioxandrofuran & \\
Ethylene Glycol Diformate & \\
Ethyl Formate & \\
Cyclohexanone & Less than 1 hour \\
Isopropyl Alcohol & \\
Ethylene Glycol & \\
\hline $\begin{array}{l}\text { Propanol } \\
\text { Acetonitrile } \\
\text { Pyridine } \\
\text { Butanone }\end{array}$ & Less than 4 hours \\
\hline Acetone & \\
\hline Tertiary butyl alcohol & 1 day \\
**Measured as the amount of time required for 2 mM of potassium permanganate to completely \\
react.
\end{tabular}

Table 4-2. Second order rate constants of oxidation of aqueous PCE by $\mathrm{KMnO}_{4}$

\begin{tabular}{|c|c|c|c|c|c|}
\hline \multicolumn{4}{|c|}{ Experimental conditions } & \multirow[t]{2}{*}{$k\left(\mathbf{M}^{-1} \mathrm{~s}^{-1}\right)^{\mathrm{a}}$} & \multirow[t]{2}{*}{ Reference } \\
\hline $\begin{array}{l}{[\mathrm{PCE}]_{0}} \\
(\mathrm{mM})\end{array}$ & $\begin{array}{l}{\left[\mathrm{KMnO}_{4}\right]_{0}} \\
(\mathrm{mM})\end{array}$ & $\begin{array}{l}\text { Solvent } \\
\text { matrix }\end{array}$ & $\begin{array}{l}\text { Temper- } \\
\text { ature }\end{array}$ & & \\
\hline$<0.1$ & 1 & $\begin{array}{l}\text { Water } \\
\text { pH } 7\end{array}$ & & $0.045 \pm 0.003$ & $\begin{array}{l}\text { Yan and } \\
\text { Schwartz } 1999\end{array}$ \\
\hline $0.28 \sim 0.67$ & $3.2 \sim 27.2$ & Water & $\begin{array}{l}\text { Ambient } \\
\left(21^{\circ} \mathrm{C}\right) \text {; not } \\
\text { controlled } \\
\end{array}$ & $0.041 \pm 0.011$ & $\begin{array}{l}\text { Hood et al. } \\
2000\end{array}$ \\
\hline 0.12 & 1.6 & $\begin{array}{l}\text { Water } \\
\text { pH } 7\end{array}$ & $25^{\circ} \mathrm{C}$ & $0.051 \pm 0.002$ & $\begin{array}{l}\text { Huang et al. } \\
2002\end{array}$ \\
\hline 0.69 & 15.8 & $\begin{array}{l}\text { Water } \\
\text { pH } 7\end{array}$ & $25^{\circ} \mathrm{C}$ & $0.046 \pm 0.002$ & This work \\
\hline 0.62 & 15.8 & $\begin{array}{l}20 \% \text { TBA } \\
(\mathrm{pH} \mathrm{7)}\end{array}$ & $25^{\circ} \mathrm{C}$ & $0.036 \pm 0.003$ & This work \\
\hline 0.69 & 16.1 & $\begin{array}{l}20 \% \\
\text { acetone } \\
(\mathrm{pH} \mathrm{7)}\end{array}$ & $25^{\circ} \mathrm{C}$ & $0.031 \pm 0.002$ & This work \\
\hline
\end{tabular}

Notes: ${ }^{\text {a }}$. mean \pm 3 standard deviation

These rate constants were measured in the absence of free-phase PCE. 


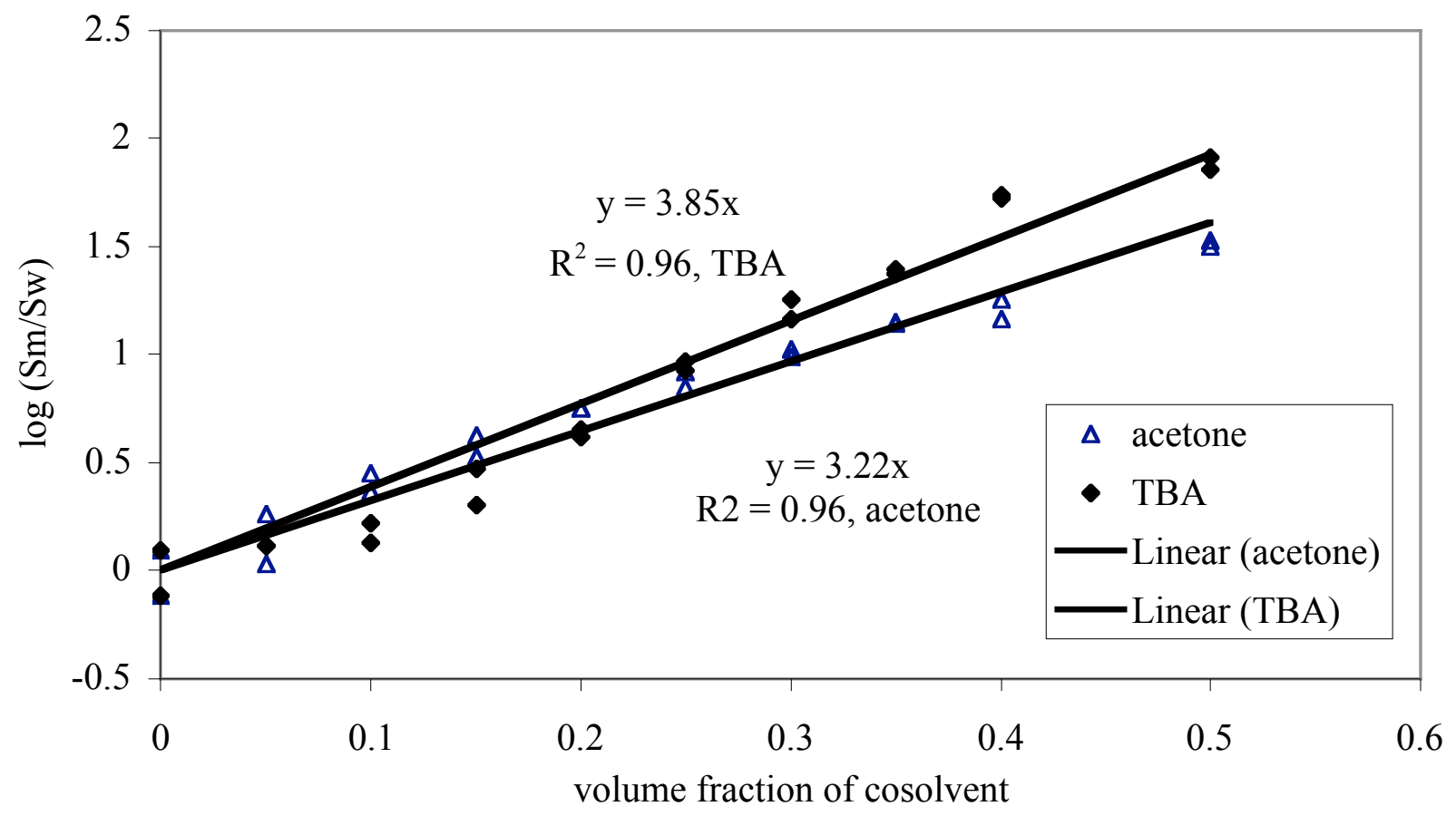

Figure 4-1. Log of normalized solubility $\left(\mathrm{S}_{\mathrm{m}} / \mathrm{S}_{\mathrm{w}}\right)$ versus the volume fraction of cosolvent.

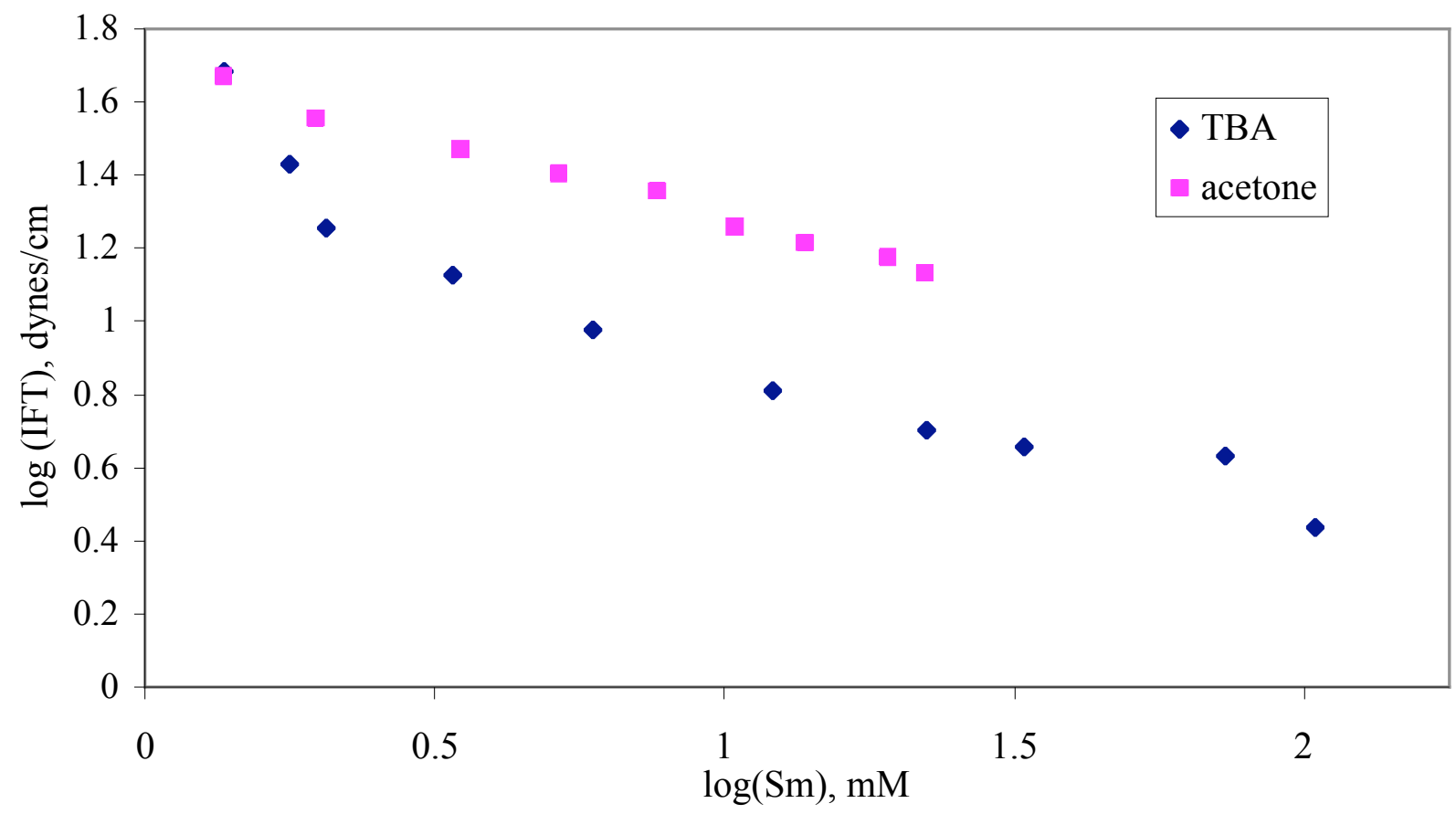

Figure 4-2. Log of interfacial tension (IFT) between cosolvent/water mixture and PCE versus log of solubility of PCE in the mixtures. 


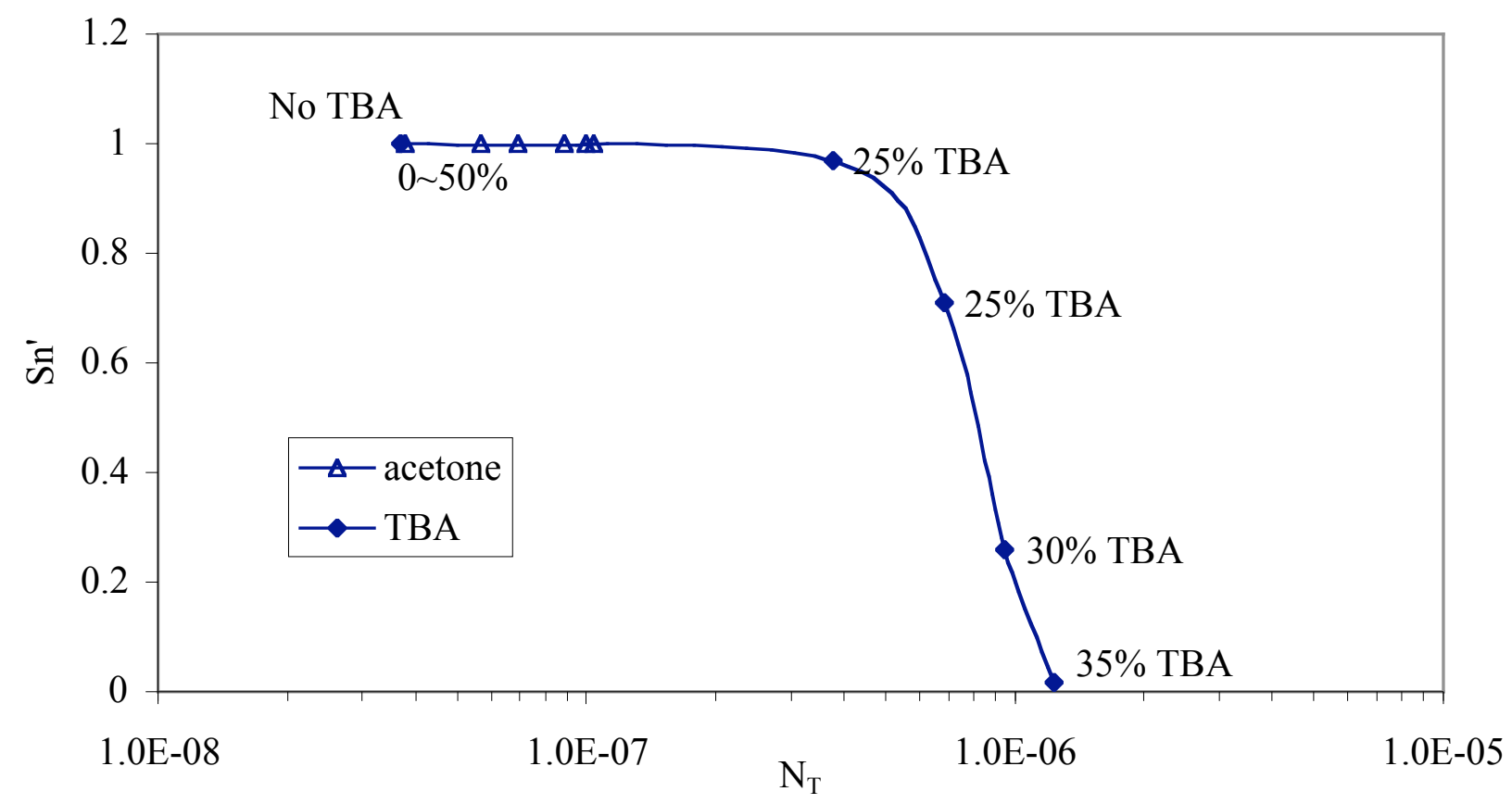

Figure 4-3. Relative residual saturation ( $\left.\mathrm{Sn}^{\prime}\right)$ versus total trapping number $\left(\mathrm{N}_{\mathrm{T}}\right)$.

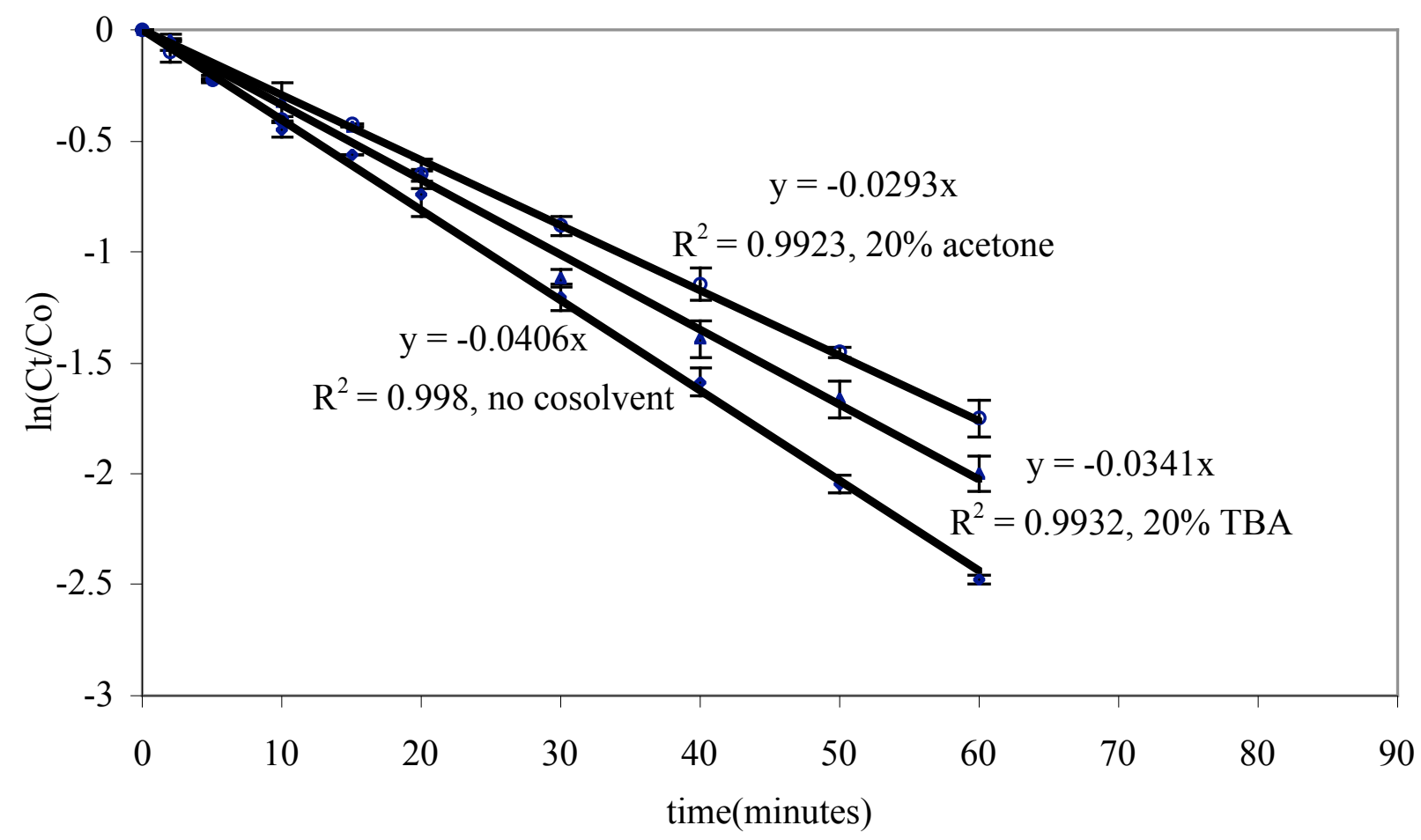

Figure 4-4. Pseudo-first order model for PCE concentration in kinetic experiment (absence of free phase PCE). $\mathrm{pH}=7$ buffered by $\mathrm{Na}_{2} \mathrm{HPO}_{4}$ and $\mathrm{NaH}_{2} \mathrm{PO}_{4} .25^{\circ} \mathrm{C}$ water bath, $[\mathrm{PCE}]_{0}=6.2 \sim 6.9$ $\mathrm{mM},\left[\mathrm{KMnO}_{4}\right]_{0}=15.8 \sim 16.1 \mathrm{mM}$ (see table 2 for details). 


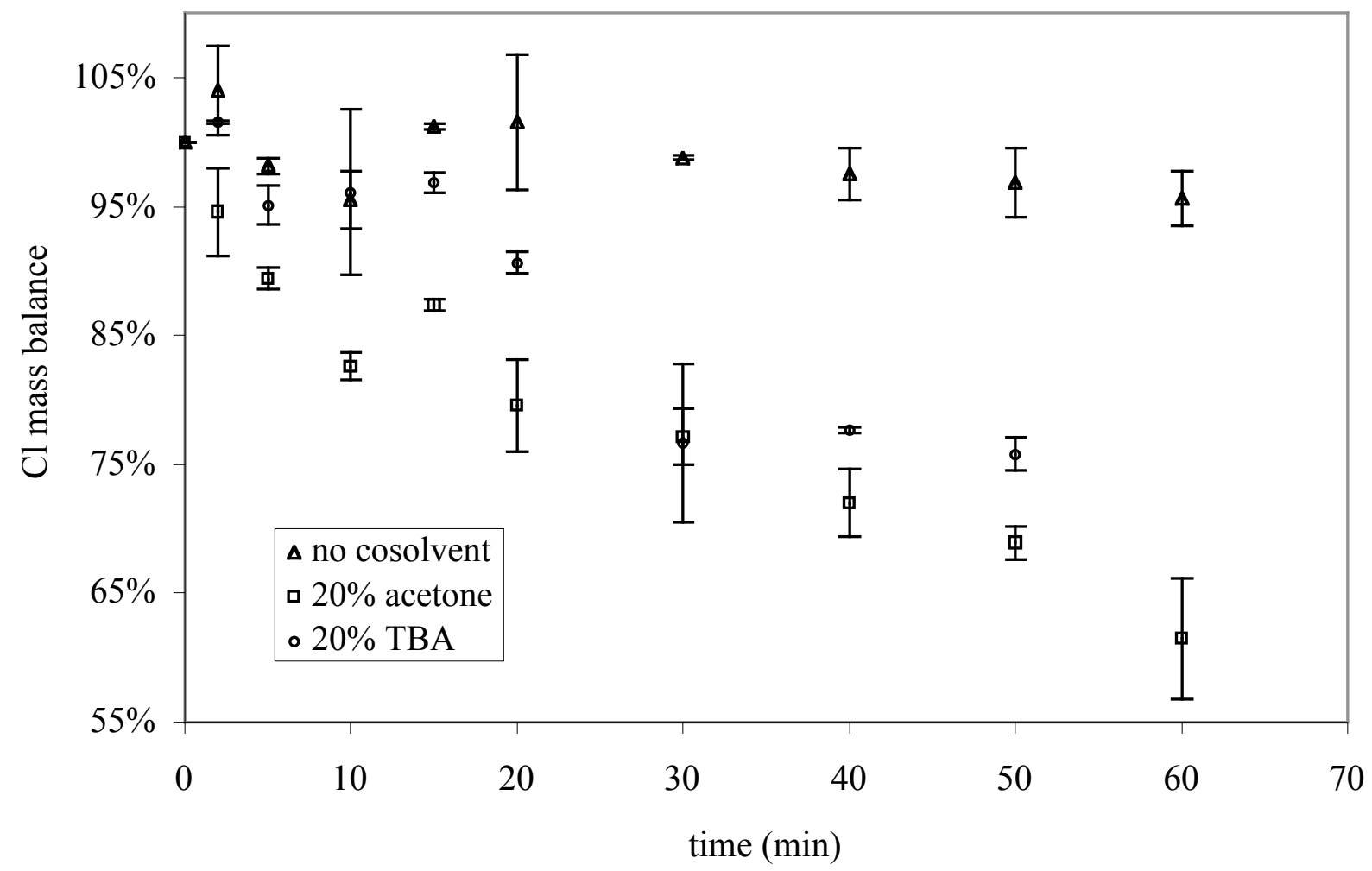

Figure 4-5. Chlorine mass balance for PCE oxidation in the absence of free phase PCE. Refer to table 2 for details.

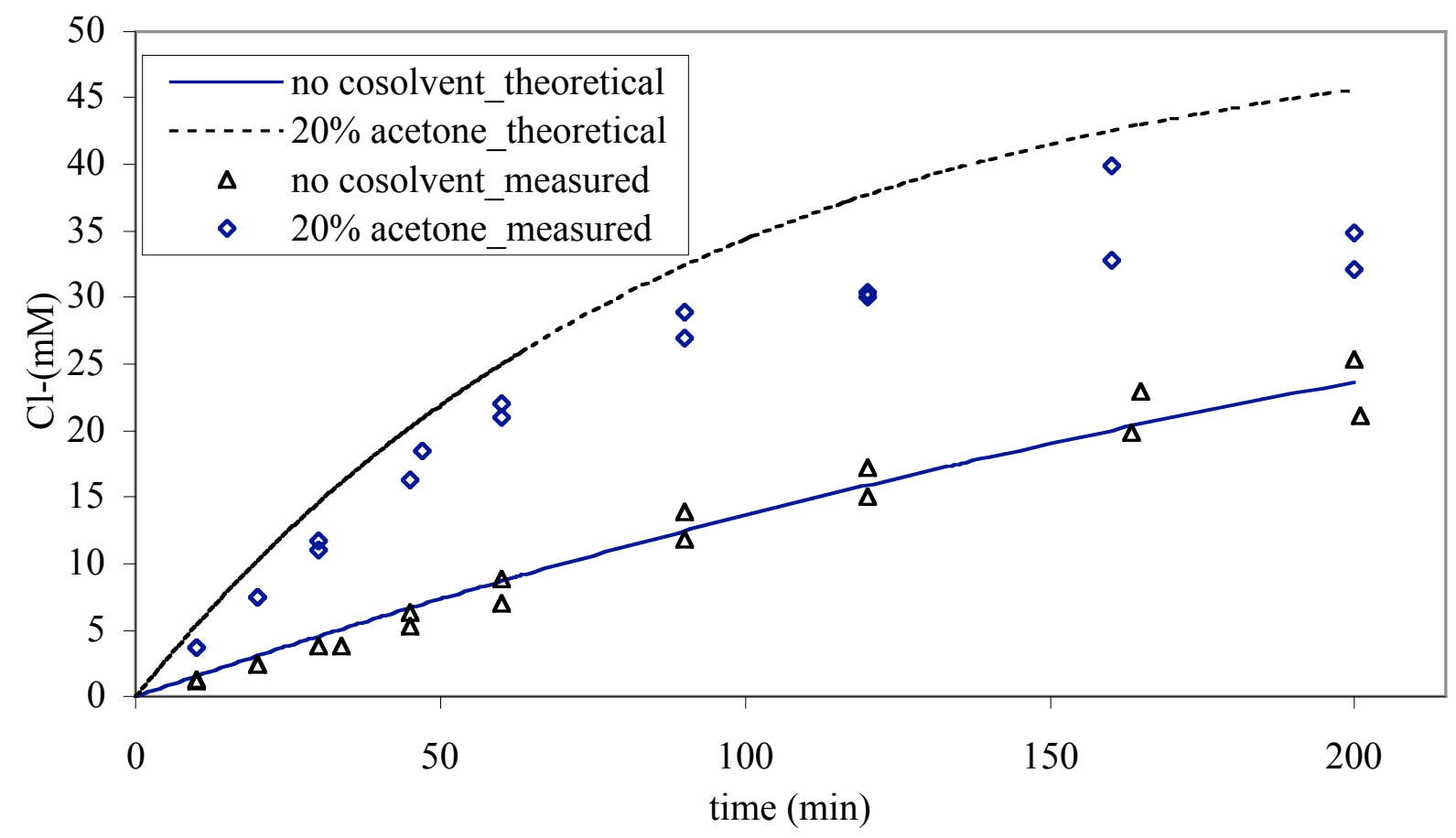

Figure 4-6. Chloride production during co-solvent enhanced oxidation of PCE. $2 \mathrm{~mL}$ free phase PCE in $250 \mathrm{~mL}$ glass reactor, $25^{\circ} \mathrm{C}$ water bath, $\left[\mathrm{KMnO}_{4}\right]_{0}=17 \mathrm{mM}$. 


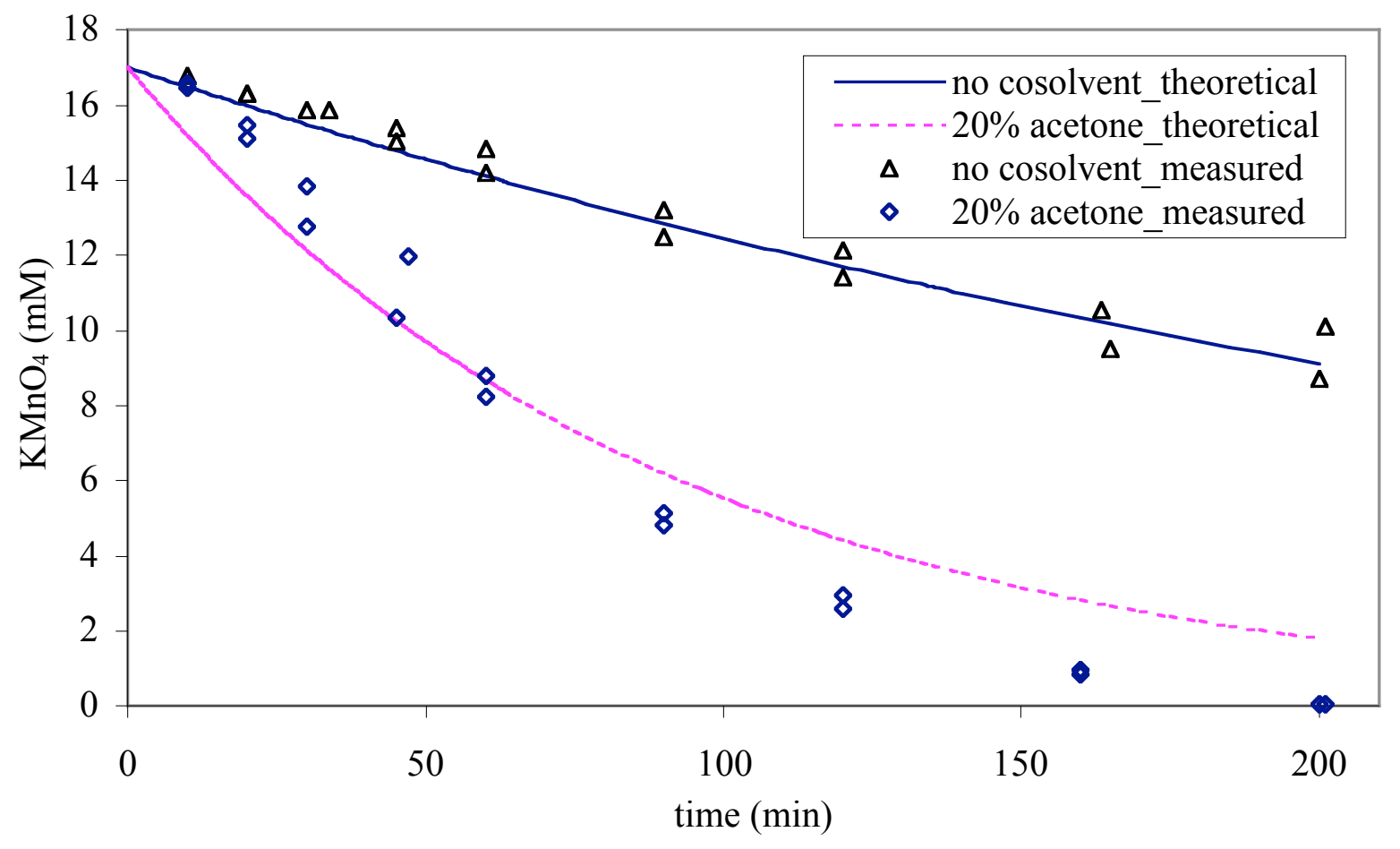

Figure 4-7. $\mathrm{KMnO}_{4}$ concentration in the presence of $2 \mathrm{~mL}$ free phase PCE in 250-mL glass reactor, $25^{\circ} \mathrm{C}$ water bath, $\left[\mathrm{KMnO}_{4}\right]_{0}=17 \mathrm{mM}$, gently stirring, run in duplicates.

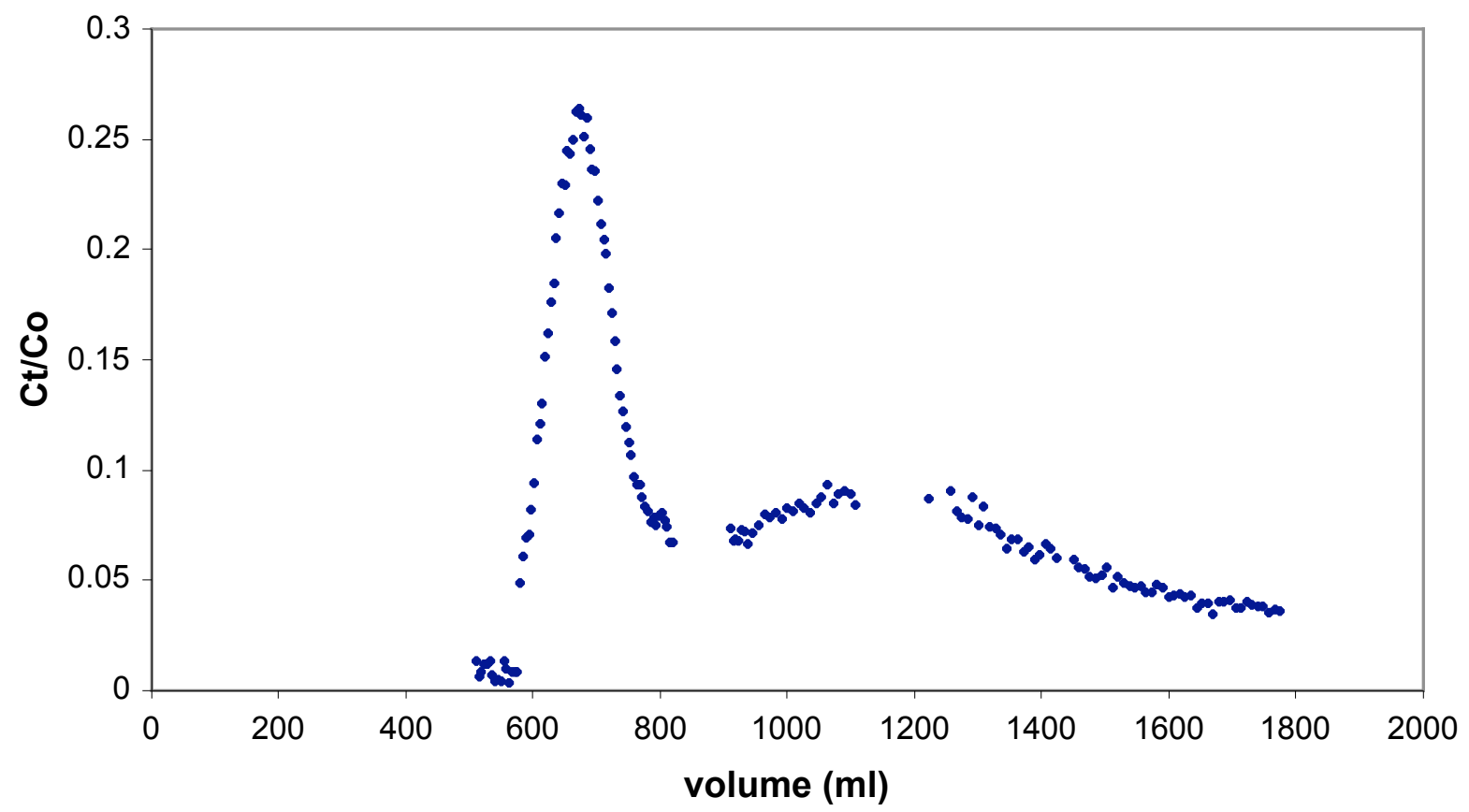

Figure 4-8. Breakthrough of $\mathrm{KMnO}_{4}$ from the box during the dye tracer test. 


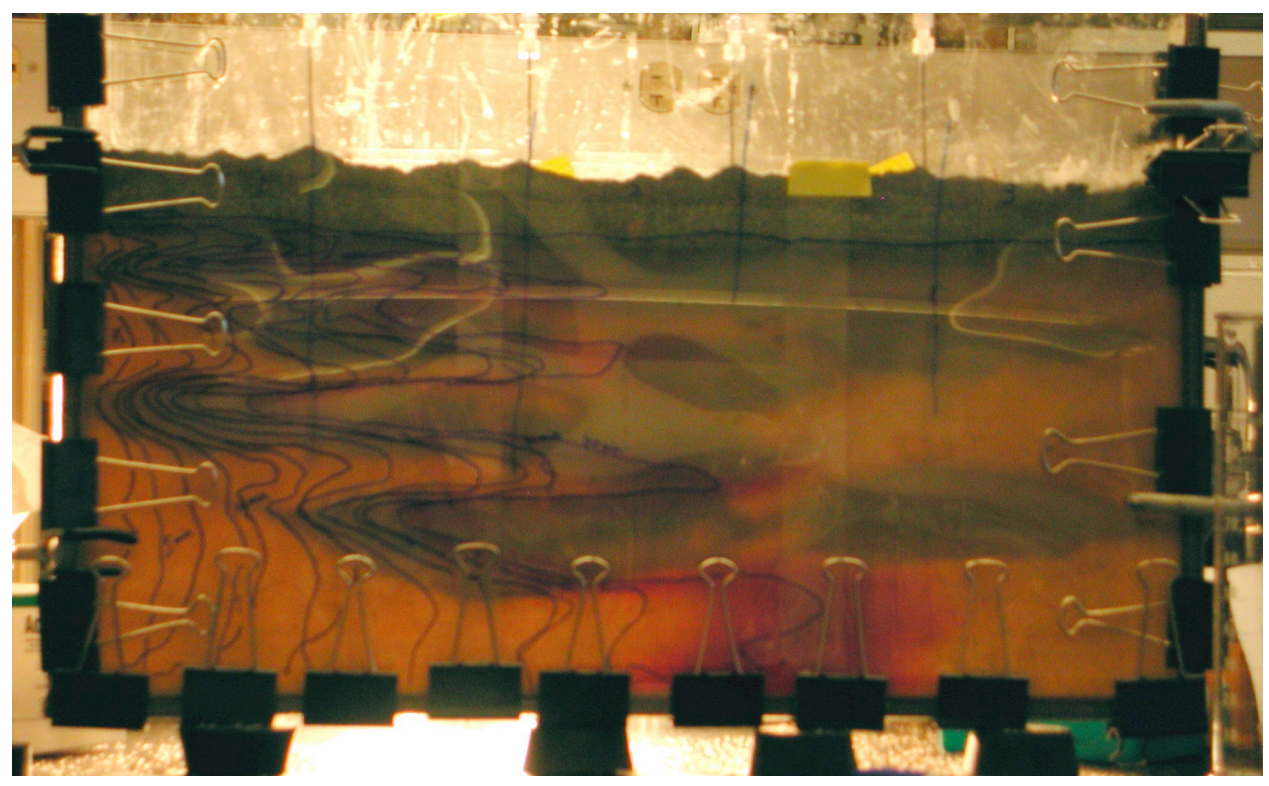

Figure 4-9. Distribution of $\mathrm{KMnO}_{4} 40$ minutes after injection. 


\section{Chapter 5: Field Site Assessments and Visits}

Inez Hua, P. Suresh C. Rao, Linda S. Lee

Project staff visited the Warsaw Sub-district site on March 23, 2002. After discussions with INDOT, further information was requested regarding site characteristics. In response to the request, additional sampling (by ATC Associates, Inc.) and site characterization was conducted on May 15, 2002. Inez Hua, Linda Lee, and Ben Lawrence were also present at the site that day. Soil and groundwater samples were collected for analysis. The groundwater samples were analyzed for benzene, toluene, ethyl benzene, xylene (BTEX) and methyl tert-butyl ether (MTBE). The soil samples were tested for Total Petroleum Hydrocarbons (TPH) in the gasoline range. Contaminants in all samples were reported non-detectible. ATC also performed a slug test.

In addition, investigations of ISCO supported by JTRP/INDOT are currently being complemented by another research project (sponsored by the Showalter Trust Foundation) which is focused on innovative technologies for accelerated groundwater clean-up and remediation performance assessment at contaminated sites. The Purdue PIs are Suresh Rao, Inez Hua, Linda Lee, and Chad Jafvert; additionally, there are numerous off-campus collaborators.

Sites were screened and selected based upon both hydrogeologic and contaminant criteria. Optimal geologic formations include coarse geologic parent material with high intrinsic permeability, less than 50 feet $(15 \mathrm{~m})$ deep, and underlain by a low permeability fine textured material serving as the confining geologic unit. Sites contaminated with dense non-aqueous liquids (DNAPLs), with an identified source zone and an extended dissolved plume in the groundwater were preferred. Access to the site, a site owner who is willing to provide in-kind services and who plans to implement some site remediation is also important.

Some of the potential sites are being considered for demonstrating a new technology for measuring contaminant fluxes (allowing for an estimation of the DNAPL source strength) before and after site/source remediation. This would require installation of a transect of wells perpendicular to the mean flow of the dissolved plume and just down gradient from the source area. This method is being tested at a number of sites outside Indiana, and flux measurement will become increasingly common component of site characterization and assessment. Second, 
the sites are being evaluated for field scale testing of innovative remediation techniques for source cleanup, solvent flushing and chemical oxidation.

Table 5-1: Potential Sites for ISCO Field Test/Study in Indiana

\begin{tabular}{|l|l|l||}
\hline \hline Location & Status & Future Tasks \\
\hline $\begin{array}{l}\text { Warsaw } \\
\text { (INDOT) }\end{array}$ & $\begin{array}{l}\text { Visited site twice; on the basis of consultant } \\
\text { reports and further characterization of } \\
\text { groundwater and soil- declined as potential site }\end{array}$ & $\mathrm{n} / \mathrm{a}$ \\
\hline $\begin{array}{l}\text { Alexandria } \\
\text { (INDOT) }\end{array}$ & $\begin{array}{l}\text { Site investigation concluded; remediation work } \\
\text { bid out. Site declined for field study. }\end{array}$ & $\mathrm{n} / \mathrm{a}$ \\
\hline $\begin{array}{l}\text { Crawfordsville } \\
\text { (INDOT) }\end{array}$ & $\begin{array}{l}\text { Aerial photos received. Site visit and meeting } \\
\text { with INDOT staff on January 13, 2004. }\end{array}$ & \\
\hline $\begin{array}{l}\text { Winamac } \\
\text { (INDOT) }\end{array}$ & $\begin{array}{l}\text { Received and analyzed facility log for this site. } \\
\text { Decision pending. }\end{array}$ & \\
\hline $\begin{array}{l}\text { Dyer } \\
\text { (INDOT) }\end{array}$ & $\begin{array}{l}\text { Well-log and groundwater concentrations map } \\
\text { received. Decision pending. }\end{array}$ & \\
\hline $\begin{array}{l}\text { Anderson } \\
\text { (General Motors) }\end{array}$ & $\begin{array}{l}\text { Site visit and meeting with IDEM planned for } \\
\text { January 28, 2004. }\end{array}$ & \\
\hline \hline
\end{tabular}




\section{Chapter 6. Conclusions and Implementation Suggestions}

Inez Hua and Ben Lawrence

\subsection{Conclusions}

A primary goal of the research project is to improve the efficiency and effectiveness of chemical oxidation systems during in-situ treatment of non-aqueous phase liquid (NAPL) source zones. Efficiency and effectiveness are defined in Table 1-1; other selection criteria include time required to achieve acceptable levels of treatment, oxidant selectivity, and oxidant delivery methods. Several novel approaches have been taken to reach the goals of the study. The first approach enhances the application of Fenton's reagent in soil slurry systems, resulting in a better understanding of the magnitude of non-specific oxidant losses relative to consumption by the target compounds. The second approach explores minimizing non-specific losses of the oxidant by introducing the oxidant $\left(\mathrm{KMnO}_{4}\right)$ in an encapsulated form. Finally, solubility enhancers are examined to enhance the aqueous NAPL concentrations. Significant enhancements in NAPL aqueous concentration will result in corresponding enhancements of the observed oxidation rate. The outcomes of these three approaches are summarized below.

In order to enhance the rate and extent of in situ oxidation of BTEX compounds, Fentontype treatment of BTEX-contaminated soil slurries was investigated. A characterized soil

(Warsaw, IN) was spiked with BTEX compounds, and the performance of Fenton treatment was evaluated using a matrix of $\mathrm{H}_{2} \mathrm{O}_{2}$ concentrations and iron catalysts (Fe(II), $\mathrm{Fe}(\mathrm{III})$, and $\mathrm{Fe}(\mathrm{III})$ organic ligand complexes) in the range of near-neutral $\mathrm{pH}$. The results indicate that for initial concentrations of BTEX (0.26-0.34 mmol / $\mathrm{kg}$ soil), 63.3-96.1\% mass reduction in $24 \mathrm{~h}$ was achieved by Fenton processes where $\mathrm{H}_{2} \mathrm{O}_{2}(150$ and $300 \mathrm{mM})$ with combinations of $\mathrm{Fe}(\mathrm{II})$ or $\mathrm{Fe}(\mathrm{III})$ or Fe(III)-organic ligand complexes (2 and $5 \mathrm{mM}$ ) were utilized. 
Soluble iron catalyst was a key parameter for effective performance of Fenton oxidation. In addition, Fenton treatment of toluene could be significantly enhanced in the presence of a chelating agent for Fe(III). It is anticipated that as long as a sufficient amount of soluble iron is augmented or effective chelating agents are employed, Fenton processes could be effectively utilized for remediation of gasoline-contaminated soils and groundwater within a fairly short clean-up time scale (hours to days).

It is possible to minimize non-specific losses during ISCO by controlling the release of oxidant into the aqueous phase. Paraffin wax was applied as an environmentally benign and inert matrix for protecting solid $\mathrm{KMnO}_{4}$ particles from rapid dissolution and undesirable reactions in moist conditions. The release of $\mathrm{KMnO}_{4}$ from the EPPs into reagent grade water was characterized by a relatively fast initial rate due to fast dissolution of partly coated $\mathrm{KMnO}_{4}$ near the surface of the paraffin wax matrix, followed by a significantly slower rate in the later phase due probably to reduced mass of $\mathrm{KMnO}_{4}$ that remained in the paraffin wax matrix. The wax coating completely dissolved almost immediately upon contact with a target contaminant (PCE). When transported with ground water flow, organic contaminants such as TCE and PCE dissolved in aqueous phase would preferentially partition into the paraffin wax coating due to their significant solubilities in the paraffin wax. Consequently, enhanced contact may occur between the contaminant and the locally high concentrations of $\mathrm{KMnO}_{4}$ released into the interfacial region of EPPs and the aqueous phase. The $\mathrm{KMnO}_{4}$ concentration in the vicinity of the EPPs will be close to its maximum aqueous solubility.

The time-efficiency of PCE oxidation by potassium permanganate is enhanced under solubility conditions that mimic a contaminant source zone. Both TBA and acetone are sufficiently recalcitrant to oxidation by $\mathrm{KMnO}_{4}$ to be used individually as co-solvents. At 
specific volume fractions, TBA $(20 \%)$ and acetone $(<50 \%)$, increase the solubility of PCE significantly without mobilizing the DNAPL. The chloride production from PCE oxidation with $\mathrm{KMnO}_{4}$ in a $20 \%$ acetone system was about twice as much as that in the absence of co-solvent, indicating the former system has a higher time-efficiency in utilizing $\mathrm{KMnO}_{4}$.

Based on input from INDOT staff, selected sites have been assessed for amenability to remediation via in-situ oxidation. Site visits were also be made by research assistants to collect soil samples for laboratory experiments.

\subsection{Implementation Suggestions}

INDOT should consider the use of ISCO when standard excavation of contaminated source soil would not be practical or cost-effective. This might be due to the depth of the source (especially with DNAPLs) or proximity to utilities, buildings, or a roadway. Ideally INDOT would have ownership or unlimited access rights to the prospective property. This would simplify investigation and implementation of the chosen remedial option.

Geologically, porous soil would help in dispersing oxidants and improving access to the contaminant plume. The "ideal" situation would consist of a small, concentrated source zone (especially if free-phase NAPL is present) that feeds a large, relatively dilute plume. Plumes composed of long-chain hydrocarbons or polyaromtics (diesel, fuel oil or waste oil) would be most useful for the study. They are less mobile (and therefore easier to gain regulatory approval for unconventional treatment methods) and traditionally more limited in treatment options compared to more volatile constituents such as BTEX. High molecular weight hydrocarbons will also show a higher affinity for the proposed paraffin wax encapsulated permanganate, improving selectivity. 
The co-solvent approach would be most useful at sites where solubility is a limiting factor, such as at chlorinated hydrocarbon sites, including dry cleaner sites. Choice of solvent must take into account any neighboring receptors. Remote or industrial locations will be amenable to a more aggressive solvent than those in an urban or residential area. As with any of the techniques described in this report, regulatory approval at an early stage is critical to the success of such a remediation approach. 